University of Louisville

ThinkIR: The University of Louisville's Institutional Repository

$5-2021$

\title{
Particulate matter exposure and community-acquired pneumonia mortality among hospitalized adults with pneumococcal pneumonia: incidence study (HAPPI) participants.
}

Jack Anthony Pfeiffer

University of Louisville

Follow this and additional works at: https://ir.library.louisville.edu/etd

Part of the Epidemiology Commons

\section{Recommended Citation}

Pfeiffer, Jack Anthony, "Particulate matter exposure and community-acquired pneumonia mortality among hospitalized adults with pneumococcal pneumonia: incidence study (HAPPI) participants." (2021). Electronic Theses and Dissertations. Paper 3639.

https://doi.org/10.18297/etd/3639

This Doctoral Dissertation is brought to you for free and open access by ThinkIR: The University of Louisville's Institutional Repository. It has been accepted for inclusion in Electronic Theses and Dissertations by an authorized administrator of ThinkIR: The University of Louisville's Institutional Repository. This title appears here courtesy of the author, who has retained all other copyrights. For more information, please contact thinkir@louisville.edu. 
PARTICULATE MATTER EXPOSURE AND COMMUNITY-ACQUIRED PNEUMONIA MORTALITY AMONG HOSPITALIZED ADULTS WITH PNEUMOCOCCAL PNEUMONIA: INCIDENCE STUDY (HAPPI) PARTICIPANTS

By

\author{
Jack Anthony Pfeiffer \\ B.A., University of Louisville, 2014 \\ M.S. University of Louisville, 2017
}

\begin{abstract}
A Dissertation
Submitted to the Faculty of the

School of Public Health and Information Sciences

of the University of Louisville

in Partial Fulfillment of the Requirements

for the Degree of

Doctor of Philosophy in Public Health Sciences

Department of Epidemiology and Population Health

University of Louisville

Louisville, Kentucky
\end{abstract}

May 2021 

PARTICULATE MATTER EXPOSURE AND COMMUNITY-ACQUIRED

PNEUMONIA MORTALITY AMONG HOSPITALIZED ADULTS WITH

PNEUMOCOCCAL PNEUMONIA: INCIDENCE STUDY (HAPPI) PARTICIPANTS

\section{By}

Jack Anthony Pfeiffer

B.A., University of Louisville, 2014

M.S., University of Louisville, 2017

A Dissertation Approved on

March 25, 2021

by the following Dissertation Committee:

Natalie DuPre, ScD (Chair)

Richard Baumgartner, $\mathrm{PhD}$

Kira Taylor, PhD

Charlie Zhang, PhD

Forest Arnold, DO 


\section{ACKNOWLEDGEMENTS}

I would like to thank my doctoral advisor and dissertation committee chair, Dr. Natalie DuPre, for her guidance, patience, and understanding during this lengthy project. I would also like to thank the other committee members, Dr. Richard Baumgartner, Dr. Kira Taylor, Dr. Charlie Zhang, and Dr. Forest Arnold, for their insights, comments, and assistance. I would also like to thank my wife, Isabella, for her constant support during this time, and for keeping me going even when I saw no end in sight. Additionally, I would like to thank Dr. Kristina Zierold, Dr. Lonnie Sears, Dr. Lindsay Tompkins, Dr. Joy Hart, Dr. Kandi Walker, and all the countless others who provided support, encouragement, and advice during this most arduous of processes. 


\begin{abstract}
PARTICULATE MATTER EXPOSURE AND COMMUNITY-ACQUIRED

PNEUMONIA MORTALITY AMONG HOSPITALIZED ADULTS WITH

PNEUMOCOCCAL PNEUMONIA: INCIDENCE STUDY (HAPPI) PARTICIPANTS

Jack Anthony Pfeiffer
\end{abstract}

March 25, 2021

The role of air pollution as an agent of elevated morbidity and mortality has come under increasingly intense scrutiny in recent years. As the body of literature grows, so too does our understanding of how extensive the harm of such pollutants can be. Particulate matter (PM) particularly harmful due to its small size, ability to travel great distance while airborne, and capacity to infiltrate numerous bodily systems, often to the detriment of those exposed. Besides being associated with increased mortality risk in more heavily exposed populations, PM exposure has also been associated with complications in the respiratory, cardiovascular, and nervous systems. Additionally, exposures to PM are often unequally distributed among populations, with the greatest burden placed upon already marginalized groups. The purpose of this dissertation study was to examine the impact of PM exposure at the time of hospitalization on pneumonia-related mortality risk among individuals hospitalized due to community-acquired pneumonia (CAP).

The study sample for this dissertation work came from the Hospitalized Adults with Pneumococcal Pneumonia: Incidence (HAPPI) study conducted in Jefferson County, KY, USA from 2014 to 2016, containing adult residents of the county who were hospitalized 
due to $\mathrm{CAP}$ during that timeframe. $\mathrm{PM}_{10}$ and $\mathrm{PM}_{2.5}$ concentration data were derived from online sources published by the US Environmental Protection Agency (EPA) based on a limited number of air monitoring stations located within Jefferson County. A spatial interpolation method called spatial averaging was used to determine specific levels of PM exposure ascribed to each participant at the time of their hospitalization. Mortality within thirty days of hospitalization was the primary outcome examined as it is likely to reflect CAP-specific mortality. The relationships between PM exposures and mortality were examined using a variety of methods, including logistic and Cox proportional hazards regression and we additionally conducted effect modification analyses. Feasibility of alternative spatial interpolation methods was also examined.

Age and race, as well as a number of hospitalization and medical history-oriented covariates, were found to be significantly associated with mortality in preliminary regression analysis. According to the preferred model containing all noted confounders and strong predictors, the primary PM exposures of interest were not found to be significantly associated with mortality; however, effect modification analysis did yield significant results. Black participants exposed to higher levels of $\mathrm{PM}_{10}$ had a greater odds of thirtyday mortality, based on both continuous $\mathrm{PM}_{10}(\mathrm{AOR}=1.19$ per five-unit increase, $95 \% \mathrm{CI}$ $=1.04-1.37$ ) and $\mathrm{PM}_{10}$ quartiles (greatest versus lowest quartile; $\mathrm{AOR}=2.70,95 \% \mathrm{CI}=$ 1.31-5.55). Female participants in the greatest $\mathrm{PM}_{10}$ exposure quartile had higher odds of death within thirty days versus those in the lowest quartile $(\mathrm{AOR}=1.46,95 \% \mathrm{CI}=1.01$ 2.14). The same elevated associations were not observed among white or male participants. Additionally, the more advanced spatial interpolation method kriging was not found to be feasible due to sparsity of monitor data at a given time point. 
The results of the study indicate that certain segments of the population may be disproportionately impacted by $\mathrm{PM}_{10}$ exposure. Additionally, the results provide insight into the risks and benefits associated with specific hospitalization / medical historyoriented covariates. Given the simplistic nature of spatial averaging and the inability to properly conduct kriging with the data that was available, future research on this subject would benefit greatly from alternative, more extensive sources of PM data within cities. For now, it appears that $\mathrm{PM}_{10}$ exposure is associated with elevated thirty-day mortality among Black and female populations within Jefferson County, KY. 
TABLE OF CONTENTS

PAGE

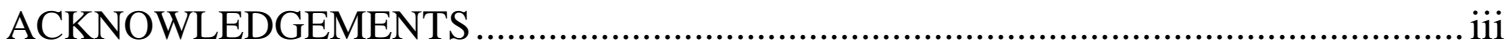

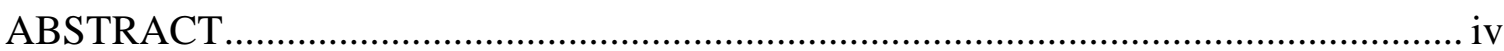

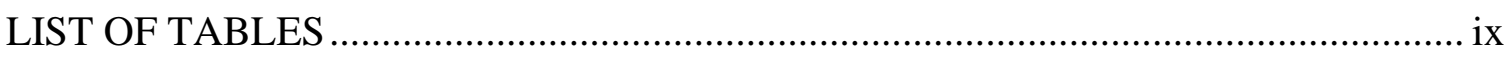

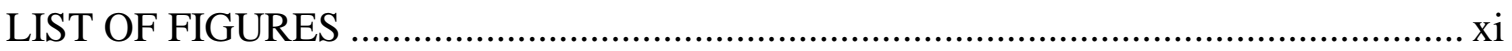

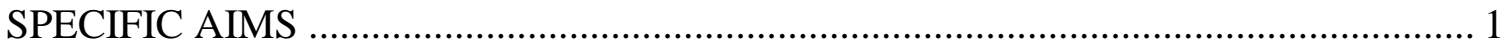

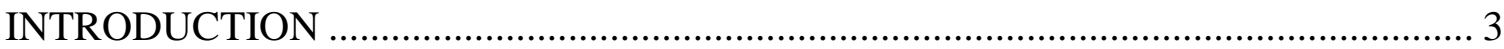

Pneumonia Classification and Etiology ............................................................... 4

Epidemiology of Community-Acquired Pneumonia................................................. 6

Incidence of Community-Acquired Pneumonia ........................................................... 6

Mortality from Community-Acquired Pneumonia ...................................................... 11

Pneumonia and Particulate Matter ......................................................................... 14

Air Pollution in Jefferson County, Kentucky ......................................................... 17

Particulate Matter, Mortality, and Effect Modifiers ................................................. 18

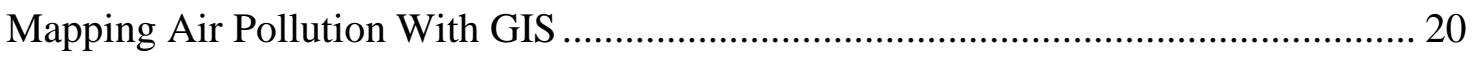

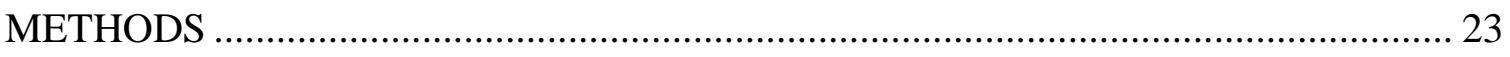

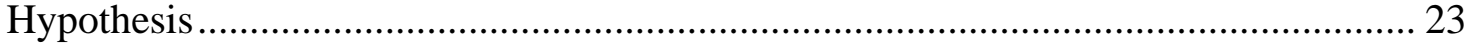

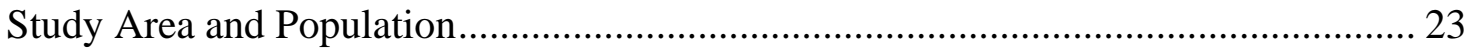

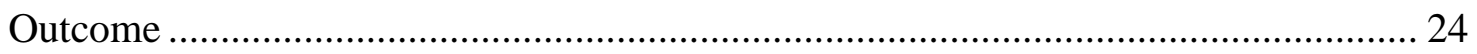

Exposure

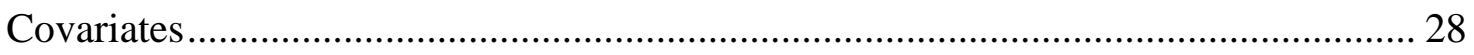

Demographic Variables ……………………………........................................ 28

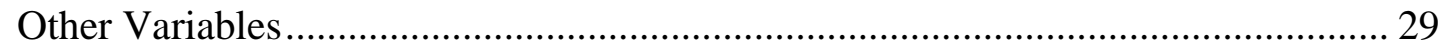

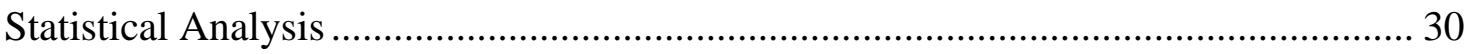

General Statistical Methods.............................................................................. 30

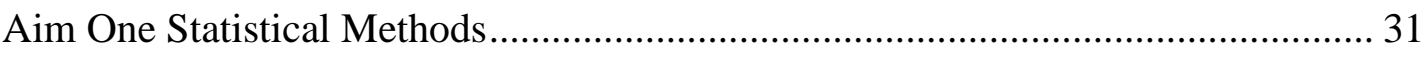

Aim Two Statistical Methods ............................................................................. 33 


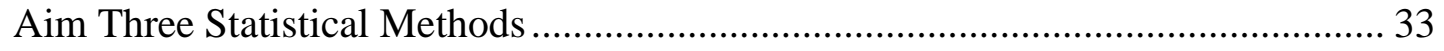

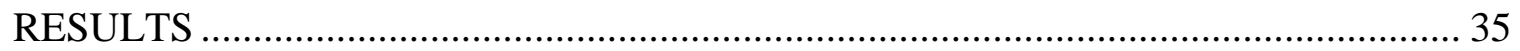

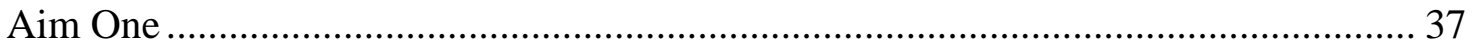

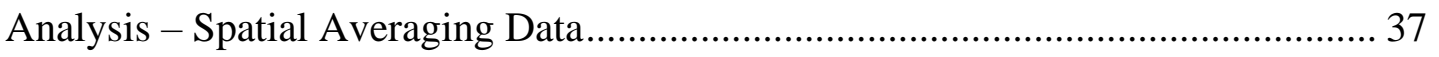

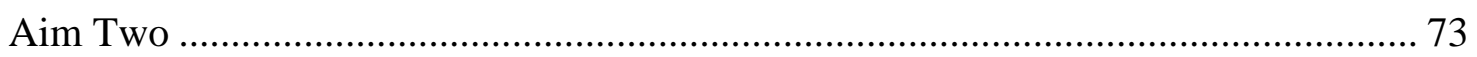

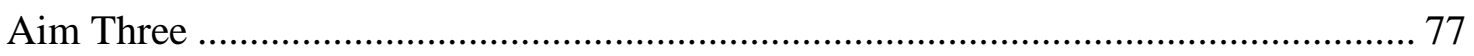

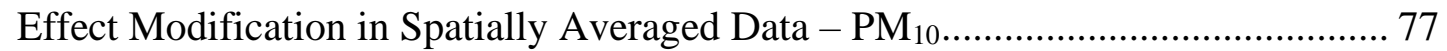

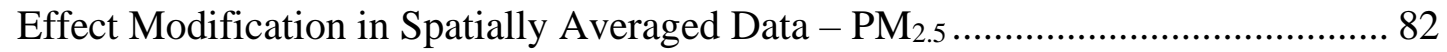

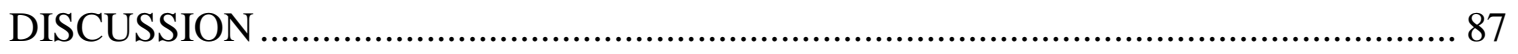

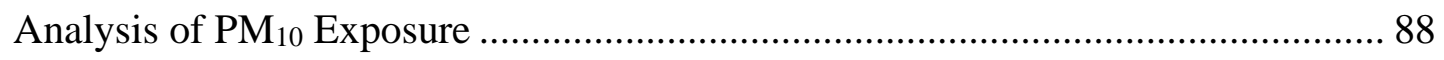

Comments Concerning Analysis of $\mathrm{PM}_{2.5}$ Exposure............................................... 94

Comments Concerning the Use of Kriging ......................................................... 94

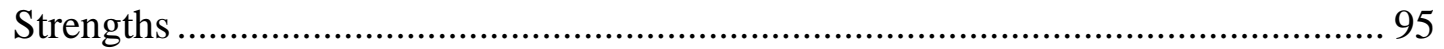

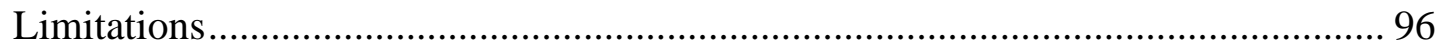

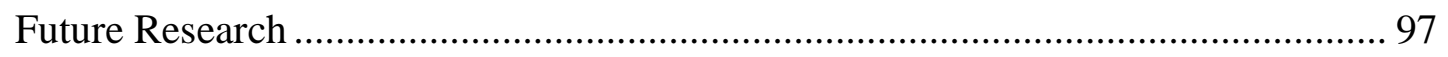

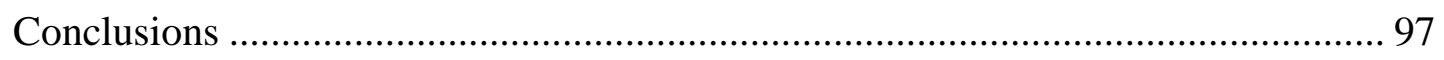

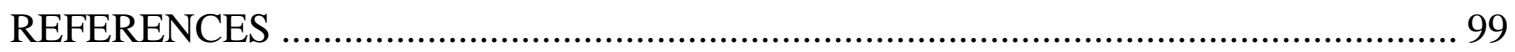

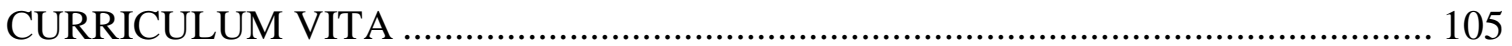




\section{LIST OF TABLES}

TABLE

PAGE

1. Particulate matter (PM) data provided by corresponding Jefferson County 26 monitoring station, 2014-2016

2. Descriptive statistics of HAPPI population by mortality within thirty days of hospital admission

3. Quartiles $\left(\mathrm{PM}_{10}\right)$ by mortality at thirty days

4. Quartiles $\left(\mathrm{PM}_{2.5}\right)$ by mortality at thirty days

5. Descriptive statistics of HAPPI population by quartile of $\mathrm{PM}_{10}$ exposure at time of hospitalization

6. Descriptive statistics of HAPPI population by quartile of $\mathrm{PM}_{2.5}$ exposure at time of hospitalization

7. Logistic regression examining association between $\mathrm{PM}_{10}$ (continuous) exposure at time of hospitalization and mortality at thirty days - minimally adjusted

8. Logistic regression examining association between $\mathrm{PM}_{10}$ (continuous) exposure at time of hospitalization and mortality at thirty days - partially adjusted

9. Logistic regression examining association between $\mathrm{PM}_{2.5}$ (continuous) exposure at time of hospitalization and mortality at thirty days - minimally adjusted

10. Logistic regression examining association between $\mathrm{PM}_{2.5}$ (continuous) exposure at time of hospitalization and mortality at thirty days - partially adjusted

11. Logistic regression examining association between $\mathrm{PM}_{10}$ (quartile) exposure at time of hospitalization and mortality at thirty days - minimally adjusted

12. Logistic regression examining association between $\mathbf{P M}_{10}$ (quartile) exposure at time of hospitalization and mortality at thirty days - partially adjusted

13. Logistic regression examining association between $\mathrm{PM}_{2.5}$ (quartile) exposure at time of hospitalization and mortality at thirty days - minimally adjusted

14. Logistic regression examining association between $\mathbf{P M}_{2.5}$ (quartile) exposure at time of hospitalization and mortality at thirty days - partially adjusted

15. Cox proportional hazards regression examining association between $\mathrm{PM}_{10}$ (continuous) exposure at time of hospitalization and mortality at thirty days - minimally adjusted

16. Cox proportional hazards regression examining association between $\mathrm{PM}_{10}$ (continuous) exposure at time of hospitalization and mortality at thirty days - partially adjusted

17. Cox proportional hazards regression examining association between $\mathrm{PM}_{2.5}$ (continuous) exposure at time of hospitalization and mortality at thirty days - minimally adjusted

18. Cox proportional hazards regression examining association between $\mathrm{PM}_{2.5}$ (continuous) exposure at time of hospitalization and mortality at thirty days - partially adjusted 
19. Cox proportional hazards regression examining association between $\mathrm{PM}_{10}$

.......... (quartile) exposure at time of hospitalization and mortality at thirty days minimally adjusted

20. Cox proportional hazards regression examining association between $\mathrm{PM}_{10}$ (quartile) exposure at time of hospitalization and mortality at thirty days partially adjusted

21. Cox proportional hazards regression examining association between $\mathrm{PM}_{2.5}$ (quartile) exposure at time of hospitalization and mortality at thirty days minimally adjusted

22. Cox proportional hazards regression examining association between $\mathbf{P M}_{2.5}$ (quartile) exposure at time of hospitalization and mortality at thirty days partially adjusted

23. Effect modification by age (category) on the relationship between $\mathrm{PM}_{10}$ (quartile) exposure and mortality at 30 days - partially adjusted logistic regression model with interaction term

24. Effect modification by sex on the relationship between $\mathbf{P M}_{10}$ (quartile) exposure and mortality at 30 days - partially adjusted logistic regression model with interaction term

25. Effect modification by race on the relationship between $\mathrm{PM}_{10}$ (quartile) exposure and mortality at 30 days - partially adjusted logistic regression model with interaction term

26. Effect modification by age (category) on the relationship between $\mathrm{PM}_{2.5}$ (quartile) exposure and mortality at 30 days - partially adjusted logistic regression model with interaction term

27. Effect modification by sex on the relationship between $\mathrm{PM}_{2.5}$ (quartile) exposure and mortality at 30 days - partially adjusted logistic regression model with interaction term

28. Effect modification by race on the relationship between $\mathrm{PM}_{2.5}$

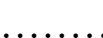

........

.........

(quartile) exposure and mortality at 30 days - partially adjusted logistic regression model with interaction term 


\section{LIST OF FIGURES}

FIGURE

PAGE

1. $\mathrm{PM}_{10}$ monitoring station locations within Jefferson County, 2014-2016

2. $\mathrm{PM}_{2.5}$ monitoring station locations within Jefferson County, 2014-2016

....... 27

3. Distribution of spatially averaged continuous $\mathrm{PM}_{10}\left(\mu \mathrm{g} / \mathrm{m}^{3}\right)$ concentrations at

....... 28 the time of hospitalization across the study sample

4. Distribution of spatially averaged continuous $\mathrm{PM}_{2.5}\left(\mu \mathrm{g} / \mathrm{m}^{3}\right)$ concentrations at the time of hospitalization across the study sample

....... 39

. Distribution of spatially averaged continuous, log-transformed $\mathbf{P M}_{10}$ concentrations at the time of hospitalization across the study sample

6. Distribution of spatially averaged continuous, log-transformed $\mathbf{P M}_{2.5}$ concentrations at the time of hospitalization across the study sample

7. Example of directional pattern of low to high values across three point sources from east to west

8. Example of homogenous pattern resulting from similar values across three point sources

9. Example of localized variation patterns based on differing values across four point sources 


\section{SPECIFIC AIMS}

Particulate matter (PM) is a type of air pollutant produced through natural and anthropogenic means. Due to its small size, PM travels easily through the air, with exposure most commonly occurring through inhalation. PM has been linked to numerous detrimental health outcomes, including elevated all-cause and cause-specific mortality risk. Studies have shown that exposure to PM is associated with increased pneumonia risk, but limited studies exist on the impact of PM exposure on pneumonia mortality. Pneumonia is responsible for approximately 50,000 deaths in the United States (US) each year. Given the ubiquitous nature of PM and its known association with respiratory complications, exacerbation of pneumonia symptoms by PM exposure may pose a serious threat to public health, particularly for the populations that are most vulnerable, such as those over the age of sixty-five years.

Jefferson County, Kentucky has a dense automotive-reliant population, has occurrences of violations of ambient PM concentration limits set by the US Environmental Protection Agency (EPA), and contains many point sources of PM within its boundaries, suggesting elevated exposure may be a concern for area residents. In this dissertation, the relationship between $\mathrm{PM}_{10}$ and $\mathrm{PM}_{2.5}$ exposure and mortality in adults hospitalized for community acquired pneumonia (CAP) in Jefferson County from the Hospitalized Adults with Pneumococcal Pneumonia: Incidence Study (HAPPI) cohort acquired from University of Louisville (UofL) School of Medicine Division of Infectious Diseases was 
evaluated. Various spatial interpolation methods exist for estimating PM concentration; two methods, one simple and one comparatively complex, were employed to allow for the comparison of PM estimation methods. This study examined the relationship between PM exposure and pneumonia mortality in the HAPPI cohort of predominately elderly population within Jefferson County, KY.

To achieve this goal, the following specific aims were evaluated:

1. Analysis of the relationship between $\mathrm{PM}_{10}$ and $\mathrm{PM}_{2.5}$ exposure and 30-day mortality in HAPPI participants, with PM concentration values being interpolated using spatial averaging, and said values examined using the following criteria: dichotomization based on National Ambient Air Quality Standards (NAAQS) cutoffs, analysis as a continuous exposure variable, and creation of quartiles to assess non-linear associations with mortality.

2. Examination of kriging validity as a means of interpolation given sparsity of data.

3. Investigation of effect modification on 30-day mortality by age, race, and sex. 


\section{INTRODUCTION}

Pneumonia can be generally defined as inflammation of the lungs, most commonly caused by an infectious agent, and often characterized by the presence of fluid or pus within the affected areas. The condition can be categorized based on a variety of parameters, including the geographic location where the patient acquired the condition, the type of infectious agent causing the condition, and the affected area of the lung. Pneumonia symptoms may vary depending on the type of pneumonia present and the individual's profile can include cough, fever, chills, pleuritic chest pain, shortness of breath, sputum production, tachypnea, and tachycardia. Despite being treatable in many cases, pneumonia remains a leading infectious cause of death among the very young and old and is responsible for approximately 50,000 deaths per year in the United States of America (USA) alone (1). An estimated three million died from lower respiratory tract infections, including pneumonia, globally in 2016 (2). Community-acquired pneumonia is a type of lower respiratory tract infection. Lower respiratory tract infections are a category of diseases estimated to be the greatest communicable cause of death and fourth leading cause of death worldwide (2).

In this introduction, a general background for pneumonia classifications is provided, along with epidemiologic information about community-acquired pneumonia among adults eighteen years of age and older, and whether air pollutants can affect mortality and hospitalization rates in this adult patient population. 


\section{Pneumonia Classification and Etiology}

The type of pneumonia diagnosed is classified based upon several factors: where the disease was acquired, etiology, and the affected area of the lung. The setting in which the disease was acquired is of great clinical importance, as this often helps dictate the type of treatment that will be used. Community-acquired pneumonia and nosocomial pneumonia are two primary classifications of setting-specific pneumonia (3).

Community-acquired pneumonia is pneumonia that develops outside of a hospital or healthcare-related setting, resulting in either outpatient or inpatient treatment depending on severity. Community-acquired pneumonia is the most common type observed (4). In addition to high rates of morbidity and mortality, this condition also results in massive cost burdens on the US healthcare system; a study published in 2018 estimated the yearly amount spent on community-acquired pneumonia hospitalizations of individuals 65 years and older alone exceeded one billion dollars (5), and data from 2011 suggested overall US pneumonia-related medical expenditures for the year to be in excess of ten billion dollars (6).

The infectious agents capable of inducing community-acquired pneumonia are legion, encompassing a wide array of bacterial, fungal, protozoal, and viral entities. Bacteria and viruses are the most common causal pathogens. The onset of communityacquired pneumonia can be attributed to such pathogenic agents as severe acute respiratory syndrome coronavirus 2 (COVID-19), human metapneumovirus, human parainfluenza virus, influenza, legionnaires disease, Mycoplasma pneumoniae, pneumococcus, pneumocystis, respiratory syncytial virus, and rhinovirus, among other etiologies (7). The most common etiological causes of community-acquired pneumonia resulting in outpatient 
treatment are Streptococcus pneumoniae, Mycoplasma pneumoniae, Haemophilus influenzae, Chlamydophila pneumoniae, and respiratory viruses such as adenovirus, influenza A and B, parainfluenza, and respiratory syncytial virus (7). The most common etiological causes of community-acquired pneumonia resulting in non-intensive care unit inpatient treatment are Streptococcus pneumoniae, Mycoplasma pneumoniae, Chlamydophila pneumoniae, Haemophilus influenzae, Legionella species, aspiration, and respiratory viruses - those previously detailed (7). The most common etiological causes of community-acquired pneumonia resulting in intensive care unit inpatient treatment are Streptococcus pneumoniae, Staphylococcus aureus, Legionella species, gram-negative bacilli, and Haemophilus influenzae (7). In light of the recent pandemic, it is likely severe acute respiratory syndrome coronavirus 2 would be included in these lists as well.

Nosocomial pneumonia includes subclassifications such as hospital-acquired pneumonia and ventilator-associated pneumonia. Hospital-acquired pneumonia is pneumonia that develops after a minimum of two days following hospital admission, presumably due to a hospital-related cause. Healthcare-associated pneumonia was a classification connected to, but different from hospital-acquired pneumonia, and encompassed pneumonia that could be attributed to such factors as being on dialysis treatment, use of immunosuppression therapies, recent hospital stays, and being a resident of a nursing facility. In recent years, healthcare-associated pneumonia has been removed as a classification. It was once believed that those exposed to the various facets of the healthcare system connected to the healthcare-associated pneumonia classification were more likely to develop pneumonia as a result of infection by multidrug-resistant organisms, but this was later contested (8, 9); use of healthcare-associated pneumonia as a 
classification resulted in the improper usage of antibiotic treatments. Lastly, ventilatorassociated pneumonia is pneumonia that develops after a minimum of two days after endotracheal intubation.

\section{Epidemiology of Community-Acquired Pneumonia}

\section{Incidence of Community-Acquired Pneumonia}

Great efforts have been made to adequately characterize community-acquired pneumonia incidence. In the United States, one such effort was the 2010 Etiology of Pneumonia in the Community (EPIC) study carried out by the Centers for Disease Control and Prevention (CDC) and eight affiliated hospitals and medical centers (6). The purpose of the study was to determine the burden of community-acquired pneumonia hospitalizations among children and adults. A total of 2,488 adult participants (median age was 57 years) hospitalized for pneumonia in any of five affiliated hospitals located in Chicago and Nashville were enrolled between January 2010 and June 2012. Among the 2,320 participants with radiographic evidence of pneumonia, 498 (21.5\%) required intensive care and $52(2.2 \%)$ died. Among the 2,259 participants with pathogens detected from biological specimens and radiographic evidence of pneumonia, viruses were the pathogen most frequently found to be present, followed by bacteria. The most common pathogens found were human rhinovirus, influenza virus, and Streptococcus pneumoniae.

The average annual community-acquired pneumonia incidence for the EPIC population was found to be 24.8 cases per 10,000 adults (95\% CI: 23.5 - 26.1) (6). Older adults had higher incidence, with adults 18 to 49 years of age having an incidence of 6.7 cases per 10,000 adults (95\% CI: $6.1-7.3$ ), adults 50 to 64 years of age having an incidence of 26.3 cases per 10,000 adults ( $95 \%$ CI: $24.1-28.7$ ), adults 65 to 79 years of age having 
an incidence of 63.0 cases per 10,000 (95\% CI: $56.4-70.3$ ), and adults 80 years of age or older having an incidence of 164.3 cases per 10,000 adults (95\% CI: $141.9-189.3)$. The average annual incidence from EPIC was similar to the 26.7 cases per 10,000 adults found in a previous prospective study carried out in Ohio in 1991 (10), suggesting that overall community-acquired pneumonia incidence has not changed that greatly in the US. Incidence of community acquired pneumonia in the US is higher within older age groups, and average incidence is relatively similar to rates seen in some western countries (11-13). Another more recent study conducted on this topic was the Pneumonia Incidence Study, carried out by the University of Louisville (UofL) Pneumonia Study Group (14). The Group was a multidisciplinary association including UofL Infectious Disease, Pulmonary Medicine, and Pathology, Louisville Metro Public Health and Wellness, and the Kentucky Office of Vital Statistics. The study was a prospective, population-based study containing all hospitalized adults with CAP in Louisville, KY between June 1, 2014, and May 31,2016. The purpose of the study was to determine the incidence of patients hospitalized with CAP. CAP incidence was calculated for both the study area and for the US as a whole; US incidence was calculated by multiplying the Louisville incidence by the total approximate US adult population of 2014. Unique (non-repeat) annual CAP incidence for the study area was found to be 634 cases per 100,000 adults (63.4 per 10,000 adults); age-adjusted annual incidence was 649 cases per 100,000 adults. CAP incidence for the US was estimated to be 1,555,034 adults per year; age-adjusted incidence was estimated to be 1,591,825 adults per year. Incidence distinctions by age were observed, annual unique incidence in patients 18-64 years of age being 327 per 100,000 adults, while annual unique incidence in patients $65+$ years of age was 2,093 cases per 100,000 adults. 
Community-acquired pneumonia incidence estimates have been observed to fluctuate by country in some instances. For example, the average rates were reported to be 29.6 cases per 10,000 individuals in Germany in $2009,15.9$ cases per 10,000 individuals in Malaysia in 2016, 29.5 cases per 10,000 individuals in the Netherlands in 2015, 31.2 cases per 10,000 individuals in the United Kingdom (UK) in 2016, and 8.1 cases per 10,000 individuals in Vietnam in 2013, with incidence varying greatly by age group in a manner similar to the patterns observed in the EPIC study $(11-13,15,16)$. It is quite possible that variations in age distribution of populations in different countries contributed to the differences seen in overall incidence rates.

Risk for acquiring community-acquired pneumonia include several factors, such as being of older age, having comorbidities, certain lifestyle factors, and some environmental factors (17). Age is a factor of considerable importance when examining the risk of acquiring community-acquired pneumonia $(18,19)$. As demonstrated by the EPIC study, being in the elderly population - defined as 65 years of age or greater - results in a marked increase in incidence over prior age groups (6). A study published in 2018 analyzing 20142015 Medicare claims data of elderly adults in the US noted that community-acquired pneumonia resulted in a higher incidence of hospitalization (846.7 hospitalizations per 100,000 person-years) than myocardial infarction, osteoporotic fractures, and stroke, which resulted in 405, 343.9, and 278.9 hospitalizations per 100,000 person-years, respectively (20).

Elderly individuals are at greater risk for community-acquired pneumonia due to a number of factors. First and foremost, the aging process results in certain impairments in immune and lung function over time, such as reduced efficiency of nasal mucociliary 
clearance, chronic low-grade pulmonary inflammation, and decreased functionality of immune cells (21-24). Additionally, the elderly may begin to experience swallowing disorders, increasing risk for aspiration - a known risk factor of pneumonia (25). Ageassociated malnutrition, weight loss, general reduction in quality of life, and declines in physical functionality are also risk factors for community-acquired pneumonia (26-28). Finally, elderly individuals often incur a greater burden of comorbidities than those seen in younger age groups, many of which have been associated with community-acquired pneumonia (28).

The comorbidities associated with risk for community-acquired pneumonia are numerous, spanning various bodily systems. Chronic heart disease and respiratory conditions, including asthma, bronchitis, chronic obstructive pulmonary disease (COPD), and history of pneumonia, have been strongly associated with risk of community-acquired pneumonia $(18,19,29-34)$. Cerebrovascular disease, such as stroke, and neurological conditions such as dementia, epilepsy, multiple sclerosis, and Parkinson's disease have been linked to increased risk; elevated risk may occur due to swallowing disorders resulting from these conditions and sedative medications used to treat them, possibly resulting in aspiration (17). Conditions that result in immune system deficiencies or dysfunction, such as asplenia, cancer, human immunodeficiency virus (HIV) / acquired immunodeficiency syndrome (AIDS), and rheumatoid arthritis have been associated with increased risk (19, $34,35)$. Other conditions that have been associated with increased community-acquired pneumonia risk are anemia, chronic renal and liver disease, diabetes mellitus, dysphagia, and functional impairment $(19,34,36)$. 
Several demographic and lifestyle factors have been associated with risk for community-acquired pneumonia. Some risk factors, such as having poor nutritional status (ex. underweight or malnutrition), having poor dental hygiene, and smoking, have been definitively linked to increased risk in the literature $(19,32,33,37)$. Others have been less consistent in their association; these risk factors include misuse of intravenous drugs, being overweight, being male, being unmarried/single, exposure to passive smoking, having high alcohol intake, and having regular contact with children $(19,32,33,38-41)$. The literature examining protective factors is inconclusive, but some studies have shown that meeting daily physical exercise requirements, higher education level, and being vaccinated against influenza can reduce risk (42). The existing adult vaccine for Streptococcus pneumoniae has shown varied efficacy in numerous studies, with some studies showing a protective effect and others showing minimal efficacy $(34,43)$.

The literature examining community-acquired pneumonia risk as it relates to environmental factors is relatively sparse. An association between increased risk and occupational exposure to airborne contaminants such as asbestos and agricultural, coal, and stone dusts has been detected (44). Another study noted an association between increased risk with recent rapid changes in temperature in the occupational setting (32). It has been found that self-report of regular occupational exposure to gases, fumes, and chemicals and in-home exposure to fumes from gasoline, paints, and solvents has been associated with increased risk in individuals aged 65 years and older (19).

A Canadian study published in 2009 observed that two-year exposure to nitrogen dioxide and $\mathrm{PM}_{2.5}$ in individuals aged 65 years and older was associated with significantly elevated odds of community-acquired pneumonia hospitalization, with odds ratios of 2.30 
(95\% CI: 1.25-4.21) for nitrogen dioxide and 2.26 (95\% CI: 1.20-4.24) for $\mathrm{PM}_{2.5}$, adjusting for age, sex, education, smoking history, and history of exposure to workplace environmental contaminants (45). Participants were recruited from within the Hamilton catchment area in Ontario, Canada, with 345 patients hospitalized for community acquired pneumonia randomly recruited and 494 controls from the same community randomly recruited. Nitrogen dioxide and $\mathrm{PM}_{2.5}$ data were gathered from monitoring stations operated by the Ontario Ministry of Environment; participant address-specific ambient pollutant values were estimated using inverse distance weighting and bicubic splines methods, and also land use regression for nitrogen dioxide exclusively, though primary association results were reported using inverse distance weighting-based exposure values. Mortality from Community-Acquired Pneumonia

Community-acquired pneumonia associated mortality rates tend to be the highest among adults over the age of sixty-five years, with mortality rates ranging from $10 \%$ to $30 \%$, though elevated long term mortality rates have been observed even after adjusting for age $(46,47)$. Several chronic diseases and conditions have been associated with increased risk for mortality from community-acquired pneumonia, including cardiovascular disease, COPD, human immunodeficiency virus (HIV), malignant cancers, neurodegenerative disorders, and malnutrition $(46,48)$. The number of factors implicated in the risk for community-acquired pneumonia mortality led to the development of a pneumonia severity index (PSI) to identify those at low risk for dying from the disease within thirty days of presentation (49) and to influence clinical care and management.

PSI scores are based on the presence, or lack, of several variables that are known to be associated with community-acquired pneumonia mortality. The PSI score can range 
from 0 to 395; point values vary by variable, and points are accumulated depending on selections made. These variables fall into several categories, including demographic factors, comorbidities, findings from physical examination, and findings from laboratory and radiographic examination. Demographic factors include increasing age, nursing home residence status, and male sex. Comorbidities include cerebrovascular disease, congestive heart failure, liver disease, neoplastic disease, and renal disease. Factors from physical examination include altered mental state status, pulse greater than or equal to 125 heartbeats per minute, respiratory rate greater than or equal to 30 breaths per minute, systolic blood pressure less than $90 \mathrm{mmHg}$, and temperature less than 35 degrees Celsius or greater than or equal to 40 degrees Celsius. Risk factors from laboratory or radiographic examination include arterial $\mathrm{pH}$ less than 7.35 , blood urea nitrogen greater than or equal to $30 \mathrm{mg} / \mathrm{dL}$, glucose greater than or equal to $250 \mathrm{mg} / \mathrm{dL}$, hematocrit less than 30 percent, partial pressure of arterial oxygen less than $60 \mathrm{mmHg}$ or oxygen saturation less than $90 \%$, presence of pleural effusion, and sodium levels less than $130 \mathrm{mEq} / \mathrm{L}$.

The adult PSI is categorized in to five classes, each of which represents a mortality risk range to which an individual is assigned (49). The classes are as follows: Class I (0-50 points) indicates an estimated mortality risk of approximately $0.1 \%$, Class II (51-70 points) indicates an estimated mortality risk of $0.7 \%$, Class III (71-90 points) indicates an estimated mortality risk of $0.9 \%$, Class IV (91-130 points) indicates an estimated mortality risk of 9.3\%, and Class V (131-395 points) indicates an estimated mortality risk of $27 \%$. Those falling into Classes I and II are at low risk for mortality and are generally referred to outpatient care. Those who fall into Class III are at moderate risk for mortality and may be either referred to outpatient care or admitted for observation. Classes IV and V are high 
mortality risk classes, generally resulting in hospitalization for inpatient care. Though often cited as being a quality decision aid in pneumonia prognosis, it has been stated that the PSI should not be relied upon as the sole indicator for decision to hospitalize due to low positive predictive values $(50,51)$.

Other comorbidities and conditions not included in the adult PSI have been associated with mortality from community-acquired pneumonia, including Barthel Indexindicated functional status, chronic obstructive pulmonary disease (COPD) status, and ineffective antibiotic therapy $(35,52,53)$. Additionally, there is a small body of evidence that suggests that environmental exposures such as air pollution can increase communityacquired pneumonia associated mortality risk. A case-crossover study published in 2018 found that short-term exposure to $\mathrm{PM}_{2.5}$ - within six days of outcome presentation - was associated with increased hospitalization (lag day 1 adjusted odds ratio (AOR) per $10 \mathrm{ug} / \mathrm{m}^{3}$ over $12 \mathrm{ug} / \mathrm{m}^{3}: 1.35,95 \%$ CI: 1.16-1.57) and mortality (lag day 5 AOR: $1.50,95 \%$ CI: 1.03-2.16) from pneumonia in individuals aged 65 years and older, based on results from 4,336 pneumonia cases from seven hospitals in the Wasatch Front metropolitan area in Utah (54). Air pollutant data were derived from ten EPA air monitoring stations located in the same topographical basin as the corresponding participant. Participant address-specific values were interpolated using inverse distance weighting. An occupational study of Swedish construction workers noted that exposure to inorganic dusts, such as those from asbestos, cement, concrete, man-made mineral fibers, and quartz, was associated with increased mortality from community-acquired pneumonia (55). Additionally, higher levels of physical activity have been associated with reduced mortality from community-acquired 
pneumonia and other respiratory conditions (56). Sequential rounds of antibiotic therapy have been shown to be protective, as well (52).

\section{Pneumonia and Particulate Matter}

Air pollution, including PM, has been increasingly recognized as a global health threat by the World Health Organization (WHO), who held the Global Conference on Air Pollution and Health at the end of October 2018 to discuss measures to combat this increasingly pervasive source of premature death (57). An ever-growing body of research has been compiled on the topic of respiratory outcomes and PM exposure, suggesting with relative uniformity that there exists a relationship between the two. Despite its status as a leading cause of death, pneumonia seems to make up a comparatively small percentage of these studies. Some evidence exists that associates environmental exposures such as air pollution with increased pneumonia mortality risk; however, likelihood of hospitalization is more often studied, and an association is well established $(54,58,59)$.

Particulate matter (PM) is a form of air pollution primarily categorized into different size fractions - typically $\mathrm{PM}_{10}$ and $\mathrm{PM}_{2.5}(60)$. $\mathrm{PM}_{10}$ can be defined as particles that are less than 10 micrometers in diameter. $\mathrm{PM}_{2.5}$, a subset of $\mathrm{PM}_{10}$, can be defined as particles that are 2.5 micrometers in diameter or smaller and are referred to as fine PM. Coarse PM is a category of PM where the particles are between 2.5 and 10 micrometers in diameter. The chemical compositions of these particles largely depend on their sources of origin, which can be both natural and anthropogenic $(60,61)$. Natural sources include soil, dust, minerals, sea salt, and bioaerosols; naturally-derived PM is typically larger, belonging to the classification $\mathrm{PM}_{10}$, while $\mathrm{PM}_{2.5}$ is often anthropogenically produced and commonly

attributed to combustion processes, both anthropogenic and natural (62). Anthropogenic 
sources include incomplete combustion processes, automobile emissions, dusts from agriculture and construction, and emissions from cooking (63). Due to their diminutive size, these particles are capable of traveling great distances through the air and are easily inhaled. Once inhaled, PM can penetrate deep into the lungs and bloodstream; the fraction of inhaled particles capable of penetrating beyond the larynx and unciliated airways are known as the thoracic and respirable fraction, respectively (64).

National Ambient Air Quality Standards (NAAQS) are used by the US EPA to determine the cutoff points for maximum levels of unsafe exposure to criteria pollutants, which include airborne lead $(\mathrm{Pb})$, carbon monoxide $(\mathrm{CO})$, nitrogen dioxide $\left(\mathrm{NO}_{2}\right)$ and nitric oxides $\left(\mathrm{NO}_{\mathrm{x}}\right)$, ozone $\left(\mathrm{O}_{3}\right), \mathrm{PM}_{10}$ and $\mathrm{PM}_{2.5}$, and sulfur dioxide $\left(\mathrm{SO}_{2}\right)$. NAAQS are divided into primary and secondary standards (65). Primary standards are generally more stringent as they are designed to provide public health protection to both the general population and populations deemed to be at-risk or "sensitive," such as those suffering from chronic respiratory conditions, children, and the elderly. Secondary standards can be - but are not always - less stringent and are put in place to protect the public welfare by reducing the likelihood of such events as reduced visibility and property and resource damage. The standard for $\mathrm{PM}_{10}$ is set to a twenty-four-hour average of $150 \mu \mathrm{g} / \mathrm{m}^{3}$, which cannot be exceeded more than once per year on average over three years. $\mathrm{PM}_{2.5}$ has a primary standard set to a one-year average of $12.0 \mu \mathrm{g} / \mathrm{m}^{3}$, based upon the annual mean averaged over three years, a secondary standard set to a one-year average of $15.0 \mu \mathrm{g} / \mathrm{m}^{3}$, based upon the annual mean averaged over three years, and a standard set to a twenty-four-hour average of 35 $\mu \mathrm{g} / \mathrm{m}^{3}$, based upon the $98^{\text {th }}$ percentile averaged over three years. 
Exposure to these particles has been associated with all-cause mortality, causespecific mortality, and morbidities, including cardiovascular and respiratory outcomes (63, 66-69), with stronger associations for smaller PM size fractions. The study of PM's influence on pneumonia incidence, mortality, and hospitalization has been complicated by the fact that seasonal climate seems to play a significant role on the magnitude of the observed associations. A case-crossover analysis including 1,384,813 pneumonia hospital admissions based on data from 1986 to 1999 in 36 US cities determined that ambient $\mathrm{PM}_{10}$ levels, gathered using the US EPA's Aerometric Retrieval System, were associated with increased hospitalization for pneumonia (69). The increase in pneumonia hospital admissions was higher by $0.84 \%$ (95\% CI: $0.50 \%-1.19 \%)$ for a 10 microgram per cubic meter $\left(\mu \mathrm{g} / \mathrm{m}^{3}\right)$ increase in $\mathrm{PM}_{10}$ at the time of hospital admission, adjusting for day of the week and apparent temperature. While $\mathrm{PM}_{10}$ levels generally remained consistent throughout the year, it was found that those cities with a higher summer apparent temperature and a greater percentage of homes containing central air conditioning experienced a lower increase in hospitalizations due to pneumonia, possibly due to the fact that those living in homes with central air conditioning would have lower outdoor air pollutant exposure within their homes than those relying on open windows for ventilation during warmer months.

Another study by Qui et al., published in 2014, examined the relationship between exposure to $\mathrm{PM}_{10}, \mathrm{PM}_{2.5}$, and emergency hospital admissions due to pneumonia in Hong Kong, China (70), where pneumonia was the second leading cause of death that year. PM data were gathered from ten general monitoring stations throughout the region. The study included 75,863 hospital admissions for pneumonia spanning the period from January 1, 
2011 to December 31, 2012. Utilizing generalized additive Poisson modeling and unconstrained distributed lag modeling, it was found that for every $10 \mu \mathrm{g} / \mathrm{m}^{3}$ increase in $\mathrm{PM}_{10}$ over the previous four days, emergency hospitalizations increased by 3.33\% (95\% CI: $1.54 \%-5.15 \%$ ), adjusting for long-term trends, seasonality, weather factors, calendar effect, and influenza epidemics. Under the same conditions, it was found that for every 10 $\mu \mathrm{g} / \mathrm{m}^{3}$ increase in $\mathrm{PM}_{2.5}$ over the previous four days, emergency hospitalizations increased by $1.69 \%$ (95\% CI: $0.68 \%-2.70 \%)$.

\section{Air Pollution in Jefferson County, Kentucky}

Jefferson County, Kentucky (KY), is located in the northwest portion of the Commonwealth, and falls within the Ohio River Valley. The Ohio River Valley is known to contain a high number of pollutant-generating facilities, including coal-fired power plants, mining sites, and industrial sites (71). Attributed to the geographic characteristics of the Ohio River Valley, it has been shown that pollutants generated in the area become trapped during periods of meteorological high pressure, and are subsequently transported across the region when low pressure fronts move through (72). These regional characteristics suggest particulate matter to be a relevant exposure to study in relation to community-acquired pneumonia mortality in Jefferson County, KY.

Despite being located within this region, in 2018, Jefferson County was reported to have met the majority of the EPA-mandated NAAQS for criteria pollutants (73). Of these pollutants, Jefferson County failed to meet the NAAQS in 2018 for only ozone, earning the designation of "non-attainment" status; failing to meet even one NAAQS is enough for a county to be placed in "non-attainment" status by the EPA. Sulfur dioxide levels were formerly in "non-attainment," but have since fallen below the NAAQS, and "attainment" 
re-designation is being petitioned by the Louisville Metro Air Pollution Control District (APCD). The Louisville Metro APCD works alongside the EPA, Kentucky Division for Air Quality, and Indiana Department of Environmental Management to implement and enforce air-related legislation, such as the Clean Air Act, in Jefferson County.

Though Jefferson County air pollution generally falls within NAAQS parameters, it is possible that specific locations within the county, such as those closer to heavily trafficked roadways or point sources, may experience higher levels of PM exposure than those recorded at monitoring sites. Many individuals in this county rely upon motor vehicles to get to work. According to 2017 American Community Survey data, 293,791 (80.2\%) out of 366,473 surveyed Jefferson County workers aged sixteen years and over had access to at least one motor vehicle and used it to drive to work alone (74). A thorough satellite-level observation of the county revealed that a number of residential areas fall within a short distance of busy highways and other frequently driven roadways (75); automobile-generated PM exposure may be increased within these areas.

\section{Particulate Matter, Mortality, and Effect Modifiers}

Effect modification occurs when a third variable, present on the proverbial pathway linking exposure and outcome, is introduced, and varyingly affects the outcome depending on the level, or stratum, of the third variable. Though perhaps not specific to pneumonia mortality as the outcome, there have been studies examining effect modification as it pertains to the relationship between PM exposure and general and cause-specific mortality. Among these studies, the variables age, sex, and presence of specific comorbidities, such as type 2 diabetes and cardiovascular disease, are commonly examined, suggesting in some cases that they serve as effect modifiers in the aforementioned relationship (76-79). 
Older age has been consistently associated with elevated mortality resulting from PM exposure in the literature. Individuals 85 years and older within the 2000-2012 US Medicare population were found to have significantly elevated relative risk of mortality associated with each $10 \mu \mathrm{g} / \mathrm{m}^{3}$ increase in $\mathrm{PM}_{2.5}(79,80)$. A study of the residents of Oslo, Norway published in 2007 noted that both men and women at or above the age of 51 years who were exposed to higher levels of $\mathrm{PM}_{10}$ and $\mathrm{PM}_{2.5}$, indicated by exposure quartiles, had significantly elevated adjusted hazard ratios of all-cause and cause-specific mortality versus those observed in the referent lowest exposure quartile; significant trend $p$-values were consistently reported among PM quartiles as well (81). A 12-year population-based retrospective study carried out in Shenyang, China reported that both those over and under 60 years of age had significantly elevated adjusted hazard ratios for mortality associated with a $10 \mu \mathrm{g} / \mathrm{m}^{3}$ increase in $\mathrm{PM}_{10}(\leq 60$ years: $\mathrm{AHR}=1.68,95 \% \mathrm{CI}=1.52-1.86 ;>60$ years: AHR $=1.66,95 \% \mathrm{CI}=1.59-1.74)$, adjusting for age, gender, education level, smoking status, personal income, occupational exposure, BMI, and exercise (82).

In more than one instance, females have been noted to have greater mortality risk from air pollution exposure than males (77-79). This result seems to be more closely tied to PM exposure than to other air pollutants. For example, females among the $2000-2012$ US Medicare population had a greater relative risk of mortality due to increased $\mathrm{PM}_{2.5}$ exposure than males, but such an effect was not seen due to increased ozone exposure (79). The possibility that females may experience PM exposure differently from males has been examined in past literature. One such study, conducted in a laboratory setting, noted that female participants with otherwise normal respiratory health were found to have greater total and coarse particle deposition in the lungs versus male participants (83). Another 
study noted that female marathon runners, but not male runners, had significantly reduced performance as a result of $\mathrm{PM}_{10}$ exposure, with performance being reduced by approximately $1.4 \%$ for every $10 \mu \mathrm{g} / \mathrm{m}^{3}$ increase in $\mathrm{PM}_{10}$ concentration present during events (84).

Race less commonly appeared as an effect modifier in the literature but was present enough for it to warrant investigation. In one study, the geographic distribution of racial groups within an area ultimately reveals itself to be a cause for concern, with worse health outcomes revealed in predominately African American neighborhoods (85). African Americans have been found to have higher hospital mortality due to pneumonia than whites within the same hospital as well (86), and have also been found to have a significantly greater burden of PM exposure versus the general population (87). In the same 2000-2012 US Medicare population previously mentioned, non-whites were borderline significantly more likely to have increased mortality as a result of increased $\mathrm{PM}_{2.5}$ exposure than whites (79)

\section{Mapping Air Pollution With GIS}

Air pollution data used in research is commonly gathered from monitoring stations established throughout the locations of interest. In the US, the EPA maintains many such monitors across the country and makes the data freely and easily available through their website. Though offering a plethora of generalized information, the unfortunate downside to utilizing these resources is visible when, in certain parts of the country, the number of monitors is sparse compared to the areas being monitored. For example, a single monitoring station may be rated for county-wide representation, but it still only reflects data from a given geographic point. This is not to say that the information gathered is 
without use, but a single monitor fails to take into account localized variations in pollutant concentrations that may be crucial to understanding variability in air pollution across space that impact health outcomes in areas being studied.

Geographic Information Systems (GIS) provide a way to circumvent this issue through the use of spatial interpolation techniques. Several such techniques exist, ranging in complexity and ease of implementation (88). Spatial averaging is a technique in which the values for a given pollutant at a specified time are gathered from all monitors within a designated radius from the point of interest and are averaged, the result of which is assigned to a geocoded location (88). The nearest neighbor technique requires only that a point of interest be assigned the pollutant concentration value of its nearest monitoring site, which for some points may be quite close while for other points may be very far from the monitor (88). Inverse distance weighting involves the calculation of interpolation weights as a function of the distance between monitoring sites and the point of interest, with values provided by monitoring sites closer to the point of interest weighing more heavily than those further away (88). Kriging involves the smoothing of data from point measurements scattered across a geographic area, providing weights that can be used to determine values for a given variable $(88,89)$.

Despite sharing some similarities in that distance is utilized by both methodologies, inverse distance weighting and Kriging are separate approaches. While kriging is geostatistical, inverse distance weighting is a deterministic interpolation method that suggests an inherent simplicity in how it is applied, whereas kriging uses statistical models and spatial autocorrelation is considered (90). Inverse distance weighting is more appropriately used when the variable value being interpolated is dependent on location and 
the variable's value is assumed to decrease as distance increases from the sampling location, while Kriging is best used when a spatially correlated distance or directional bias is known to exist in the data being examined $(90,91)$. Given that the air monitoring stations simply detect levels of air pollutants and are not sources of these pollutants, it is unlikely that the inverse distance weighting assumptions hold true, making it less suitable than the kriging interpolative method. Unfortunately, both inverse distance weighting and kriging only function properly when sufficient data points are available from which to interpolate. 


\section{METHODS}

The primary objective of the study was to examine the relationship between exposure to airborne particulate matter at diagnosis and incidence of 30-day mortality among adults hospitalized with community-acquired pneumonia in Jefferson County, Kentucky. The study analyzed data from the Hospitalized Adults with Pneumococcal Pneumonia: Incidence Study (HAPPI) cohort based out of the University of Louisville Division of Infectious Diseases (UofL ID). Exposure values were interpolated using GIS spatial interpolation methods, which were largely reliant on data gathered by US EPA monitoring sites that were available online.

\section{Hypothesis}

The hypothesis of this study is that higher exposure to $\mathrm{PM}_{10}$ and $\mathrm{PM}_{2.5}$ is associated with increased incidence of mortality among adults hospitalized for community-acquired pneumonia in Jefferson County, KY.

\section{Study Area and Population}

The study area was Jefferson County in the Commonwealth of Kentucky, USA. The county covers an area of approximately 398 square miles. Based upon data from the 2017 American Community Survey, the total population of the study area was 764,378 people, $51.7 \%$ of which were female and $48.3 \%$ of which were male (92). The median age of Jefferson County residents was 38.0 years. Approximately $77.4 \%$ of the population was over the age of eighteen years. An estimated $14.9 \%$ of the population was over the age of 
65 years. $72.3 \%$ of residents identified as White, $21.2 \%$ as Black or African American, 2.7\% as Asian, $0.1 \%$ as American Indian and Alaska Native, 2.8\% as two or more races, and $0.8 \%$ as other race.

All HAPPI participants were recruited after being hospitalized in Jefferson County due to community-acquired pneumonia between June 1, 2014 and June 1, 2016. In total, 6,176 participants were recruited. HAPPI participants included adults eighteen years of age or older hospitalized and diagnosed with community-acquired pneumonia at one of nine HAPPI-affiliated hospitals (Baptist East, Jewish Hospital, Norton Audubon, Norton Brownsboro, Norton Downtown, Norton Suburban, St. Mary and Elizabeth, University Hospital, or the Veterans Affairs (VA) Hospital) and who had a permanent home address and residence in Jefferson County. The addresses could not be PO Boxes or extended stay hotels. Participants were excluded from participation in HAPPI if they were in the corrections system, had an invalid Social Security Number, had missing vital status data, or were missing geocoded address data.

\section{Outcome}

The outcome examined was all-cause mortality at or within thirty days. Mortality was reported at discharge from initial hospitalization, thirty days, six months, and one year, though only those who fell within the first two categories will be included in this analysis. Mortality was verified by the Kentucky Office of Vital Statistics through the release of limited death certificate information, which included confirmation and date of death but not cause. Due to monetary cost, cause of death information was not available for analysis. Mortality at or within thirty days was assumed to be most closely linked to pneumonia and therefore served as the proxy outcome of pneumonia-specific mortality; this was by 
recommendation of a member of the committee, but also appears to be a common outcome when examining pneumonia-related outcomes $(93,94) .597(9.7 \%)$ of participants had died at or within thirty days. Cause of death was only reported for $12(0.20 \%)$ participants, which was attributed to the cost of acquiring this information, with 5 of those deaths attributed to respiratory complications.

Where survival time was needed for Cox proportional hazards regression, persontime (days) was calculated by finding the difference between date of death and date of enrollment, as participants were enrolled at the time of hospitalization. Those who did not die were assumed to have the maximum amount of survival time - thirty days.

\section{Exposure}

The primary exposures of interest were concentrations of $\mathrm{PM}_{10}$ and $\mathrm{PM}_{2.5}$ at hospital admission date. The sources of information for $\mathrm{PM}_{10}$ and $\mathrm{PM}_{2.5}$ were from EPA air monitoring sites operated by the Louisville Metro APCD throughout Jefferson County (Table 1) $(95,96)$. In 2014, $\mathrm{PM}_{2.5}$ concentration values were gathered by four monitoring sites located at Southwick (site ID - 211110043), Watson Lane (site ID - 211110051), Cannons Lane (site ID - 211110067), and Durrett Lane (site ID - 211110075); in 2014, $\mathrm{PM}_{10}$ concentration values were gathered by three monitoring sites located at Southwick, Wyandotte Park (site ID - 211110051), and Watson Lane, though the Wyandotte Park monitor only provided results early in the year and prior to the beginning of HAPPI recruitment. In 2015, $\mathrm{PM}_{2.5}$ concentration values were gathered by four monitoring sites located at Southwick, Watson Lane, Cannons Lane, and Durrett Lane; in this year, $\mathrm{PM}_{10}$ concentration values were gathered by two monitoring sites located at Southwick and Watson Lane. In 2016, $\mathrm{PM}_{2.5}$ concentration values were gathered by four monitoring sites 
located at Southwick, Watson Lane, Cannons Lane, and Durrett Lane; in this year, $\mathrm{PM}_{10}$ concentration values were gathered by two monitoring sites located at Southwick and Watson Lane. Data from these sites were generally reported every one to three days and are available for download through the EPA's website (96). Concentration values are recorded in units of microgram per cubic meter $\left(\mu \mathrm{g} / \mathrm{m}^{3}\right)$. See Figures $\mathbf{1}$ and $\mathbf{2}$ for mapped monitor locations within Jefferson County.

Table 1: Particulate matter (PM) data provided by corresponding Jefferson County monitoring station, 2014-2016

\begin{tabular}{|l|c|c|c|}
\hline \multicolumn{1}{|c|}{ Monitoring Station } & 2014 & 2015 & 2016 \\
\hline Southwick & $\mathrm{PM}_{2.5}, \mathrm{PM}_{10}$ & $\mathrm{PM}_{2.5}, \mathrm{PM}_{10}$ & $\mathrm{PM}_{2.5}, \mathrm{PM}_{10}$ \\
\hline Watson Lane & $\mathrm{PM}_{2.5}, \mathrm{PM}_{10}$ & $\mathrm{PM}_{2.5}, \mathrm{PM}_{10}$ & $\mathrm{PM}_{2.5}, \mathrm{PM}_{10}$ \\
\hline Cannons Lane & $\mathrm{PM}_{2.5}$ & $\mathrm{PM}_{2.5}$ & $\mathrm{PM}_{2.5}$ \\
\hline Durrett Lane & $\mathrm{PM}_{2.5}$ & $\mathrm{PM}_{2.5}$ & $\mathrm{PM}_{2.5}$ \\
\hline Wyandotte Park & $\mathrm{PM}_{10}$ & & \\
\hline & & & \\
\hline
\end{tabular}




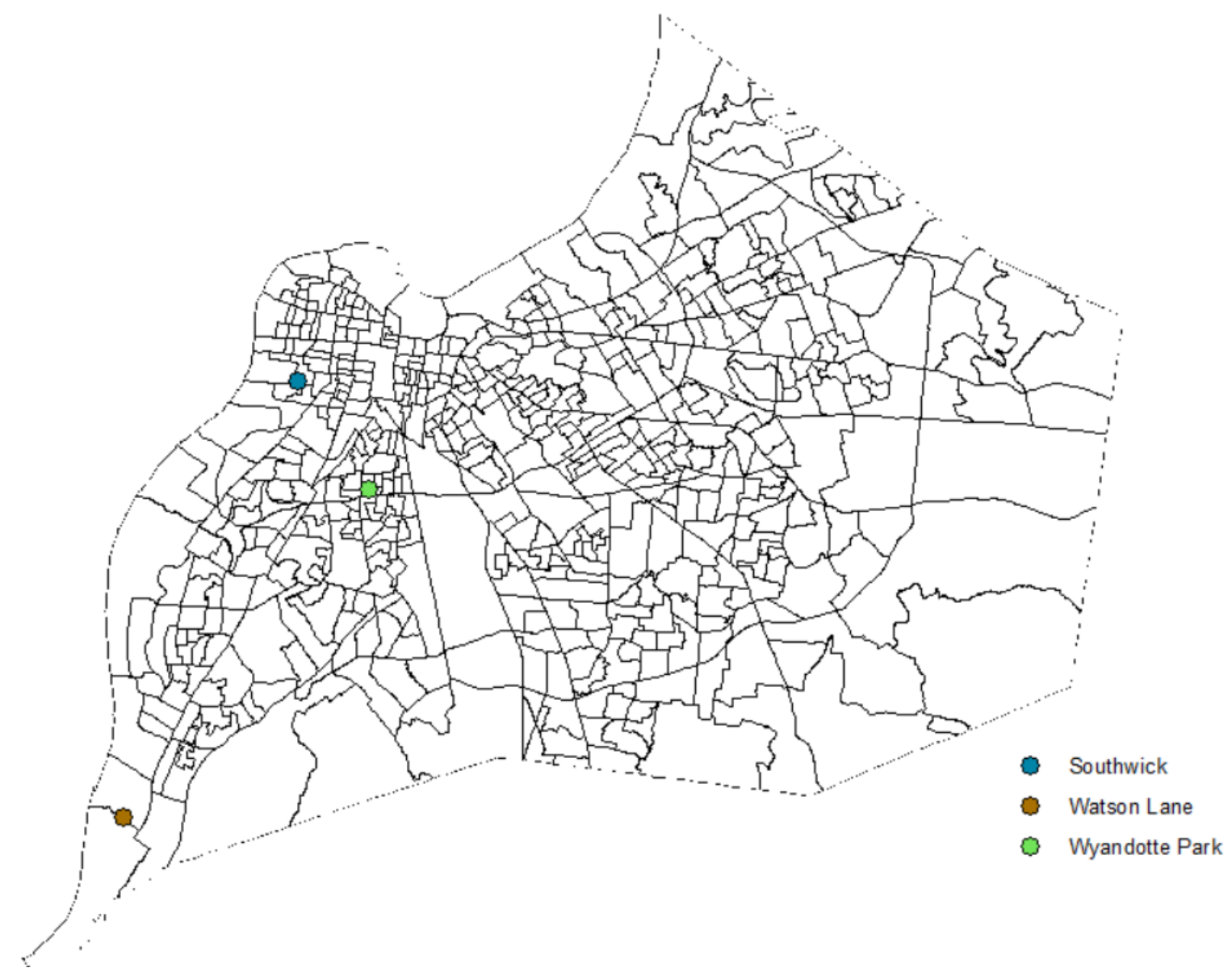

Figure 1 - PM10 monitoring station locations within Jefferson County, 2014-2016. 


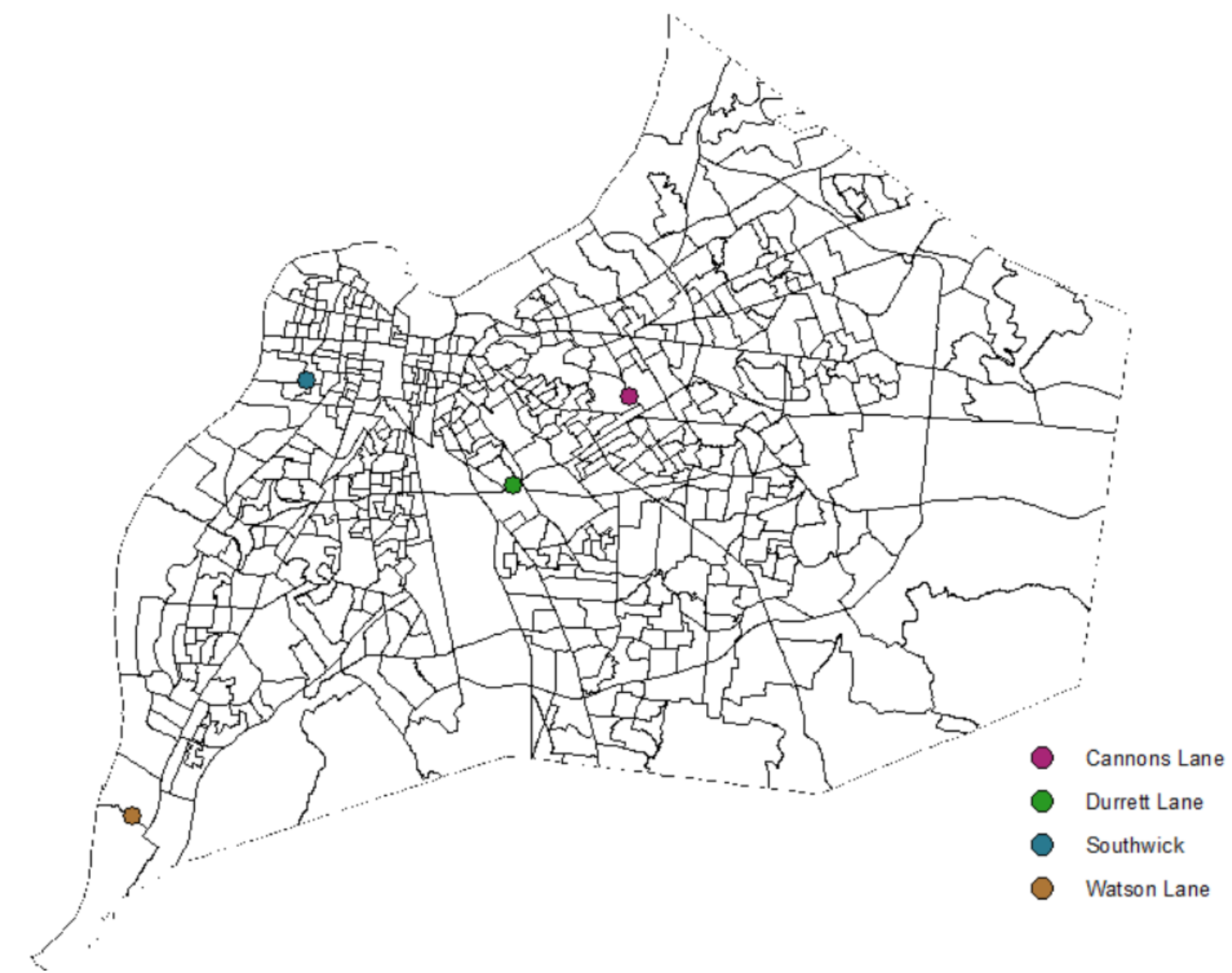

Figure 2 - $\mathbf{P M}_{2.5}$ monitoring station locations within Jefferson County, 2014-2016.

$\mathrm{PM}_{10}$ and $\mathrm{PM}_{2.5}$ concentration values for geocoded participant addresses at the time of hospitalization were interpolated through the use of two different spatial methodologies: spatial averaging and Kriging.

\section{Covariates}

\section{Demographic Variables}

To better assess the relationship between air pollution exposure and mortality, several demographic variables were adjusted for including age, sex, and race. These variables were possible predictors of pneumonia-specific mortality. Age, sex, and race information were collected from electronic medical records. Age was defined in years and primarily presented as a continuous variable; where represented in categories, age 
categories were established as individuals 18-64 years and individuals 65 years and older. Sex was defined as female and male. Race was defined as black, white, and other.

\section{Other Variables}

Other variables considered for adjustment were those associated with communityacquired pneumonia mortality, including PSI classification, active intravenous drug use status, alcoholic status, intensive care unit transfer status at time of initial hospitalization, past thirty-days oral antimicrobial therapy receival status, past ninety-days intravenous antibacterial therapy receival status, pneumococcal vaccine receival status, seasonal influenza vaccine receival status, smoking status, suspected aspiration status, and ventilatory support requirement status at time of initial hospitalization. Variable data were collected from, or calculated using, electronic medical records.

Participant PSI values represented the cumulative effect of all variables represented by this value and were defined as classes I through V. Active intravenous drug use status, alcoholic status, intensive care unit transfer status, past thirty-day oral antimicrobial therapy receival status, past ninety-day intravenous antibacterial therapy receival status, pneumococcal vaccine receival status, and seasonal influenza vaccine receival status are defined as yes or no. Smoking status was defined as either being a current smoker, having past history of smoking, or having never been a smoker. Suspected aspiration status was defined as yes or no. Ventilatory support requirement status was defined as yes or no. 


\section{Statistical Analysis}

\section{General Statistical Methods}

Categorical demographic characteristics and other covariates were cross tabulated by dichotomous mortality status variables (i.e. death within thirty days), and were compared using Chi-square tests of independence.

Univariate and regression results were reported as significant when alpha was less than $0.05(\mathrm{p}<0.05) .95 \%$ confidence intervals $(\mathrm{CI})$ were also reported. The presence of extreme outliers among the exposure data was investigated, with extreme outliers identified as being those values that were ( $3.0 \mathrm{x}$ IQR) below the first quartile or above the third quartile; outliers identified in this fashion were removed. Multicollinearity was assessed by examining tolerance and variance inflation factors, with the tolerance cutoff set at less than 0.2 and variation inflation factor cutoff at greater than 4.0. In instances where correlation among categorical variables was examined, the coefficient Cramer's V was utilized, where strength of association was determined by values that fall on a scale of 0 (no association) to 1 (perfect association); strength of association scale was approximately as follows: $0.00-0.10$ suggests no relationship or lack of useful information, $0.10-0.20$ suggests a weak association, $0.20-0.25$ suggests an association of moderate strength, 0.250.30 suggests a moderately strong association, $0.30-0.35$ suggests a strong association, 0.35-0.40 suggests a very strong association, $0.40-0.45$ suggests an extremely strong association that may be indicative of measurement of the same concept, and $>0.45$ suggests redundancy in that the variables being examined are likely measuring the same concept (97). Statistical analyses were carried out using SAS statistical software. GIS-related 
functions were carried using Esri ArcGIS (ArcMap version 10.6.1). The map projection for ArcGIS functions was the geographic coordinate system NAD 1983 (2011).

\section{Aim One Statistical Methods}

Continuous $\mathrm{PM}_{10}$ and $\mathrm{PM}_{2.5}$ data were examined for normality using the AndersonDarling test for normality. Continuous $\mathrm{PM}_{10}$ and $\mathrm{PM}_{2.5}$ data at hospital admission date were compared against mortality status using nonparametric Wilcoxon rank-sum tests, as they were not normally distributed. Additionally, both PM variables were analyzed as dichotomous values using their corresponding twenty-four hour NAAQS means as cutoff points, and as quartiles, and compared against mortality status using Chi-square tests, or Fisher's exact test where appropriate. Covariates were cross-tabulated by quartile of PM exposure to examine the association between covariate categories and level of exposure. Analyses were conducted using interpolated PM data based on the geospatial techniques spatial averaging.

The spatial averaging technique utilized the PM values detected by each active monitoring station within the study area at the day of participant diagnosis. These values were averaged and the resulting values were attributed to the participant as their exposure. We considered a log-transformation of spatially averaged PM to improve normality; however, associations did not change substantially.

The relationship between PM exposure and mortality during hospitalization or within thirty days was analyzed using crude and multivariable logistic regression. The covariates included in this analysis were chosen based upon their known relevance in the existing literature, as outlined in the Introduction. Covariates were considered confounders if they are independently associated with exposure and outcome, and were not on the causal 
pathway; determination was achieved by stratifying covariates by outcome and by exposure, placing the resulting values in tables, and examining the relationships, in addition to examining the impact of covariate inclusion on reported relationships. Non-confounders that appeared to have an association with the outcome were included as predictors; this was determined based on observed associations with the outcome in the covariate/outcome table created, and by examining significance of p-values from the univariate results therein. Strong predictors were those predictors that were perceived as being highly related to the outcome based upon the results of the covariate/outcome table created. Multiple models were presented: a minimally adjusted model containing only confounders, a partially adjusted model containing both confounders and strong predictors, and a fully adjusted model containing confounders and all predictors.

A similar process was implemented to analyze the aforementioned relationship using Cox proportional hazards regression. Survival time (person/days) was calculated by finding the difference between participant date of death and participant enrollment date; participant enrollment date corresponds with date of hospitalization. Both regression types were included due to the fact that they ultimately examine different outcomes, despite yielding results that can be interpretted in a similar manner. The logistic regression in this analysis examined a pre-coded dichotomous outcome within the dataset that acted as a proxy for mortality associated with CAP; the Cox proportional hazards regression in this analysis examined time to death, based upon the presence of a death date for those participants who manifested the outcome and calculated survival time.

Where PM exposure was examined as quartiles, a p-value of trend was calculated to determine if a significant trend existed between quartiles of a given PM type (e.g, $\left.\mathrm{PM}_{10}\right)$. 
To accomplish this, a dummy variable was created with four different levels, or levels one through four, with each level representing a numerically corresponding quartile. The median PM value for each numerically corresponding quartile was attributed to the appropriate level in the dummy variable; for example, the median value of $\mathrm{PM}_{10}$ within quartile one was attributed to all participants within quartile one, and therefore level one of the dummy variable. Within the regression models, the dummy variable was run in place of the quartile exposure and the resulting p-value of trend was noted.

\section{Aim Two Statistical Methods}

Interpolation by the Kriging technique was achieved using the ArcGIS Kriging feature under the available Spatial Analyst toolbar, utilizing the relevant PM values from each monitor within the study area for the given day and the location of the monitor as the location of the point value, as localized PM measurements for each participant address were not available. Ordinary Kriging was used, as the mean of the point values was not assumed to be constant over the study area. The feasablity of kriging as a valid technique given data availability constraints will be examined. Example kriging models were generated for ten dates at different points in time (June 1-5, 2014 and December 1-5, 2014) to examine model feasibility, usefulness, and variability; these characteristics were examined by asking such questions as "what do model distributions look like," "are observed patterns reliable, and "does Kriging appear to function properly given the sparsity of data available."

\section{Aim Three Statistical Methods}

The potential presence of effect modification was also of interest, and was examined for age, race, and sex. Though specific comorbidities may also be effect 
modifiers, the use of the generalized PSI covariate including such information rather than individual comorbidity statuses removed the ability to examine effect modification as a result of specific comorbidities within this study. The presence of significant effect modification was determined using the likelihood ratio test (LRT), comparing the standard partially adjusted model for the PM exposure type against the partially adjusted model containing the exposure / potential effect modifier interaction term. Effect modification analysis was performed on partially adjusted logistic regression models for all variations of exposure; this model was more parsimonious than the full model while still containing all covariates of interest. Where determined to be relevant, further examination of significant associations was pursued, including examination of relative risk among specific participant groups and examination of PSI class distribution between participant groups. 


\section{RESULTS}

The following are the results of the statistical analyses carried out during this project, broken down by their corresponding specific aim and exposure data group to which they belong, when relevant.

Preliminary Analysis

In total, data for 8,284 participants were present in the dataset received. Within the dataset, 2,088 participants did not belong to HAPPI, and were therefore not included, leaving the data of 6,176 participants to be analyzed. The exposure variable "PM 10 " was

missing 8 values, and the exposure variable " $\mathrm{PM}_{2.5}$ " was missing 1 value. The outcome variable "mortality within thirty days" was missing 2 values. Those missing outcome and exposure values were excluded, resulting in a total of 8 participants being removed from the analysis. An additional 23 participants were removed due to the detection of extreme outlier exposure data. Missing values for covariates within the sample are as follows: 1 missing value for "suspicion of aspiration at time of hospitalization," 5 missing values for "received oral antimicrobial therapy within the past 30 days," 107 missing values for "received pneumococcal vaccination at or prior to time of hospitalization," and 118 missing values for "received seasonal influenza vaccine at or prior to time of hospitalization." Those with missing values attributed to covariates were classified as "missing" and included in the analysis. 
A total of 6,145 participants were included in this analysis, after the removal of missing exposure and outcome values. Their characteristics are presented in Table 2. Of the 6,145 participants, $46.5 \%$ were male and $53.5 \%$ were female. The mean age of the study sample was 65.9 years, with a standard deviation of $16.5 .84 .1 \%$ were above the age of 50 years, and $55.9 \%$ were at or above the age of 65 years. $79.3 \%$ identified as White, $20.2 \%$ as Black, and $0.5 \%$ as Other. A large portion of the study sample was at moderate to high risk of pneumonia-associated mortality, with $18.7 \%$ falling into PSI Risk Class III, 35.6\% into Risk Class IV, and 22.9\% into Risk Class V.

\begin{tabular}{|c|c|c|c|c|}
\hline Variables & Total & & lity & p Value \\
\hline & $\mathrm{N}=6145^{\mathrm{a}}$ & $\begin{array}{c}\text { Yes } \\
\mathrm{n}=597^{\mathrm{b}}\end{array}$ & $\begin{aligned} & \text { No } \\
\mathrm{n}= & 5548^{\mathrm{b}}\end{aligned}$ & \\
\hline Mean age at enrollment, years (SD) & $65.9(16.5)$ & $75.3(13.6)$ & $64.9(16.5)$ & $<0.0001$ \\
\hline Sex & & & & 0.0012 \\
\hline Female & $3288(53.5)$ & $282(47.2)$ & $3006(54.2)$ & \\
\hline Male & 2857 (46.5) & $315(52.8)$ & $2542(45.8)$ & \\
\hline Race & & & & $<0.0001$ \\
\hline Black & $1241(20.2)$ & $74(12.4)$ & $1167(21.0)$ & \\
\hline White & $4872(79.3)$ & $522(87.4)$ & $4350(78.4)$ & \\
\hline Other & $32(0.5)$ & $1(0.2)$ & $31(0.6)$ & \\
\hline PSI $^{\mathrm{d}}$ class & & & & $<<0.0001$ \\
\hline Class I & $393(6.4)$ & $4(0.7)$ & $389(7.0)$ & \\
\hline Class II & $1007(16.4)$ & $9(1.5)$ & $998(18.0)$ & \\
\hline Class III & $1149(18.7)$ & $32(5.4)$ & $1117(20.1)$ & \\
\hline Class IV & 2187 (35.6) & $193(32.3)$ & $1994(36.0)$ & \\
\hline Class V & $1409(22.9)$ & $359(60.1)$ & $1050(18.9)$ & \\
\hline $\begin{array}{l}\text { Direct transfer to ICU }{ }^{\mathrm{d}} \text { upon hospital } \\
\text { admission }\end{array}$ & & & & $<0.0001$ \\
\hline Yes & $998(16.2)$ & $201(33.7)$ & $797(14.4)$ & \\
\hline No & $5147(83.8)$ & $396(66.3)$ & $4751(85.6)$ & \\
\hline $\begin{array}{l}\text { Received intravenous antibiotic therapy } \\
\text { within the past } 90 \text { days }\end{array}$ & & & & $<0.0001$ \\
\hline Yes & $1009(16.4)$ & $146(24.5)$ & $863(15.6)$ & \\
\hline No & $5136(83.6)$ & $451(75.5)$ & $4685(84.4)$ & \\
\hline $\begin{array}{l}\text { Received oral antimicrobial therapy } \\
\text { within the past } 30 \text { days }\end{array}$ & & & & 0.6802 \\
\hline Yes & $1280(20.8)$ & $129(21.6)$ & $1151(20.7)$ & \\
\hline No & $4860(79.1)$ & $468(78.4)$ & $4392(79.2)$ & \\
\hline Missing & $5(0.1)$ & $0(0.0)$ & $5(0.1)$ & \\
\hline Alcoholic status & & & & 0.3098 \\
\hline Yes & $344(5.6)$ & $28(4.7)$ & $316(5.7)$ & \\
\hline No & $5801(94.4)$ & $569(95.3)$ & $5232(94.3)$ & \\
\hline Active intravenous drug use status & & & & 0.0418 \\
\hline
\end{tabular}




\begin{tabular}{|c|c|c|c|c|}
\hline Yes & $89(1.5)$ & $3(0.5)$ & $86(1.5)$ & \\
\hline No & 6056 (98.5) & $594(99.5)$ & $5462(98.5)$ & \\
\hline Smoking history & & & & $<0.0001$ \\
\hline Current smoker & 2038 (33.2) & $121(20.3)$ & $1917(34.5)$ & \\
\hline Past smoker & $2419(39.4)$ & $288(48.2)$ & $2131(38.4)$ & \\
\hline Non-smoker & $1688(27.4)$ & $188(31.5)$ & $1500(27.1)$ & \\
\hline $\begin{array}{l}\text { Suspicion of aspiration at time of } \\
\text { hospitalization }\end{array}$ & & & & $<0.0001$ \\
\hline Yes & $622(10.1)$ & $123(20.6)$ & $499(9.0)$ & \\
\hline No & $5522(89.9)$ & $474(79.4)$ & $5048(91.0)$ & \\
\hline Missing & $1(0.0)$ & $0(0.0)$ & $1(0.0)$ & \\
\hline $\begin{array}{l}\text { Required ventilatory support at time of } \\
\text { initial hospitalization }\end{array}$ & & & & $<0.0001$ \\
\hline Yes & $808(13.2)$ & $157(26.3)$ & $651(11.7)$ & \\
\hline No & $5337(86.8)$ & $440(73.7)$ & $4897(88.3)$ & \\
\hline $\begin{array}{l}\text { Received pneumococcal vaccination at or } \\
\text { prior to time of hospitalization }\end{array}$ & & & & 0.0226 \\
\hline Yes & 3356 (54.6) & $301(50.4)$ & $3055(55.1)$ & \\
\hline No & $2685(43.7)$ & $290(48.6)$ & $2395(43.2)$ & \\
\hline Missing & $104(1.7)$ & $6(1.0)$ & $98(1.7)$ & \\
\hline $\begin{array}{l}\text { Received seasonal influenza vaccine at or } \\
\text { prior to time of hospitalization }\end{array}$ & & & & 0.0138 \\
\hline Yes & $2906(47.3)$ & $257(43.0)$ & $2649(47.7)$ & \\
\hline No & $3124(50.8)$ & $334(55.9)$ & $2790(50.3)$ & \\
\hline Missing & $115(1.9)$ & $6(1.0)$ & $109(2.0)$ & \\
\hline \multicolumn{5}{|c|}{$\begin{array}{l}\text { a: Percentages (\%) as percent of total column } \mathrm{N} \\
\text { b: Percentages (\%) as percent of total column n } \\
\text { c: Chi-square / Fisher exact / Wilcoxon rank sum p-value for comparison between mortality status categories } \\
\text { d: PSI - pnemonia severity index, ICU - intensive care unit }\end{array}$} \\
\hline
\end{tabular}

\section{Aim One}

Analysis - Spatial Averaging Data

Continuous $\mathrm{PM}_{10}$ and $\mathrm{PM}_{2.5}$ data were determined to be non-normally distributed using the Anderson-Darling test ( $\mathrm{p}=<0.0050$ for both). Log transforming the PM values did not result in the achievement of statistical normalcy ( $\mathrm{p}=<0.0050$ for both). Preliminary univariate analysis was conducted using the nonparametric Wilcoxon rank-sum test; results for both $\mathrm{PM}_{10}$ and $\mathrm{PM}_{2.5}$ were not significant, with determined p-values being 0.3008 and 0.2361, respectively. The median $\mathrm{PM}_{10}$ value was found to be $15.00 \mu \mathrm{g} / \mathrm{m}^{3}(\mathrm{IQR}=10.67)$. The median $\mathrm{PM}_{2.5}$ value was found to be $9.67 \mu \mathrm{g} / \mathrm{m}^{3}$ (IQR = 6.29). $\mathrm{PM}_{10}$ and $\mathrm{PM}_{2.5}$ 
distributions can be viewed in Figures 3 and 4. Log transformed $\mathrm{PM}_{10}$ and $\mathrm{PM}_{2.5}$ distributions can be viewed in Figures 5 and 6. 


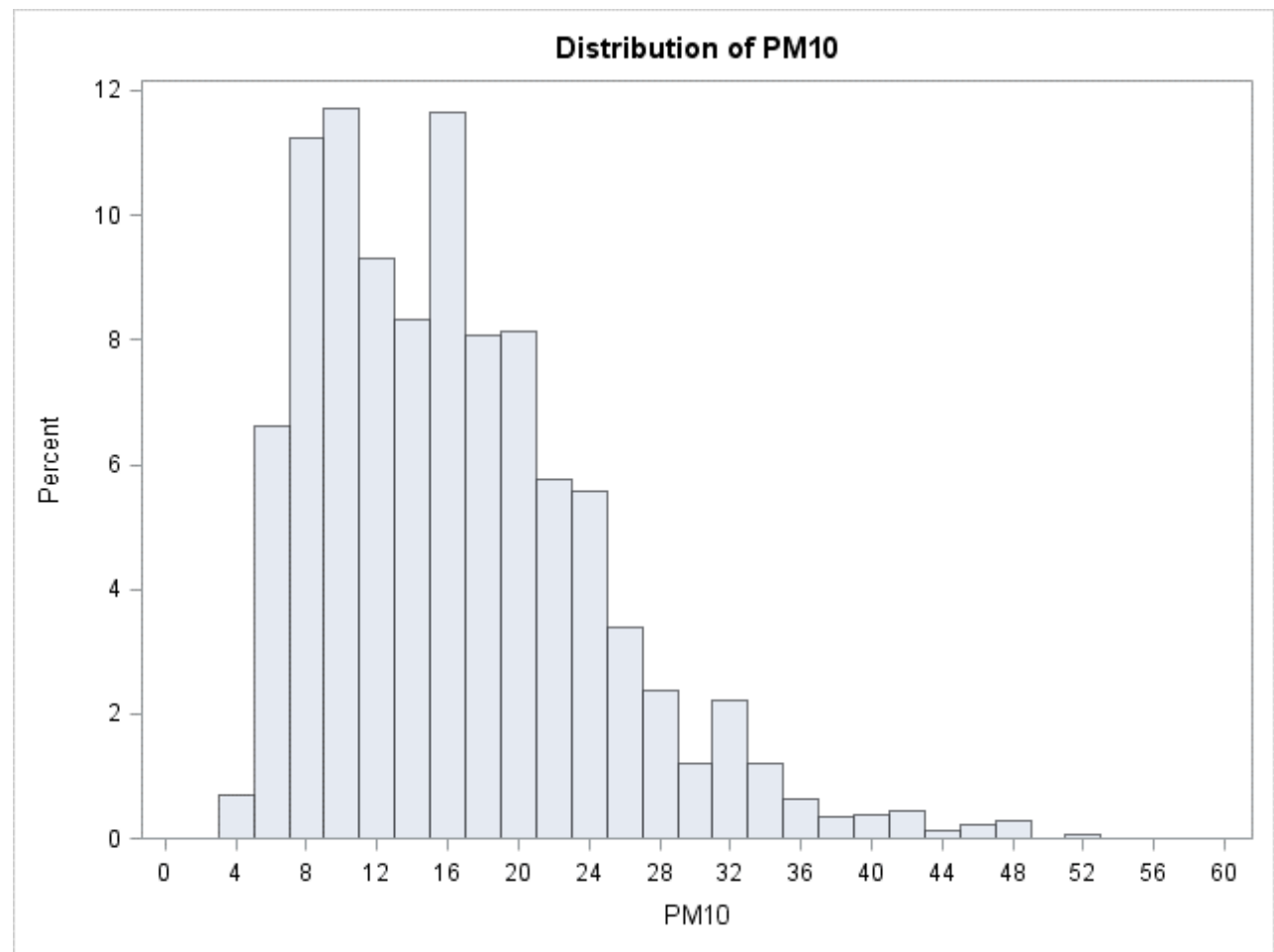

Figure 3 - Distribution of spatially averaged continuous $\mathrm{PM}_{10}\left(\mu \mathrm{g} / \mathrm{m}^{3}\right)$ concentrations at the time of hospitalization across the study sample.

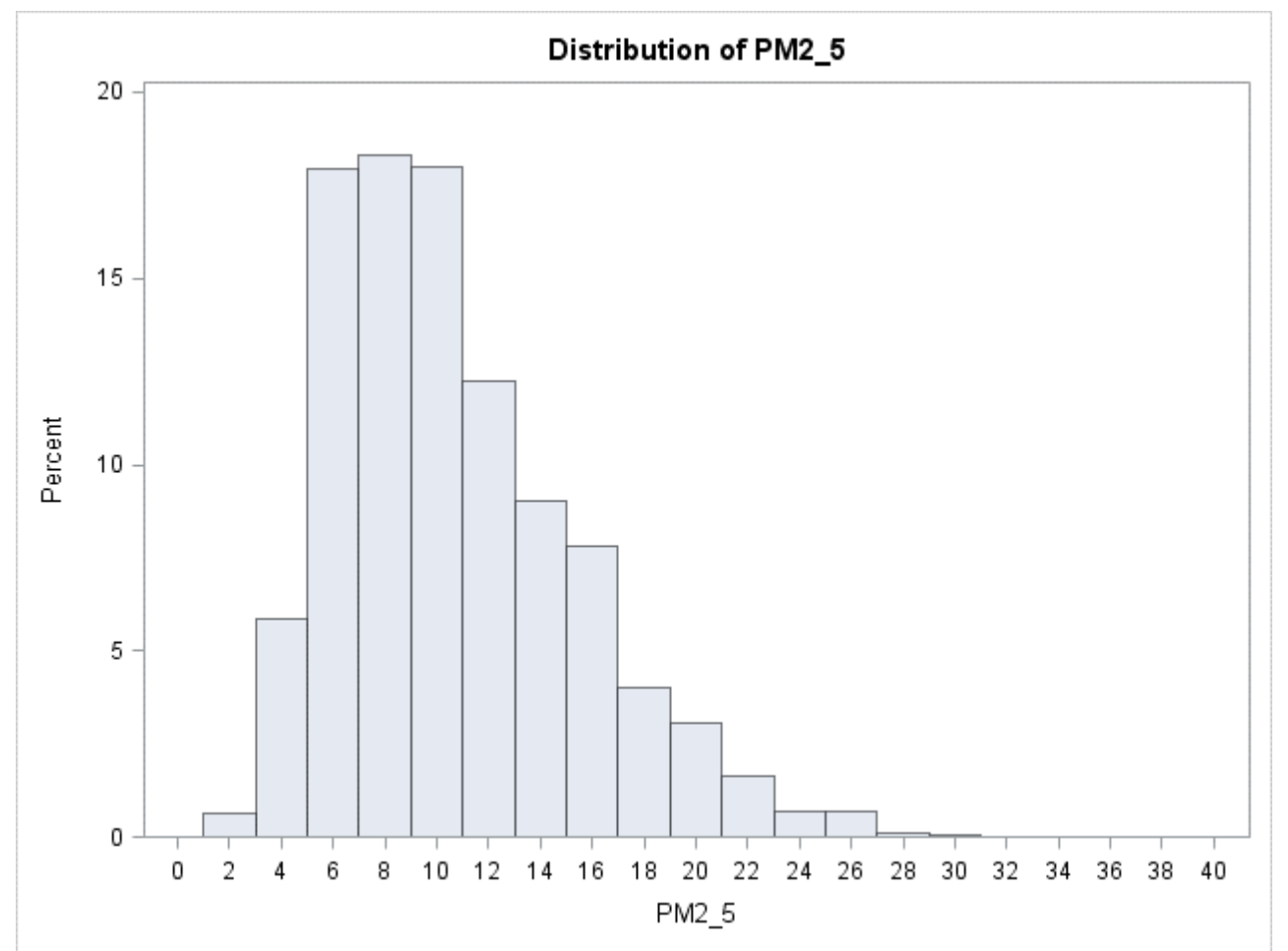

Figure 4 - Distribution of spatially averaged continuous $\mathrm{PM}_{2.5}\left(\mu \mathrm{g} / \mathrm{m}^{3}\right)$ concentrations at the time of hospitalization across the study sample. 


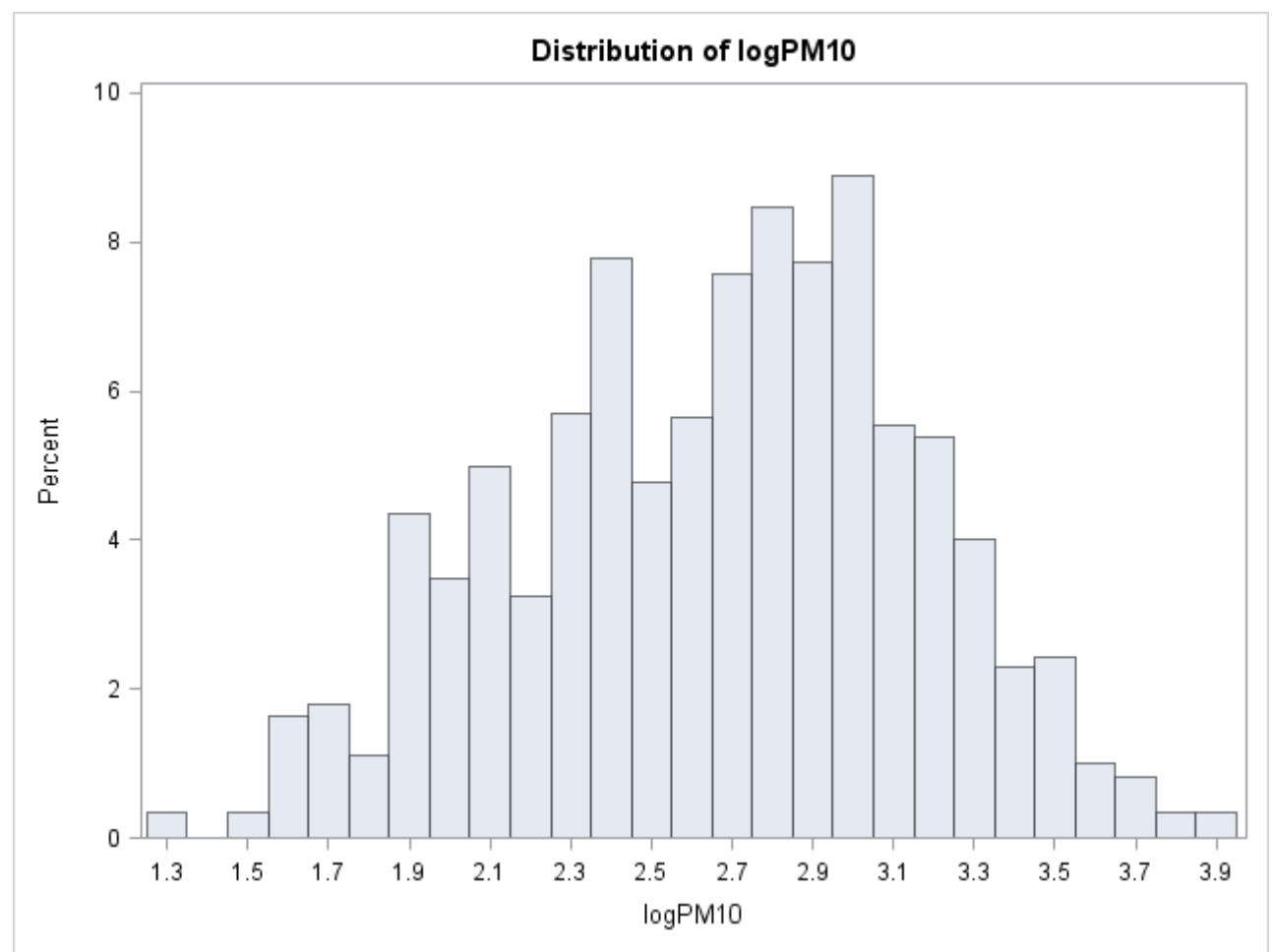

Figure 5 - Distribution of spatially averaged continuous, log-transformed $\mathrm{PM}_{10}$ concentrations at the time of hospitalization across the study sample.

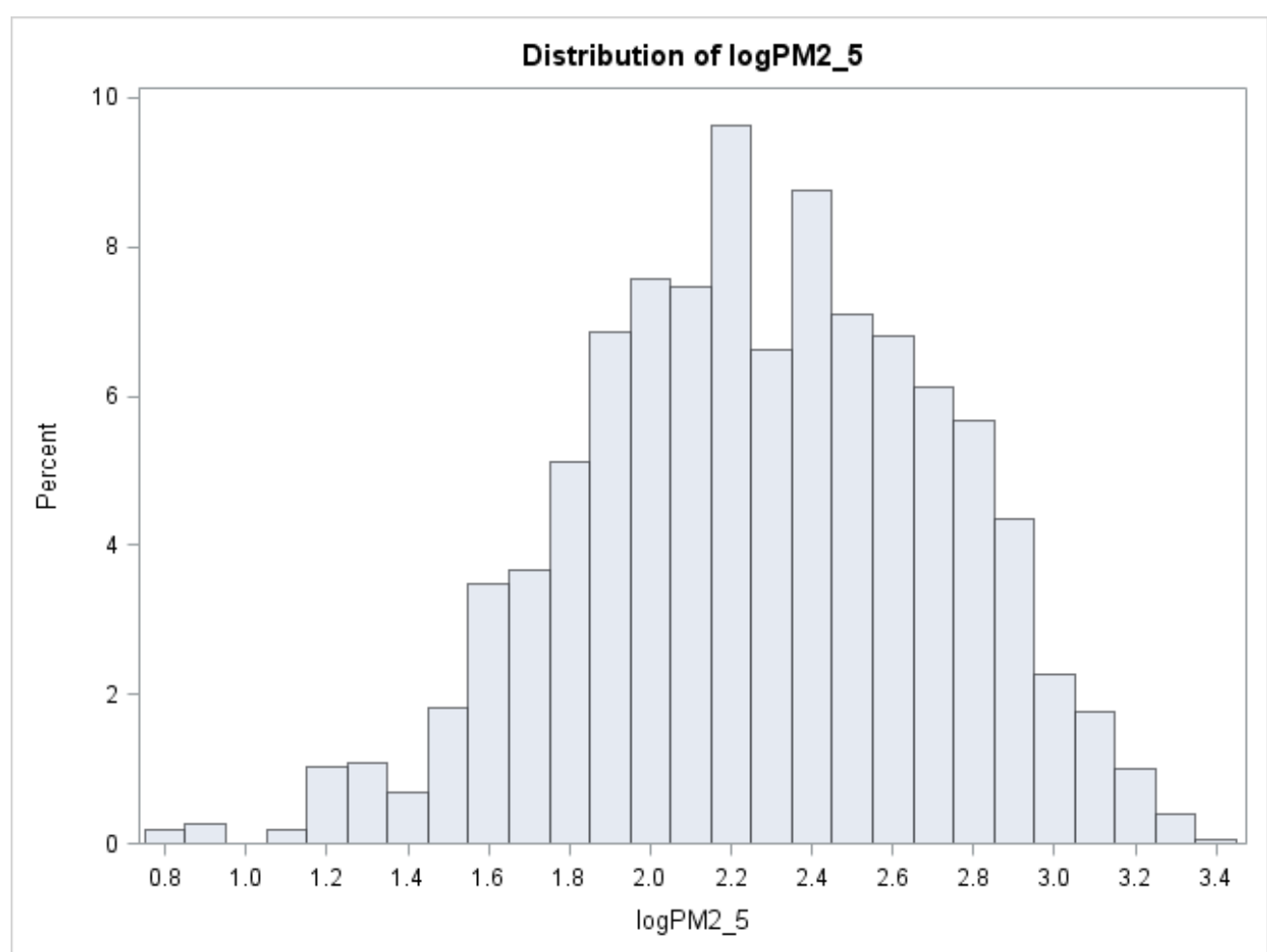

Figure 6 - Distribution of spatially averaged continuous, log-transformed $\mathbf{P M}_{2.5}$ concentrations at the time of hospitalization across the study sample. 
Analysis of dichotomous $\mathrm{PM}_{10}$ exposure using the corresponding twenty-four hour NAAQS means cutoff point could not be carried out, as no $\mathrm{PM}_{10}$ values exceeded the cutoff point. This was noted even prior to the removal of extreme outliers. Analysis of dichotomous $\mathrm{PM}_{2.5}$ exposure using the corresponding twenty-four hour NAAQS means cutoff point could not be carried out, as no $\mathrm{PM}_{2.5}$ values exceeded the cutoff point.

We calculated PM quartiles. The $\mathrm{PM}_{10}$ quartile ranges were established as follows: less than or equal to $9.67 \mu \mathrm{g} / \mathrm{m}^{3}$, greater than $9.67 \mu \mathrm{g} / \mathrm{m}^{3}$ and less than or equal to 15.00 $\mu \mathrm{g} / \mathrm{m}^{3}$, greater than $15.00 \mu \mathrm{g} / \mathrm{m}^{3}$ and less than or equal to $20.50 \mu \mathrm{g} / \mathrm{m}^{3}$, and greater than $20.50 \mu \mathrm{g} / \mathrm{m}^{3}$. The $\mathrm{PM}_{2.5}$ quartile ranges were established as follows: less than or equal to $7.07 \mu \mathrm{g} / \mathrm{m}^{3}$, greater than $7.07 \mu \mathrm{g} / \mathrm{m}^{3}$ and less than or equal to $9.63 \mu \mathrm{g} / \mathrm{m}^{3}$, greater than 9.63 $\mu \mathrm{g} / \mathrm{m}^{3}$ and less than or equal to $13.37 \mu \mathrm{g} / \mathrm{m}^{3}$, and greater than $13.37 \mu \mathrm{g} / \mathrm{m}^{3}$. Univariate analysis of quartiles by mortality status can be viewed in Table 3 and Table 4 . Neither $\mathrm{PM}_{10}$ nor $\mathrm{PM}_{2.5}$ quartile variables were found to be statistically significant $(\mathrm{p}=0.7232$ and $\mathrm{p}=0.4093$, respectively) in univariate analysis. Those located within the highest $\mathrm{PM}_{10}$ quartile had a slightly greater percentage of outcome occurrence versus those in lesser quartiles. Those located in the top two $\mathrm{PM}_{2.5}$ quartiles had a slightly greater percentage of outcome occurrence versus those in the lower two quartiles.

Cross tabulation of covariates by quartile of $\mathrm{PM}_{10}$ and $\mathrm{PM}_{2.5}$ can be viewed in Tables 5 and 6 . Those in the highest $\mathrm{PM}_{10}$ quartile contained a greater proportion of males, individuals requiring ventilatory support at time of hospitalization, individuals having required IV antimicrobrial therapy in the previous 90 days, active intravenous drug users, current smokers, individuals at risk for aspiration, and individuals who did not receive either the seasonal influenza or pneumoccocal vaccinations, as compared against the lowest 
quartile. Proportions of individuals were generally similar in terms of racial distribution, ICU direct transfer status, and non-smoker status across quartiles. Observed $\mathrm{PM}_{2.5}$ patterns were quite similar to $\mathrm{PM}_{10}$ quartile patterns overall, though slightly reduced in their perceived magnitude.

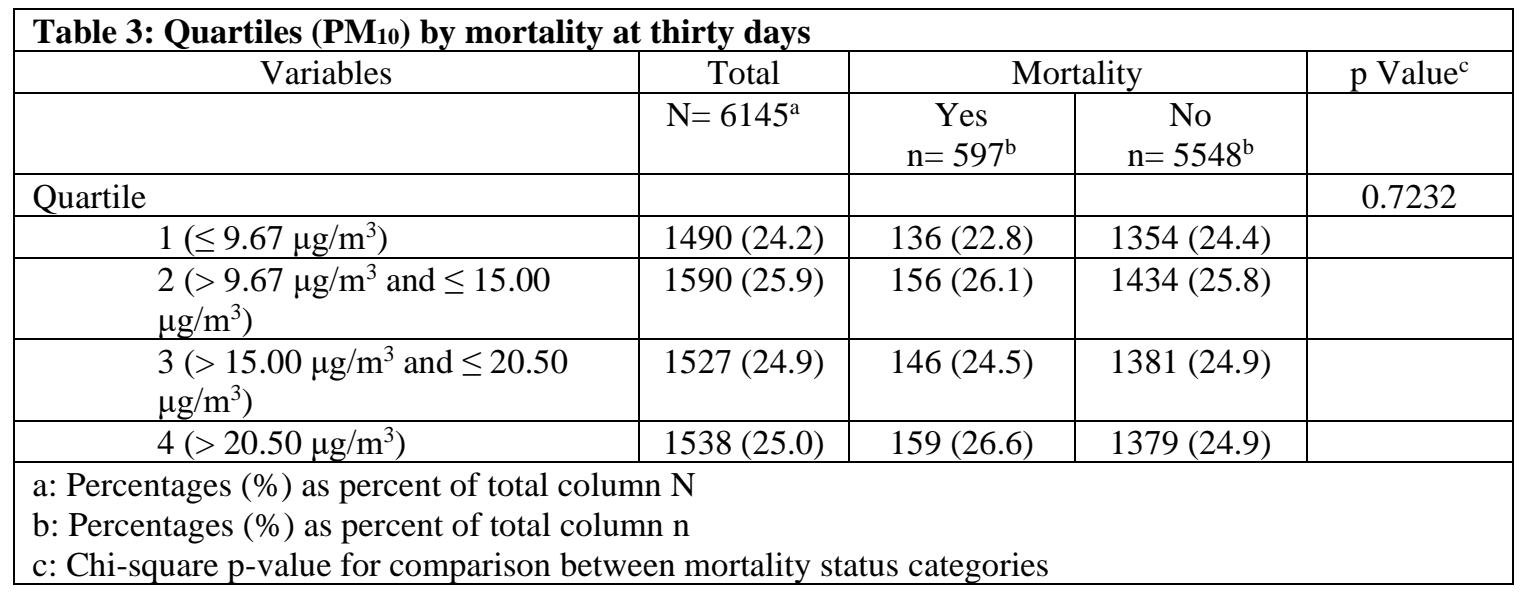

\begin{tabular}{|l|c|c|c|c|}
\hline \multicolumn{1}{|c|}{ Table 4: Quartiles (PM2.5) by mortality at thirty days } \\
\hline \multicolumn{1}{|c|}{ Variables } & Total & \multicolumn{2}{|c|}{ Mortality } & $\mathrm{p}$ Value $^{\mathrm{c}}$ \\
\hline & $\mathrm{N}=6145^{\mathrm{a}}$ & $\begin{array}{c}\text { Yes } \\
\mathrm{n}=597^{\mathrm{b}}\end{array}$ & $\begin{array}{c}\text { No } \\
\mathrm{n}=5548^{\mathrm{b}}\end{array}$ & \\
\hline Quartile & & & & 0.4093 \\
\hline $1\left(\leq 7.07 \mu \mathrm{g} / \mathrm{m}^{3}\right)$ & $1530(24.9)$ & $134(22.4)$ & $1396(25.2)$ & \\
\hline $\begin{array}{l}2\left(>7.07 \mu \mathrm{g} / \mathrm{m}^{3} \text { and } \leq 9.63\right. \\
\left.\mu \mathrm{g} / \mathrm{m}^{3}\right)\end{array}$ & $1536(25.0)$ & $148(24.8)$ & $1388(25.0)$ & \\
\hline $\begin{array}{l}3\left(>9.63 \mu \mathrm{g} / \mathrm{m}^{3} \text { and } \leq 13.37\right. \\
\left.\mu \mathrm{g} / \mathrm{m}^{3}\right)\end{array}$ & $1546(25.2)$ & $163(27.3)$ & $1383(24.9)$ & \\
\hline $4\left(>13.37 \mu \mathrm{g} / \mathrm{m}^{3}\right)$ & $1533(25.9)$ & $152(25.5)$ & $1381(24.9)$ & \\
\hline $\begin{array}{l}\text { a: Percentages }(\%) \text { as percent of total column } \mathrm{N} \\
\text { b: Percentages }(\%) \text { as percent of total column } \mathrm{n} \\
\text { c: Chi-square p-value for comparison between mortality status categories }\end{array}$ \\
\hline
\end{tabular}




\begin{tabular}{|c|c|c|c|c|}
\hline Variable & $\begin{array}{c}\text { Quartile 1 } \\
\left(\leq 9.67 \mu \mathrm{g} / \mathrm{m}^{3}\right)\end{array}$ & $\begin{array}{c}\text { Quartile } 2 \\
\left(>9.67 \mu \mathrm{g} / \mathrm{m}^{3}\right. \\
\text { and } \leq 15.00 \\
\left.\mu \mathrm{g} / \mathrm{m}^{3}\right)\end{array}$ & $\begin{array}{c}\text { Quartile } 3 \\
\left(>15.00 \mu \mathrm{g} / \mathrm{m}^{3}\right. \\
\text { and } \leq 20.50 \\
\left.\mu \mathrm{g} / \mathrm{m}^{3}\right)\end{array}$ & $\begin{array}{c}\text { Quartile } 4 \\
\left(>20.50 \mu \mathrm{g} / \mathrm{m}^{3}\right)\end{array}$ \\
\hline $\begin{array}{l}\text { Number of } \\
\text { Participants }\end{array}$ & $\mathrm{n}=1490$ & $\mathrm{n}=1590$ & $\mathrm{n}=1527$ & $\mathrm{n}=1538$ \\
\hline $\begin{array}{l}\text { Mean age at } \\
\text { enrollment, years (SD) }\end{array}$ & $65.8(16.1)$ & $66.8(16.3)$ & $65.7(16.8)$ & $65.3(16.8)$ \\
\hline \multicolumn{5}{|l|}{ Sex, n (\%) } \\
\hline Female & $807(54.2)$ & $859(54.0)$ & $831(54.4)$ & $791(51.4)$ \\
\hline Male & $683(45.8)$ & $731(46.0)$ & $696(45.6)$ & 747 (48.6) \\
\hline \multicolumn{5}{|l|}{ Race, n (\%) } \\
\hline Black & $317(21.3)$ & $312(19.6)$ & $284(18.6)$ & $328(21.3)$ \\
\hline White & $1164(78.1)$ & $1269(79.8)$ & $1234(80.8)$ & $1205(78.4)$ \\
\hline Other & $9(0.6)$ & $9(0.6)$ & $9(0.6)$ & $5(0.3)$ \\
\hline \multicolumn{5}{|l|}{ PSI class, n (\%) } \\
\hline Class I & $82(5.5)$ & $94(5.9)$ & $106(7.0)$ & $111(7.2)$ \\
\hline Class II & $266(17.8)$ & $259(16.3)$ & $249(16.3)$ & $233(15.1)$ \\
\hline Class III & $278(18.7)$ & $307(19.3)$ & $277(18.1)$ & $287(18.7)$ \\
\hline Class IV & $532(35.7)$ & $564(35.5)$ & $538(35.2)$ & $553(36.0)$ \\
\hline Class V & $332(22.3)$ & $366(23.0)$ & $357(23.4)$ & $354(23.0)$ \\
\hline \multicolumn{5}{|l|}{$\begin{array}{l}\text { Direct transfer to ICU } \\
\text { upon hospital } \\
\text { admission, } \mathrm{n}(\%)\end{array}$} \\
\hline Yes & $248(16.6)$ & $238(15.0)$ & $261(17.1)$ & $251(16.3)$ \\
\hline No & $1242(83.4)$ & $1352(85.0)$ & $1266(82.9)$ & $1287(83.7)$ \\
\hline \multicolumn{5}{|l|}{$\begin{array}{l}\text { Received intravenous } \\
\text { antibiotic therapy } \\
\text { within the past } 90 \\
\text { days, } \mathrm{n}(\%) \\
\end{array}$} \\
\hline Yes & $236(15.8)$ & $273(17.2)$ & $243(15.9)$ & $257(16.7)$ \\
\hline No & $1254(84.2)$ & $1317(82.8)$ & $1284(84.1)$ & $1281(83.3)$ \\
\hline \multicolumn{5}{|l|}{$\begin{array}{l}\text { Received oral } \\
\text { antimicrobial therapy } \\
\text { within the past } 30 \\
\text { days, } n(\%)\end{array}$} \\
\hline Yes & $320(21.5)$ & $336(21.1)$ & $325(21.3)$ & $299(19.4)$ \\
\hline No & $1169(78.5)$ & $1253(78.8)$ & $1201(78.6)$ & $1237(80.5)$ \\
\hline Missing & $1(0.0)$ & $1(0.1)$ & $1(0.1)$ & $2(0.1)$ \\
\hline \multicolumn{5}{|l|}{ Alcoholic status, n (\%) } \\
\hline Yes & $96(6.4)$ & $83(5.2)$ & $77(5.0)$ & $88(5.7)$ \\
\hline No & $1394(93.6)$ & $1507(94.8)$ & $1450(95.0)$ & $1450(94.3)$ \\
\hline \multicolumn{5}{|l|}{$\begin{array}{l}\text { Active intravenous } \\
\text { drug use status, } \mathrm{n}(\%)\end{array}$} \\
\hline Yes & $14(0.9)$ & $23(1.4)$ & $28(1.8)$ & $24(1.6)$ \\
\hline No & $1476(99.1)$ & 1567 (98.6) & $1499(98.2)$ & $1514(98.4)$ \\
\hline \multicolumn{5}{|l|}{ Smoking history, n (\%) } \\
\hline $\begin{array}{l}\text { Current } \\
\text { smoker }\end{array}$ & $486(32.6)$ & $531(33.4)$ & 507 (33.2) & $514(33.4)$ \\
\hline Past smoker & $597(40.1)$ & $626(39.4)$ & $591(38.7)$ & $605(39.3)$ \\
\hline Non-smoker & $407(27.3)$ & $433(27.2)$ & $429(28.1)$ & $419(27.3)$ \\
\hline
\end{tabular}




\begin{tabular}{|c|c|c|c|c|}
\hline $\begin{array}{l}\text { Suspicion of aspiration } \\
\text { at time of } \\
\text { hospitization, } \mathrm{n}(\%)\end{array}$ & & & & \\
\hline Yes & $143(9.6)$ & $172(10.8)$ & $146(9.6)$ & $161(10.5)$ \\
\hline No & 1347 (90.4) & $1418(89.2)$ & $1381(90.4)$ & $1376(89.5)$ \\
\hline Missing & $0(0.0)$ & $0(0.0)$ & $0(0.0)$ & $1(0.0)$ \\
\hline $\begin{array}{l}\text { Required ventilatory } \\
\text { support at time of } \\
\text { initial hospitalization, } \\
\mathrm{n}(\%)\end{array}$ & & & & \\
\hline Yes & $198(13.3)$ & $198(12.4)$ & $199(13.0)$ & $213(13.8)$ \\
\hline No & $1292(86.7)$ & $1392(87.6)$ & $1328(87.0)$ & $1325(86.2)$ \\
\hline $\begin{array}{l}\text { Received } \\
\text { pneumococcal } \\
\text { vaccination at or prior } \\
\text { to time of } \\
\text { hospitalization, } \mathrm{n}(\%)\end{array}$ & & & & \\
\hline Yes & $818(54.9)$ & $894(56.2)$ & $839(54.9)$ & $805(52.3)$ \\
\hline No & $652(43.8)$ & $675(42.5)$ & $663(43.4)$ & $695(45.2)$ \\
\hline Missing & $20(1.3)$ & $21(1.3)$ & $25(1.7)$ & $38(2.5)$ \\
\hline $\begin{array}{l}\text { Received seasonal } \\
\text { influenza vaccine at or } \\
\text { prior to time of } \\
\text { hospitalization, } \mathrm{n}(\%)\end{array}$ & & & & \\
\hline Yes & $819(55.0)$ & $807(50.7)$ & $713(46.7)$ & $567(36.9)$ \\
\hline No & 649 (43.5) & $759(47.7)$ & $787(51.5)$ & $929(60.4)$ \\
\hline Missing & $22(1.5)$ & $24(1.6)$ & $27(1.8)$ & $42(2.7)$ \\
\hline
\end{tabular}




\begin{tabular}{|c|c|c|c|c|}
\hline \multicolumn{5}{|c|}{$\begin{array}{l}\text { Table 6: Descriptive statistics of HAPPI population by quartile of PM } \mathrm{PM}_{2.5} \text { exposure at time of } \\
\text { hospitalization }(\mathrm{N}=6145)\end{array}$} \\
\hline Variable & $\begin{array}{c}\text { Quartile 1 } \\
\left(\leq 7.07 \mu \mathrm{g} / \mathrm{m}^{3}\right)\end{array}$ & $\begin{array}{c}\text { Quartile } 2 \\
\left(>7.07 \mu \mathrm{g} / \mathrm{m}^{3}\right. \\
\text { and } \leq 9.63 \\
\left.\mu \mathrm{g} / \mathrm{m}^{3}\right)\end{array}$ & $\begin{array}{c}\text { Quartile } 3 \\
\left(>9.63 \mu \mathrm{g} / \mathrm{m}^{3}\right. \\
\text { and } \leq 13.37 \\
\left.\mu \mathrm{g} / \mathrm{m}^{3}\right)\end{array}$ & $\begin{array}{c}\text { Quartile } 4 \\
\left(>13.37 \mu \mathrm{g} / \mathrm{m}^{3}\right)\end{array}$ \\
\hline $\begin{array}{l}\text { Number of } \\
\text { Participants }\end{array}$ & $\mathrm{n}=1530$ & $\mathrm{n}=1536$ & $\mathrm{n}=1546$ & $\mathrm{n}=1533$ \\
\hline $\begin{array}{l}\text { Mean age at } \\
\text { enrollment, years (SD) }\end{array}$ & $66.2(15.9)$ & $65.9(16.6)$ & $66.1(16.8)$ & $65.6(16.7)$ \\
\hline \multicolumn{5}{|l|}{ Sex, n (\%) } \\
\hline Female & $827(54.1)$ & $808(52.6)$ & $837(54.1)$ & $816(53.2)$ \\
\hline Male & $703(45.9)$ & $728(47.4)$ & 709 (45.9) & $717(46.8)$ \\
\hline \multicolumn{5}{|l|}{ Race, n (\%) } \\
\hline Black & $302(19.7)$ & $322(21.0)$ & $315(20.4)$ & $302(19.7)$ \\
\hline White & $1219(79.7)$ & $1203(78.3)$ & $1225(79.2)$ & $1225(79.9)$ \\
\hline Other & $9(0.6)$ & $11(0.7)$ & $6(0.4)$ & $6(0.4)$ \\
\hline \multicolumn{5}{|l|}{ PSI class, n (\%) } \\
\hline Class I & $77(5.0)$ & $103(6.7)$ & $105(6.8)$ & $108(7.0)$ \\
\hline Class II & $262(17.1)$ & $261(17.00)$ & $246(15.9)$ & $238(15.5)$ \\
\hline Class III & 284 (18.6) & $286(18.6)$ & $294(19.0)$ & 285 (18.6) \\
\hline Class IV & $545(35.6)$ & $531(34.6)$ & $541(35.0)$ & $570(37.2)$ \\
\hline Class V & $362(23.7)$ & $355(23.1)$ & $360(23.3)$ & $332(21.7)$ \\
\hline \multicolumn{5}{|l|}{$\begin{array}{l}\text { Direct transfer to ICU } \\
\text { upon hospital } \\
\text { admission, } \mathrm{n}(\%)\end{array}$} \\
\hline Yes & $238(15.6)$ & $251(16.3)$ & $259(16.7)$ & $250(16.3)$ \\
\hline No & $1292(84.4)$ & $1285(83.7)$ & $1287(83.3)$ & $1283(83.7)$ \\
\hline \multicolumn{5}{|l|}{$\begin{array}{l}\text { Received intravenous } \\
\text { antibiotic therapy } \\
\text { within the past } 90 \\
\text { days, } \mathrm{n}(\%)\end{array}$} \\
\hline Yes & $253(16.5)$ & $232(15.1)$ & $264(17.1)$ & $260(17.0)$ \\
\hline No & $1277(83.5)$ & $1304(84.9)$ & $1282(82.9)$ & $1273(83.0)$ \\
\hline \multicolumn{5}{|l|}{$\begin{array}{l}\text { Received oral } \\
\text { antimicrobial therapy } \\
\text { within the past } 30 \\
\text { days, } n(\%)\end{array}$} \\
\hline Yes & $331(21.6)$ & $296(19.3)$ & $342(22.1)$ & $311(20.3)$ \\
\hline No & $1199(78.4)$ & $1237(80.5)$ & $1203(77.8)$ & $1221(79.6)$ \\
\hline Missing & $0(0.0)$ & $3(0.2)$ & $1(0.1)$ & $1(0.1)$ \\
\hline \multicolumn{5}{|l|}{ Alcoholic status, n (\%) } \\
\hline Yes & $106(6.9)$ & $75(4.9)$ & $85(5.5)$ & $78(5.1)$ \\
\hline No & $1424(93.1)$ & $1461(95.1)$ & $1461(94.5)$ & $1455(94.9)$ \\
\hline \multicolumn{5}{|l|}{$\begin{array}{l}\text { Active intravenous } \\
\text { drug use status, } \mathrm{n}(\%)\end{array}$} \\
\hline Yes & $22(1.4)$ & $19(1.2)$ & $24(1.5)$ & $24(1.6)$ \\
\hline No & $1508(98.6)$ & $1517(98.8)$ & $1522(98.5)$ & 1509 (98.4) \\
\hline \multicolumn{5}{|l|}{ Smoking history, $\mathrm{n}(\%)$} \\
\hline $\begin{array}{l}\text { Current } \\
\text { smoker }\end{array}$ & $520(34.0)$ & $511(33.3)$ & 493 (31.9) & $514(33.5)$ \\
\hline Past smoker & $611(39.9)$ & $586(38.1)$ & $630(40.7)$ & $592(38.6)$ \\
\hline Non-smoker & $399(26.1)$ & 439 (28.6) & $423(27.4)$ & $427(27.9)$ \\
\hline
\end{tabular}




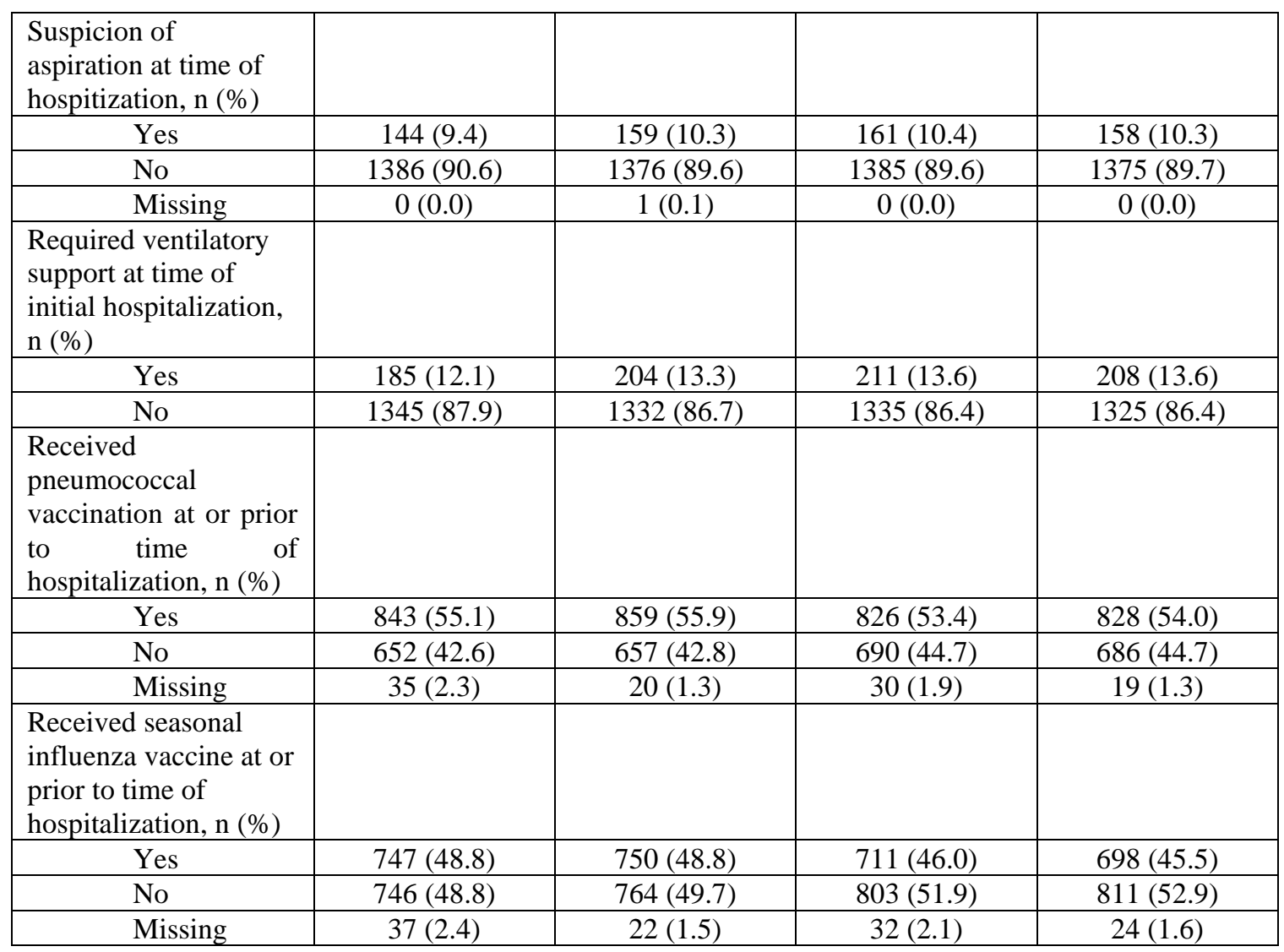

The associations between covariates related to participant hospital stay or medical attention received (e.g., direct transfer to ICU status and receival of intravenous antibiotics within the past 90 days status, receival of oral antimicrobial therapy in the past 30 days status, requirement of ventilatory support at time of hospitalization status, receival of pneumococcal vaccine at or prior to hospitalization status, receival of seasonal influenza vaccine at or prior to hospitalization status)were examined. Receival of intravenous antibiotics within the past 90 days and receival of oral antimicrobial therapy within the past 30 days were significantly associated (Chi-Square, $\mathrm{p}=<0.0001$ ), but the association was fairly weak (5.1\% “yes/yes" and 67.8\% “no/no"; Cramer's V= 0.1151). Direct transfer to ICU and both receival of oral antimicrobial therapy within the past 30 days and receival of intravenous antibiotics in the past 90 days were significantly associated (Chi-Square, $\mathrm{p}=$ 
$<0.0001)$, though these associations were also noted to be weak $(2.5 \%$ "yes/yes" / 65.4\% "no/no" and 3.4\% "yes/yes" / 70.8\% "no/no," respectively; Cramer's V = 0.0553 and 0.0549 , respectively). Requirement of ventilatory support at time of hospitalization was found to be significantly and strongly associated with direct transfer to ICU $(9.1 \%$ "yes/yes" / 80.0\% "no/no"; Chi-Square, $p=<0.0001$, Cramer’s V $=0.5624$ ), suggesting the two variables were possibly measuring the same concept; the former was chosen to be removed from further analysis to enhance parsimony. Direct transfer to ICU was significantly associated with receival of the seasonal influenza vaccine (Chi-Square, $p=$ 0.0067) and not significantly associated with receival of the pneumococcal vaccine (ChiSquare, $p=0.2295)$, but associations were weak in both situations $(7.1 \%$ "yes/yes" / 41.9\% "no/no" and 8.7\% "yes/yes" / 43.3\% "no/no," respectively; Cramer's V = 0.0404 and 0.0219 , respectively). It is worth noting that no multicollinearity was detected among the covariates chosen for further analysis.

Review of results viewable in Table 2 and Tables 5-6 were used to determine the presence of confounders, predictors, and strong predictors relating to the relationship between $\mathrm{PM}_{10}$ exposure and the outcome. The following covariates were determined to be confounders: age at enrollment, sex, receival of pneumococcal vaccine, receival of seasonal influenza vaccine. The following covariates were determined to be strong predictors: race, PSI, direct transfer to ICU, receival of intravenous antibiotic therapy with the past 90 days, smoking history, and suspicion of aspiration. The following covariate was determined to be a weak predictor: active intravenous drug use status. Confounders, predictors, and strong predictors were the same for the relationship between $\mathrm{PM}_{2.5}$ exposure and the outcome. 
As mentioned, these confounder/predictor determinations were based on observations drawn from the aforementioned tables. Consider the following observations based upon Table 2 and Table 5. The following observations are relevant to variables determined to be confounders, meaning they appeared to be related to both exposure and outcome. Mean age in years was higher in those with the outcome than those without (75.3 versus 64.9), and though variation was generally limited between exposure quartiles, enough fluctuation was present that the variable was considered to be a confounder as a matter of best practice, given the far-reaching implications of age. A greater percentage of males experienced the outcome than females (52.8\% among males versus $47.2 \%$ among females), and percentage variation between exposure quartiles was evident for both males (e.g., Q1 $=45.8 \%$ versus $\mathrm{Q} 4=48.6 \%)$ and females (e.g., $\mathrm{Q} 1=54.2 \%$ versus $\mathrm{Q} 4=51.4 \%)$. Those who received the pneumococcal vaccine appeared to experience the outcome comparatively less as a proportion than those who did not (received the vaccine: yes = $50.4 \%$ versus no $=55.1 \%$; did not receive the vaccine: yes $=48.6 \%$ versus no $=43.2 \%$, and percentage variation between exposure quartiles was present for both those who received the vaccine (e.g., Q1 $=54.9 \%$ versus $\mathrm{Q} 4=52.3 \%$ ) and those who did not (e.g., $\mathrm{Q} 1=43.8 \%$ versus $\mathrm{Q} 4=45.2 \%)$. Those who received the seasonal influenza vaccine also appeared to experience the outcome comparatively less as a proportion than those who did not (received the vaccine: yes $=43.0 \%$ versus no $=47.7 \%$; did not receive the vaccine: $y e s$ $=55.9 \%$ versus no $=50.3 \%$ ), and percentage variation between exposure quartiles was present for both those who received the vaccine (e.g., Q1 $=55.0 \%$ versus $\mathrm{Q} 4=36.9 \%$ ) and those who did not (e.g., Q1 = 43.5\% versus Q4 =60.4\%). Variables determined to be predictors lacked clear variation between exposure quartiles, but still maintained an 
observable relationship with the outcome. The variable direct ICU transfer status is a good example; a greater proportion of those directly transferred to the ICU at the time of hospitalization experienced the outcome versus those who were not transferred (transferred: yes $=33.7 \%$ versus no $=14.4 \%$; not transferred: yes $=66.3 \%$ versus no $=$ 85.6\%), but substantial percentage variation between exposure quartiles was not observed for either those transferred (e.g., Q1 $=16.6 \%$ versus Q4 $=16.3 \%$ ) or those not transferred (e.g., Q1 $=83.4 \%$ versus Q4 $=84.7 \%$ ). Very similar patterns were noted in Table 6 for $\mathrm{PM}_{2.5}$ derived observations.

Logistic regression results for the relationship between continuous $\mathrm{PM}_{10}$ exposure and mortality at thirty days can be seen in Tables $\mathbf{7 - 8}$, reflecting minimally and partially adjusted models. Logistic regression results for the relationship between continuous $\mathrm{PM}_{2.5}$ exposure and mortality at thirty days can be seen in Tables 9-10, reflecting minimally and partially adjusted models. As fully adjusted models differed only slightly from partially adjusted models with minimal change in the primary relationship of interest, the results for PM for the fully adjusted models were reported here and not as a full table; fully adjusted $\mathrm{PM}_{10}$ (per five $\mathrm{ug} / \mathrm{m}^{3}$ increase) $\mathrm{AOR}=1.02(\mathrm{p}=0.5136,95 \% \mathrm{CI}=0.96-1.08)$ and fully adjusted $\mathrm{PM}_{2.5}$ AOR (per five unit increase $)=1.06(\mathrm{p}=0.2608,95 \% \mathrm{CI}=0.96-1.16)$.

The use of $\log$ transformed $\mathrm{PM}_{10}$ and $\mathrm{PM}_{2.5}$ variables did not result in significant alterations to results in any model; e.g., minimally adjusted $\mathrm{PM}_{10}$ (per one unit increase) $\mathrm{AOR}=1.08(\mathrm{p}=0.3980,95 \% \mathrm{CI}=0.90-1.29)$ and minimally adjusted $\mathrm{PM}_{2.5}$ (per one unit increase $)$ AOR $=1.14(p=0.2009,95 \%$ CI $=0.93-1.38)$. Non-transformed exposure variables were reported due to ease of interpretation. 
The minimally adjusted $\mathrm{PM}_{10}$ (continuous) logistic model revealed increased age at enrollment $(\mathrm{AOR}=1.05,95 \% \mathrm{CI}=1.04-1.05)$, male sex $(\mathrm{AOR}=1.41,95 \% \mathrm{CI}=1.18$ 1.67), pneumococcal vaccine receival $(\mathrm{AOR}=0.78,95 \% \mathrm{CI}=0.64-0.94)$, and seasonal influenza vaccine receival $(\mathrm{AOR}=0.82,95 \% \mathrm{CI}=0.67-0.99)$ to be significantly associated with the outcome; $\mathrm{PM}_{10}$ (continuous) was not significantly associated. The partially adjusted $\mathrm{PM}_{10}$ (continuous) logistic model revealed increased age $(\mathrm{AOR}=1.02,95 \% \mathrm{CI}=$ 1.01-1.03), black race $(\mathrm{AOR}=0.68,95 \% \mathrm{CI}=0.52-0.89)$, transfer to $\mathrm{ICU}$ at hospitalization $(\mathrm{AOR}=1.65,95 \% \mathrm{CI}=1.33-2.06)$, elevated PSI $($ Class $\mathrm{IV}: \mathrm{AOR}=4.05,95 \% \mathrm{CI}=1.44-$ 11.40; Class V: $\mathrm{AOR}=11.13,95 \% \mathrm{CI}=3.91-31.65)$, use of intravenous antibiotics within the past 90 days $(\mathrm{AOR}=1.55,95 \% \mathrm{CI}=1.25-1.93)$, suspicion of aspiration $(\mathrm{AOR}=1.62$, $95 \% \mathrm{CI}=1.27-2.05)$, and pneumococcal vaccine receival $(\mathrm{AOR}=0.76,95 \% \mathrm{CI}=0.62-$ 0.93) to be associated with the outcome; $\mathrm{PM}_{10}$ (continuous) was not significantly associated.

The minimally adjusted $\mathrm{PM}_{2.5}$ (continuous) logistic model revealed increased age at enrollment $(\mathrm{AOR}=1.05,95 \% \mathrm{CI}=1.04-1.05)$, male sex $(\mathrm{AOR}=1.41,95 \% \mathrm{CI}=1.18$ 1.68), pneumococcal vaccine receival $(\mathrm{AOR}=0.78,95 \% \mathrm{CI}=0.65-0.95)$, and seasonal influenza vaccine receival $(\mathrm{AOR}=0.81,95 \% \mathrm{CI}=0.67-0.98)$ to be significantly associated with the outcome; $\mathrm{PM}_{2.5}$ (continuous) was significantly associated. The partially adjusted $\mathrm{PM}_{2.5}$ (continuous) logistic model revealed increased age $(\mathrm{AOR}=1.02,95 \% \mathrm{CI}=1.01$ 1.03), black race $(\mathrm{AOR}=0.68,95 \% \mathrm{CI}=0.52-0.89)$, transfer to $\mathrm{ICU}$ at hospitalization $(\mathrm{AOR}=1.65,95 \% \mathrm{CI}=1.33-2.05)$, elevated PSI $($ Class $\mathrm{IV}: \mathrm{AOR}=4.06,95 \% \mathrm{CI}=1.44-$ 11.42; Class V: AOR $=11.20,95 \% \mathrm{CI}=3.94-31.84$ ), use of intravenous antibiotics within the past 90 days $(\mathrm{AOR}=1.55,95 \% \mathrm{CI}=1.25-1.93)$, suspicion of aspiration $(\mathrm{AOR}=1.61$, 
$95 \% \mathrm{CI}=1.27-2.04)$, and pneumococcal vaccine receival $(\mathrm{AOR}=0.76,95 \% \mathrm{CI}=0.62-$

0.93) to be associated with the outcome; $\mathrm{PM}_{2.5}$ (continuous) was not significantly associated.

\begin{tabular}{|c|c|c|c|}
\hline Variable & $\mathrm{AOR}^{\mathrm{a}}$ & p-value & CI (95\%) \\
\hline $\begin{array}{l}\mathrm{PM}_{10} \text { (continuous), per } \\
\text { five- } \mathrm{ug} / \mathrm{m}^{3} \text { increase }\end{array}$ & 1.02 & 0.4845 & $0.96-1.08$ \\
\hline $\begin{array}{l}\text { Age at enrollment, per one- } \\
\text { year increase }\end{array}$ & 1.05 & $<0.0001$ & $1.04-1.05$ \\
\hline \multicolumn{4}{|l|}{ Sex } \\
\hline Female & referent & referent & referent \\
\hline Male & 1.41 & 0.0001 & $1.18-1.67$ \\
\hline \multicolumn{4}{|l|}{$\begin{array}{l}\text { Pneumococcal vaccine } \\
\text { receival status }\end{array}$} \\
\hline No & referent & referent & referent \\
\hline Yes & 0.78 & 0.0104 & \begin{tabular}{|c|}
$04-0.94$ \\
\end{tabular} \\
\hline Missing & 2.63 & 0.5282 & $0.13-52.86$ \\
\hline \multicolumn{4}{|l|}{$\begin{array}{l}\text { Seasonal influenza vaccine } \\
\text { receival status }\end{array}$} \\
\hline No & referent & referent & referent \\
\hline Yes & 0.82 & 0.0382 & 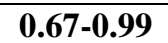 \\
\hline Missing & 0.16 & 0.2241 & $0.01-3.11$ \\
\hline
\end{tabular}




\begin{tabular}{|c|c|c|c|}
\hline \multicolumn{4}{|c|}{$\begin{array}{l}\text { Table 8: Logistic regression examining association between } P_{10} \text { (continuous) exposure at time of } \\
\text { hospitalization and mortality at thirty days - partially adjusted }(N=6145 \text {, events }=597)\end{array}$} \\
\hline Variable & $\mathrm{AOR}^{\mathrm{a}}$ & $\mathrm{p}$-value & CI (95\%) \\
\hline $\begin{array}{l}\mathrm{PM}_{10} \text { (continuous), per } \\
\text { five- } \mathrm{ug} / \mathrm{m}^{3} \text { increase }\end{array}$ & 1.02 & 0.5109 & $0.96-1.08$ \\
\hline $\begin{array}{l}\text { Age at enrollment, per one- } \\
\text { year increase }\end{array}$ & 1.02 & $<0.0001$ & 1.01-1.03 \\
\hline \multicolumn{4}{|l|}{ Sex } \\
\hline Female & referent & referent & referent \\
\hline Male & 1.04 & 0.6911 & $0.86-1.25$ \\
\hline \multicolumn{4}{|l|}{ Race } \\
\hline White & referent & referent & referent \\
\hline Black & 0.68 & 0.0051 & $0.52-0.89$ \\
\hline Other & 0.41 & 0.3960 & $0.05-3.22$ \\
\hline \multicolumn{4}{|l|}{$\begin{array}{l}\text { Transfer to ICU at } \\
\text { hospitalization }\end{array}$} \\
\hline No & referent & referent & referent \\
\hline Yes & 1.65 & $<0.0001$ & 1.33-2.06 \\
\hline \multicolumn{4}{|l|}{ PSI } \\
\hline $\mathrm{I}$ & referent & referent & referent \\
\hline II & 0.64 & 0.4631 & $0.19-2.11$ \\
\hline III & 1.50 & 0.4596 & $0.51-4.37$ \\
\hline IV & 4.05 & 0.0080 & 1.44-11.40 \\
\hline $\mathrm{V}$ & 11.13 & $<0.0001$ & 3.91-31.65 \\
\hline \multicolumn{4}{|l|}{$\begin{array}{l}\text { Use of intravenous } \\
\text { antibiotics within the past } \\
90 \text { days }\end{array}$} \\
\hline No & referent & referent & referent \\
\hline Yes & 1.55 & $<0.0001$ & 1.25-1.93 \\
\hline \multicolumn{4}{|l|}{ Smoking status } \\
\hline Non-smoker & referent & referent & referent \\
\hline Past smoker & 0.92 & 0.4411 & $0.74-1.14$ \\
\hline Current smoker & 0.79 & 0.1006 & $0.60-1.04$ \\
\hline \multicolumn{4}{|l|}{ Suspicion of aspiration } \\
\hline No & referent & referent & referent \\
\hline Yes & 1.62 & $<0.0001$ & 1.27-2.05 \\
\hline Missing & $<0.01$ & 0.9799 & $<0.01->999.99$ \\
\hline \multicolumn{4}{|l|}{$\begin{array}{l}\text { Pneumococcal vaccine } \\
\text { receival status }\end{array}$} \\
\hline No & referent & referent & referent \\
\hline Yes & 0.76 & 0.0076 & $0.62-0.93$ \\
\hline Missing & 1.14 & 0.9289 & $0.07-19.08$ \\
\hline \multicolumn{4}{|l|}{$\begin{array}{l}\text { Seasonal influenza vaccine } \\
\text { receival status }\end{array}$} \\
\hline No & referent & referent & referent \\
\hline Yes & 0.85 & 0.1163 & $0.69-1.04$ \\
\hline Missing & 0.33 & 0.4441 & $0.02-5.51$ \\
\hline
\end{tabular}




\begin{tabular}{|c|c|c|c|}
\hline Variable & & & \\
\hline $\begin{array}{l}\mathrm{PM}_{2.5} \text { (continuous), per } \\
\text { five- } \mathrm{ug} / \mathrm{m}^{3} \text { increase }\end{array}$ & 1.05 & 0.2998 & $0.96-1.15$ \\
\hline $\begin{array}{l}\text { Age at enrollment, per one- } \\
\text { year increase }\end{array}$ & 1.05 & $<0.0001$ & $1.04-1.05$ \\
\hline Sex & & & \\
\hline Female & referent & referent & referent \\
\hline Male & 1.41 & 0.0001 & 1.18-1.68 \\
\hline $\begin{array}{l}\text { Pneumococcal vaccine } \\
\text { receival status }\end{array}$ & & & \\
\hline No & referent & referent & referent \\
\hline Yes & 0.78 & 0.0114 & $0.65-0.95$ \\
\hline Missing & 2.70 & 0.5180 & $0.13-54.90$ \\
\hline $\begin{array}{l}\text { Seasonal influenza vaccine } \\
\text { receival status }\end{array}$ & & & \\
\hline No & referent & referent & referent \\
\hline Yes & 0.81 & $\mathbf{0 . 0 3 0 5}$ & $0.67-0.98$ \\
\hline Missing & 0.15 & 0.2224 & $0.01-3.10$ \\
\hline
\end{tabular}




\begin{tabular}{|c|c|c|c|}
\hline Variable & $\mathrm{AOR}^{\mathrm{a}}$ & $\mathrm{p}$-value & CI $(95 \%)$ \\
\hline $\begin{array}{lll}\mathrm{PM}_{2.5} \quad \text { (continuous), per } \\
\text { five- } \mathrm{ug} / \mathrm{m}^{3} \text { increase }\end{array}$ & 1.06 & 0.2577 & $0.96-1.16$ \\
\hline $\begin{array}{l}\text { Age at enrollment, per one- } \\
\text { year increase }\end{array}$ & 1.02 & $<0.0001$ & 1.01-1.03 \\
\hline \multicolumn{4}{|l|}{ Race } \\
\hline White & referent & referent & referent \\
\hline Black & 0.68 & 0.0051 & $0.52-0.89$ \\
\hline Other & 0.41 & 0.3974 & $0.05-3.23$ \\
\hline \multicolumn{4}{|l|}{$\begin{array}{l}\text { Transfer to ICU at } \\
\text { hospitalization }\end{array}$} \\
\hline No & referent & referent & referent \\
\hline Yes & 1.65 & $<0.0001$ & $1.33-2.05$ \\
\hline \multicolumn{4}{|l|}{ PSI } \\
\hline I & referent & referent & referent \\
\hline II & 0.64 & 0.4650 & $0.19-2.11$ \\
\hline III & 1.50 & 0.4553 & $0.51-4.39$ \\
\hline IV & 4.06 & 0.0079 & 1.44-11.42 \\
\hline $\mathrm{V}$ & 11.20 & $<0.0001$ & 3.94-31.84 \\
\hline \multicolumn{4}{|l|}{$\begin{array}{l}\text { Use of intravenous } \\
\text { antibiotics within the past } \\
90 \text { days }\end{array}$} \\
\hline No & referent & referent & referent \\
\hline Yes & 1.55 & $<0.0001$ & $1.25-1.93$ \\
\hline \multicolumn{4}{|l|}{ Smoking status } \\
\hline Non-smoker & referent & referent & referent \\
\hline Past smoker & 0.92 & 0.4378 & $0.74-1.14$ \\
\hline Current smoker & 0.79 & 0.0985 & $0.60-1.04$ \\
\hline \multicolumn{4}{|l|}{ Suspicion of aspiration } \\
\hline No & referent & referent & referent \\
\hline Yes & 1.61 & $<0.0001$ & $1.27-2.04$ \\
\hline Missing & $<0.01$ & 0.9801 & $<0.01->999.99$ \\
\hline \multicolumn{4}{|l|}{$\begin{array}{l}\text { Pneumococcal vaccine } \\
\text { receival status }\end{array}$} \\
\hline No & referent & referent & referent \\
\hline Yes & 0.76 & $\mathbf{0 . 0 0 8 1}$ & $0.62-0.93$ \\
\hline Missing & 1.17 & 0.9142 & $0.07-19.90$ \\
\hline \multicolumn{4}{|l|}{$\begin{array}{l}\text { Seasonal influenza vaccine } \\
\text { receival status }\end{array}$} \\
\hline No & referent & referent & referent \\
\hline Yes & 0.84 & 0.1005 & $0.69-1.03$ \\
\hline Missing & 0.33 & 0.4411 & $0.02-5.52$ \\
\hline
\end{tabular}

Logistic regression results for the relationship between $\mathrm{PM}_{10}$ exposure divided into quartiles and mortality at thirty days can be seen in Tables 11-12, reflecting minimally adjusted (Table 11) and partially adjusted (Table 12) models. Logistic regression results 
for the relationship between $\mathrm{PM}_{2.5}$ exposure divided into quartiles and mortality at thirty days can be seen in Tables 13-14, reflecting minimally adjusted (Table 13) and partially adjusted (Table 14) models. As fully adjusted models differed only slightly from partially adjusted models with minimal change in the primary relationship of interest, the results for PM for the fully adjusted models are reported here and not as a full table: $\mathrm{PM}_{10}$ (quartile 2) $\mathrm{AOR}=1.03(\mathrm{p}=0.8163,95 \% \mathrm{CI}=0.80-1.33)$ and fully adjusted $\mathrm{PM}_{2.5}$ (quartile 2$) \mathrm{AOR}$ $=1.11(\mathrm{p}=0.4386,95 \% \mathrm{CI}=0.85-1.44), \mathrm{PM}_{10}($ quartile 3$) \mathrm{AOR}=1.00(\mathrm{p}=0.9824,95 \%$ $\mathrm{CI}=0.77-1.30)$ and fully adjusted $\mathrm{PM}_{2.5}$ (quartile 3$) \mathrm{AOR}=1.20(\mathrm{p}=0.1617,95 \% \mathrm{CI}=$ 0.93-1.55), $\mathrm{PM}_{10}$ (quartile 4) $\mathrm{AOR}=1.10(\mathrm{p}=0.4605,95 \% \mathrm{CI}=0.85-1.43)$ and fully adjusted $\mathrm{PM}_{2.5}$ (quartile 4) $\mathrm{AOR}=1.17(\mathrm{p}=0.2372,95 \% \mathrm{CI}=0.90-1.52)$.

The minimally adjusted $\mathrm{PM}_{10}$ (quartile) logistic model revealed increased age at enrollment $(\mathrm{AOR}=1.05,95 \% \mathrm{CI}=1.04-1.05)$, male $\operatorname{sex}(\mathrm{AOR}=1.41,95 \% \mathrm{CI}=1.18$ 1.67), pneumococcal vaccine receival $(\mathrm{AOR}=0.78,95 \% \mathrm{CI}=0.64-0.94)$, and seasonal influenza vaccine receival $(\mathrm{AOR}=0.82,95 \% \mathrm{CI}=0.67-0.99)$ to be significantly associated with the outcome; $\mathrm{PM}_{10}$ (quartile) was not significantly associated and no significant trend was detected. The partially adjusted $\mathrm{PM}_{10}$ (quartile) logistic model revealed increased age $(\mathrm{AOR}=1.02,95 \% \mathrm{CI}=1.01-1.03)$, black race $(\mathrm{AOR}=0.68,95 \% \mathrm{CI}=0.52-0.89)$, transfer to ICU at hospitalization $(\mathrm{AOR}=1.66,95 \% \mathrm{CI}=1.33-2.06)$, elevated PSI (Class IV: AOR $=4.05,95 \% \mathrm{CI}=1.44-11.40 ;$ Class $\mathrm{V}: \mathrm{AOR}=11.13,95 \% \mathrm{CI}=3.91-31.65)$, use of intravenous antibiotics within the past 90 days $(\mathrm{AOR}=1.55,95 \% \mathrm{CI}=1.25-1.93)$, suspicion of aspiration $(\mathrm{AOR}=1.62,95 \% \mathrm{CI}=1.27-2.05)$, and pneumococcal vaccine receival $(\mathrm{AOR}=0.76,95 \% \mathrm{CI}=0.62-0.93)$ to be significantly associated with the outcome; $\mathrm{PM}_{10}$ (quartile) was not significantly associated and no significant trend was detected. 
The minimally adjusted $\mathrm{PM}_{2.5}$ (quartile) logistic model revealed increased age at enrollment $(\mathrm{AOR}=1.05,95 \% \mathrm{CI}=1.04-1.05)$, male $\operatorname{sex}(\mathrm{AOR}=1.41,95 \% \mathrm{CI}=1.19$ 1.68), pneumococcal vaccine receival $(\mathrm{AOR}=0.78,95 \% \mathrm{CI}=0.65-0.95)$, and seasonal influenza vaccine receival $(\mathrm{AOR}=0.81,95 \% \mathrm{CI}=0.67-0.98)$ to be significantly associated with the outcome; $\mathrm{PM}_{2.5}$ (quartile) was not significantly associated and no significant trend was detected. The partially adjusted $\mathrm{PM}_{2.5}$ (quartile) logistic model revealed increased age $(\mathrm{AOR}=1.02,95 \% \mathrm{CI}=1.01-1.03)$, black race $(\mathrm{AOR}=0.68,95 \% \mathrm{CI}=0.52-0.89)$, transfer to ICU at hospitalization $(\mathrm{AOR}=1.65,95 \% \mathrm{CI}=1.32-2.05)$, elevated PSI (Class IV: AOR $=4.10,95 \% \mathrm{CI}=1.46-11.53$; Class $\mathrm{V}: \mathrm{AOR}=11.30,95 \% \mathrm{CI}=3.97-32.15)$, use of intravenous antibiotics within the past 90 days $(\mathrm{AOR}=1.55,95 \% \mathrm{CI}=1.24-1.92)$, suspicion of aspiration $(\mathrm{AOR}=1.61,95 \% \mathrm{CI}=1.27-2.05)$, and pneumococcal vaccine receival $(\mathrm{AOR}=0.76,95 \% \mathrm{CI}=0.62-0.93)$ to be significantly associated with the outcome; $\mathrm{PM}_{2.5}$ (quartile) was not significantly associated and no significant trend was detected. 


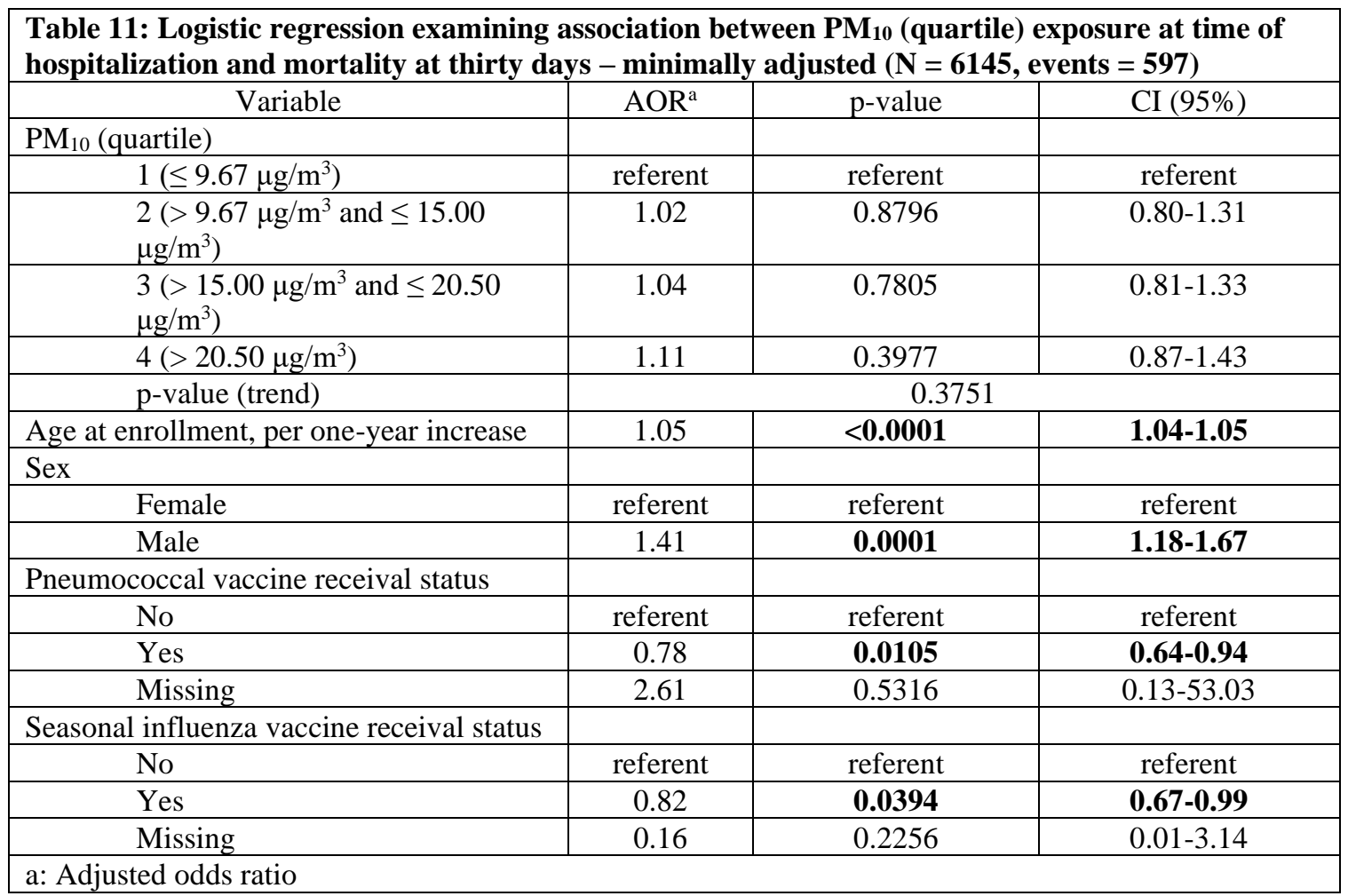




\begin{tabular}{|c|c|c|c|}
\hline Variable & $\mathrm{AOR}^{\mathrm{a}}$ & p-value & CI $(95 \%)$ \\
\hline \multicolumn{4}{|l|}{$\mathrm{PM}_{10}$ (quartile) } \\
\hline $1\left(\leq 9.67 \mu \mathrm{g} / \mathrm{m}^{3}\right)$ & referent & referent & referent \\
\hline $\begin{array}{l}2\left(>9.67 \mu \mathrm{g} / \mathrm{m}^{3} \text { and } \leq 15.00\right. \\
\left.\mu \mathrm{g} / \mathrm{m}^{3}\right)\end{array}$ & 1.03 & 0.8207 & $0.80-1.33$ \\
\hline $\begin{array}{l}3\left(>15.00 \mu \mathrm{g} / \mathrm{m}^{3} \text { and } \leq 20.50\right. \\
\left.\mu \mathrm{g} / \mathrm{m}^{3}\right)\end{array}$ & 1.00 & 0.9752 & $0.76-1.29$ \\
\hline $4\left(>20.50 \mu \mathrm{g} / \mathrm{m}^{3}\right)$ & 1.10 & 0.4604 & $0.85-1.43$ \\
\hline $\mathrm{p}$-value (trend) & \multicolumn{3}{|c|}{0.4969} \\
\hline Age at enrollment, per one-year increase & 1.02 & $<\mathbf{0 . 0 0 0 1}$ & 1.01-1.03 \\
\hline \multicolumn{4}{|l|}{ Sex } \\
\hline Female & referent & referent & referent \\
\hline Male & 1.04 & 0.7099 & $0.86-1.25$ \\
\hline \multicolumn{4}{|l|}{ Race } \\
\hline White & referent & referent & referent \\
\hline Black & 0.68 & 0.0051 & $0.52-0.89$ \\
\hline Other & 0.41 & 0.3979 & $0.05-3.23$ \\
\hline \multicolumn{4}{|l|}{ Transfer to ICU at hospitalization } \\
\hline No & referent & referent & referent \\
\hline Yes & 1.66 & $<0.0001$ & $1.33-2.06$ \\
\hline \multicolumn{4}{|l|}{ PSI } \\
\hline $\mathrm{I}$ & referent & referent & referent \\
\hline II & 0.64 & 0.4629 & $0.19-2.11$ \\
\hline III & 1.50 & 0.4594 & $0.51-4.37$ \\
\hline IV & 4.05 & $\mathbf{0 . 0 0 8 0}$ & 1.44-11.40 \\
\hline $\mathrm{V}$ & 11.13 & $<0.0001$ & 3.91-31.65 \\
\hline \multicolumn{4}{|l|}{$\begin{array}{l}\text { Use of intravenous antibiotics within the } \\
\text { past } 90 \text { days }\end{array}$} \\
\hline No & referent & referent & referent \\
\hline Yes & 1.55 & $<0.0001$ & $1.25-1.93$ \\
\hline \multicolumn{4}{|l|}{ Smoking status } \\
\hline Non-smoker & referent & referent & referent \\
\hline Past smoker & 0.92 & 0.4411 & $0.74-1.14$ \\
\hline Current smoker & 0.79 & 0.0996 & $0.60-1.04$ \\
\hline \multicolumn{4}{|l|}{ Suspicion of aspiration } \\
\hline No & referent & referent & referent \\
\hline Yes & 1.62 & $<0.0001$ & $1.27-2.05$ \\
\hline Missing & $<0.01$ & 0.9799 & $<0.01->999.99$ \\
\hline \multicolumn{4}{|l|}{ Pneumococcal vaccine receival status } \\
\hline No & referent & referent & referent \\
\hline Yes & 0.76 & 0.0077 & $0.62-0.93$ \\
\hline Missing & 1.13 & 0.9308 & $0.07-19.02$ \\
\hline \multicolumn{4}{|l|}{ Seasonal influenza vaccine receival status } \\
\hline No & referent & referent & referent \\
\hline Yes & 0.85 & 0.1141 & $0.69-1.04$ \\
\hline Missing & 0.34 & 0.4453 & $0.02-5.53$ \\
\hline
\end{tabular}




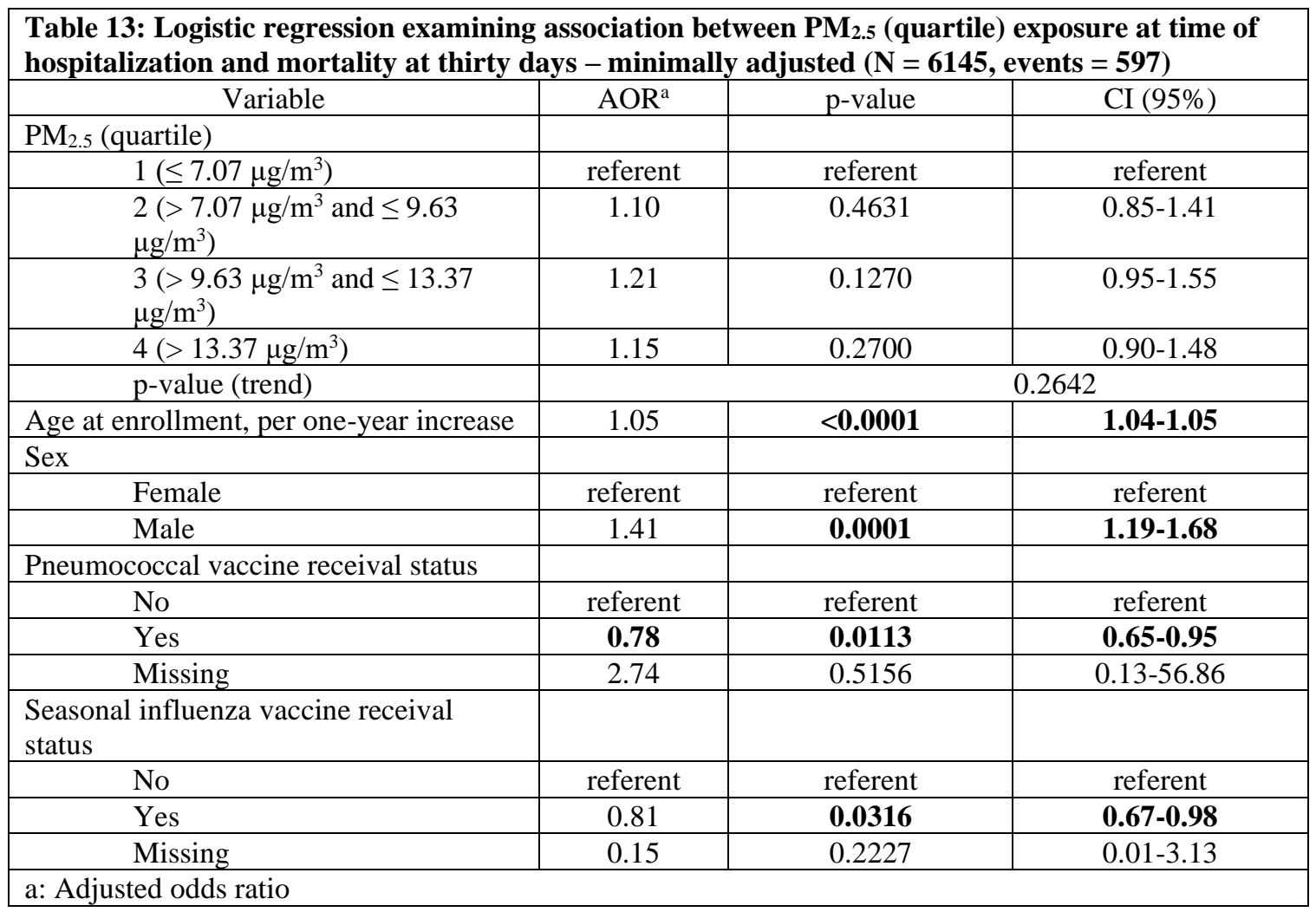




\begin{tabular}{|c|c|c|c|}
\hline Variable & $\mathrm{AOR}^{\mathrm{a}}$ & $\mathrm{p}$-value & CI $(95 \%)$ \\
\hline \multicolumn{4}{|l|}{$\mathrm{PM}_{2.5}$ (quartile) } \\
\hline $1\left(\leq 7.07 \mu \mathrm{g} / \mathrm{m}^{3}\right)$ & referent & referent & referent \\
\hline $\begin{array}{l}2\left(>7.07 \mu \mathrm{g} / \mathrm{m}^{3} \text { and } \leq 9.63\right. \\
\left.\mu \mathrm{g} / \mathrm{m}^{3}\right)\end{array}$ & 1.11 & 0.4347 & $0.85-1.44$ \\
\hline $\begin{array}{l}3\left(>9.63 \mu \mathrm{g} / \mathrm{m}^{3} \text { and } \leq 13.37\right. \\
\left.\mu \mathrm{g} / \mathrm{m}^{3}\right)\end{array}$ & 1.20 & 0.1606 & $0.93-1.55$ \\
\hline $4\left(>13.37 \mu \mathrm{g} / \mathrm{m}^{3}\right)$ & 1.17 & 0.2334 & $0.90-1.52$ \\
\hline p-value (trend) & \multicolumn{3}{|c|}{0.2390} \\
\hline Age at enrollment, per one-year increase & 1.02 & $<0.0001$ & $1.01-1.03$ \\
\hline \multicolumn{4}{|l|}{ Sex } \\
\hline Female & referent & referent & referent \\
\hline Male & 1.04 & 0.6746 & $0.86-1.25$ \\
\hline \multicolumn{4}{|l|}{ Race } \\
\hline White & referent & referent & referent \\
\hline Black & 0.68 & 0.0050 & $0.52-0.89$ \\
\hline Other & 0.41 & 0.3928 & $0.05-3.21$ \\
\hline \multicolumn{4}{|l|}{ Transfer to ICU at hospitalization } \\
\hline No & referent & referent & referent \\
\hline Yes & 1.65 & $<0.0001$ & $1.32-2.05$ \\
\hline \multicolumn{4}{|l|}{ PSI } \\
\hline $\mathrm{I}$ & referent & referent & referent \\
\hline II & 0.65 & 0.4726 & $0.20-2.13$ \\
\hline III & 1.52 & 0.4460 & $0.52-4.42$ \\
\hline IV & 4.10 & 0.0075 & 1.46-11.53 \\
\hline $\mathrm{V}$ & 11.30 & $<0.0001$ & 3.97-32.15 \\
\hline \multicolumn{4}{|l|}{$\begin{array}{l}\text { Use of intravenous antibiotics within the } \\
\text { past } 90 \text { days }\end{array}$} \\
\hline No & referent & referent & referent \\
\hline Yes & 1.55 & $<0.0001$ & 1.24-1.92 \\
\hline \multicolumn{4}{|l|}{ Smoking status } \\
\hline Non-smoker & referent & referent & referent \\
\hline Past smoker & 0.92 & 0.4526 & $0.74-1.14$ \\
\hline Current smoker & 0.80 & 0.1061 & $0.61-1.05$ \\
\hline \multicolumn{4}{|l|}{ Suspicion of aspiration } \\
\hline No & referent & referent & referent \\
\hline Yes & 1.61 & $<0.0001$ & $1.27-2.05$ \\
\hline Missing & $<0.01$ & 0.9800 & $<0.01->999.99$ \\
\hline \multicolumn{4}{|l|}{ Pneumococcal vaccine receival status } \\
\hline No & referent & referent & referent \\
\hline Yes & 0.76 & 0.0082 & $0.62-0.93$ \\
\hline Missing & 1.17 & 0.9121 & $0.07-20.41$ \\
\hline \multicolumn{4}{|l|}{ Seasonal influenza vaccine receival status } \\
\hline No & referent & referent & referent \\
\hline Yes & 0.84 & 0.1000 & $0.69-1.03$ \\
\hline Missing & 0.33 & 0.4428 & $0.02-5.61$ \\
\hline
\end{tabular}


Cox proportional hazards regression results for the relationship between continuous $\mathrm{PM}_{10}$ exposure and mortality at thirty days can be seen in Tables 15-16, reflecting minimally adjusted (Table 15) and partially adjusted (Table 16) models. Cox proportional hazards regression results for the relationship between continuous $\mathrm{PM}_{2.5}$ exposure and mortality at thirty days can be seen in Tables 17-18, reflecting minimally adjusted (Table 17) and partially adjusted (Table 18) models. As fully adjusted models differed only slightly from partially adjusted models with minimal change in the primary relationship of interest, the results for PM for the fully adjusted models were reported here and not as a full table: fully adjusted $\mathrm{PM}_{10}$ (per five unit increase) $\mathrm{AHR}=1.02(\mathrm{p}=0.4831,95 \% \mathrm{CI}=$ 0.97-1.07) and fully adjusted $\mathrm{PM}_{2.5}$ (per five unit increase) $\mathrm{AHR}=1.05(\mathrm{p}=0.2473,95 \%$ $\mathrm{CI}=0.97-1.14)$. Total survival time, in person days, was 173,814 person days.

The use of $\log$ transformed $\mathrm{PM}_{10}$ and $\mathrm{PM}_{2.5}$ variables did not result in significant alterations to results in any model; e.g., minimally adjusted $\mathrm{PM}_{10}$ (per one unit increase) AHR $=1.07(p=0.3856,95 \% \mathrm{CI}=0.91-1.27)$ and minimally adjusted $\mathrm{PM}_{2.5}$ (per one unit increase $)$ AHR $=1.13(\mathrm{p}=0.1986,95 \%$ CI $=0.94-1.35)$. Non-transformed exposure variables were reported due to ease of interpretation.

The minimally adjusted $\mathrm{PM}_{10}$ (continuous) Cox proportional hazards model revealed increased age at enrollment $(\mathrm{AOR}=1.04,95 \% \mathrm{CI}=1.04-1.05)$, male sex (AOR $=1.38,95 \% \mathrm{CI}=1.17-1.62)$, pneumococcal vaccine receival $(\mathrm{AOR}=0.79,95 \% \mathrm{CI}=0.67$ 0.95), and seasonal influenza vaccine receival $(\mathrm{AOR}=0.82,95 \% \mathrm{CI}=0.69-0.99)$ to be significantly associated with the outcome; $\mathrm{PM}_{10}$ (continuous) was not significantly associated. The partially adjusted $\mathrm{PM}_{10}$ (continuous) Cox proportional hazards model revealed increased age $(\mathrm{AOR}=1.02,95 \% \mathrm{CI}=1.01-1.03)$, black race $(\mathrm{AOR}=0.69,95 \%$ 
$\mathrm{CI}=0.54-0.88)$, transfer to $\mathrm{ICU}$ at hospitalization $(\mathrm{AOR}=1.59,95 \% \mathrm{CI}=1.32-1.93)$, elevated PSI (Class IV: AOR $=4.05,95 \% \mathrm{CI}=1.46-11.24$; Class V: AOR $=10.19,95 \%$ $\mathrm{CI}=3.64-28.53)$, use of intravenous antibiotics within the past 90 days $(\mathrm{AOR}=1.45,95 \%$ $\mathrm{CI}=1.20-1.75)$, suspicion of aspiration $(\mathrm{AOR}=1.49,95 \% \mathrm{CI}=1.22-1.83)$, and pneumococcal vaccine receival $(\mathrm{AOR}=0.79,95 \% \mathrm{CI}=0.66-0.94)$ to be significantly associated with the outcome; $\mathrm{PM}_{10}$ (continuous) was not significantly associated.

The minimally adjusted $\mathrm{PM}_{2.5}$ (continuous) Cox proportional hazards model revealed increased age at enrollment $(\mathrm{AOR}=1.04,95 \% \mathrm{CI}=1.04-1.05)$, male sex $(\mathrm{AOR}$ $=1.38,95 \% \mathrm{CI}=1.17-1.62)$, pneumococcal vaccine receival $(\mathrm{AOR}=0.80,95 \% \mathrm{CI}=0.67-$ 0.95), and seasonal influenza vaccine receival $(\mathrm{AOR}=0.82,95 \% \mathrm{CI}=0.67-0.98)$ to be significantly associated with the outcome; $\mathrm{PM}_{2.5}$ (continuous) was not significantly associated. The partially adjusted $\mathrm{PM}_{2.5}$ (continuous) Cox proportional hazards model revealed increased age $(\mathrm{AOR}=1.02,95 \% \mathrm{CI}=1.01-1.03)$, black race $(\mathrm{AOR}=0.69,95 \%$ $\mathrm{CI}=0.54-0.88)$, transfer to $\mathrm{ICU}$ at hospitalization $(\mathrm{AOR}=1.59,95 \% \mathrm{CI}=1.32-1.92)$, elevated PSI (Class IV: AOR $=4.06,95 \% \mathrm{CI}=1.46-11.26$; Class V: $\mathrm{AOR}=10.24,95 \%$ $\mathrm{CI}=3.66-28.67)$, use of intravenous antibiotics within the past 90 days $(\mathrm{AOR}=1.45,95 \%$ $\mathrm{CI}=1.20-1.75)$, suspicion of aspiration $(\mathrm{AOR}=1.49,95 \% \mathrm{CI}=1.21-1.82)$, and pneumococcal vaccine receival $(\mathrm{AOR}=0.79,95 \% \mathrm{CI}=0.66-0.94)$ to be significantly associated with the outcome; $\mathrm{PM}_{2.5}$ (continuous) was not significantly associated. 


\begin{tabular}{|c|c|c|c|}
\hline \multicolumn{4}{|c|}{$\begin{array}{l}\text { Table 15: Cox proportional hazards regression examining association between } \mathrm{PM}_{10} \text { (continuous) } \\
\text { exposure at time of hospitalization and mortality at thirty days }- \text { minimally adjusted ( } \mathrm{N}=6 \mathbf{6 1 4 5} \\
\text { events }=597 \text {, person/days }=173814 \text { ) }\end{array}$} \\
\hline Variable & $\mathrm{AHR}^{\mathrm{a}}$ & $\mathrm{p}$-value & CI $(95 \%)$ \\
\hline $\begin{array}{l}\mathrm{PM}_{10} \text { (continuous), per } \\
\text { five- } \mathrm{ug} / \mathrm{m}^{3} \text { increase }\end{array}$ & 1.02 & 0.4719 & $0.97-1.07$ \\
\hline $\begin{array}{l}\text { Age at enrollment, per one- } \\
\text { year increase }\end{array}$ & 1.04 & $<0.0001$ & 1.04-1.05 \\
\hline \multicolumn{4}{|l|}{ Sex } \\
\hline Female & referent & referent & referent \\
\hline Male & 1.38 & 0.0001 & $1.17-1.62$ \\
\hline \multicolumn{4}{|l|}{$\begin{array}{l}\text { Pneumococcal vaccine } \\
\text { receival status }\end{array}$} \\
\hline No & referent & referent & referent \\
\hline Yes & 0.79 & 0.0103 & $0.67-0.95$ \\
\hline Missing & 2.34 & 0.5279 & $0.17-32.78$ \\
\hline \multicolumn{4}{|l|}{$\begin{array}{l}\text { Seasonal influenza vaccine } \\
\text { receival status }\end{array}$} \\
\hline No & referent & referent & referent \\
\hline Yes & 0.82 & $\mathbf{0 . 0 3 4 7}$ & 0.69-0.99 \\
\hline Missing & 0.18 & 0.2103 & $0.01-2.59$ \\
\hline
\end{tabular}




\begin{tabular}{|c|c|c|c|}
\hline Variable & $\mathrm{AHR}^{\mathrm{a}}$ & p-value & $\mathrm{CI}(95 \%)$ \\
\hline $\begin{array}{lll}\mathrm{PM}_{10} \text { (continuous), } & \text { per } \\
\text { five- } \mathrm{ug} / \mathrm{m}^{3} \text { increase } & \end{array}$ & 1.02 & 0.4796 & $0.97-1.07$ \\
\hline $\begin{array}{l}\text { Age at enrollment, per one- } \\
\text { year increase }\end{array}$ & 1.02 & $<0.0001$ & 1.01-1.03 \\
\hline \multicolumn{4}{|l|}{ Sex } \\
\hline Female & referent & referent & referent \\
\hline Male & 1.04 & 0.6570 & $0.88-1.23$ \\
\hline \multicolumn{4}{|l|}{ Race } \\
\hline White & referent & referent & referent \\
\hline Black & 0.69 & 0.0033 & $0.54-0.88$ \\
\hline Other & 0.43 & 0.4007 & $0.06-3.07$ \\
\hline \multicolumn{4}{|l|}{$\begin{array}{l}\text { Transfer to ICU at } \\
\text { hospitalization }\end{array}$} \\
\hline No & referent & referent & referent \\
\hline Yes & 1.59 & $<0.0001$ & $1.32-1.93$ \\
\hline \multicolumn{4}{|l|}{ PSI } \\
\hline $\mathrm{I}$ & referent & referent & referent \\
\hline II & 0.65 & 0.4794 & $0.20-2.13$ \\
\hline III & 1.53 & 0.4292 & $0.53-4.42$ \\
\hline IV & 4.05 & 0.0073 & 1.46-11.24 \\
\hline $\mathrm{V}$ & 10.19 & $<0.0001$ & 3.64-28.53 \\
\hline \multicolumn{4}{|l|}{$\begin{array}{l}\text { Use of intravenous } \\
\text { antibiotics within the past } \\
90 \text { days }\end{array}$} \\
\hline No & referent & referent & referent \\
\hline Yes & 1.45 & 0.0001 & $1.20-1.75$ \\
\hline \multicolumn{4}{|l|}{ Smoking status } \\
\hline Non-smoker & referent & referent & referent \\
\hline Past smoker & 0.93 & 0.4366 & $0.77-1.12$ \\
\hline Current smoker & 0.81 & 0.1049 & $0.64-1.04$ \\
\hline \multicolumn{4}{|l|}{ Suspicion of aspiration } \\
\hline No & referent & referent & referent \\
\hline Yes & 1.49 & 0.0001 & $1.22-1.83$ \\
\hline Missing & 0.00 & 0.9693 & $0.00-0.00$ \\
\hline \multicolumn{4}{|l|}{$\begin{array}{l}\text { Pneumococcal vaccine } \\
\text { receival status }\end{array}$} \\
\hline No & referent & referent & referent \\
\hline Yes & 0.79 & 0.0090 & 0.66-0.94 \\
\hline Missing & 1.06 & 0.9607 & $0.10-11.60$ \\
\hline \multicolumn{4}{|l|}{$\begin{array}{l}\text { Seasonal influenza vaccine } \\
\text { receival status }\end{array}$} \\
\hline No & referent & referent & referent \\
\hline Yes & 0.86 & 0.1047 & $0.72-1.03$ \\
\hline Missing & 0.39 & 0.4379 & $0.03-4.24$ \\
\hline
\end{tabular}




\begin{tabular}{|c|c|c|c|}
\hline \multicolumn{4}{|c|}{$\begin{array}{l}\text { Table 17: Cox proportional hazards regression examining association between PM2.5 (continuous) } \\
\text { exposure at time of hospitalization and mortality at thirty days }- \text { minimally adjusted }(\mathrm{N}=6145 \text {, } \\
\text { events }=597 \text {, person/days }=173814 \text { ) }\end{array}$} \\
\hline Variable & $\mathrm{AHR}^{\mathrm{a}}$ & $\mathrm{p}$-value & $\mathrm{CI}(95 \%)$ \\
\hline $\begin{array}{l}\mathrm{PM}_{2.5} \text { (continuous), per } \\
\text { five- } \mathrm{ug} / \mathrm{m}^{3} \text { increase }\end{array}$ & 1.05 & 0.2959 & $0.96-1.14$ \\
\hline $\begin{array}{l}\text { Age at enrollment, per one- } \\
\text { year increase }\end{array}$ & 1.04 & $<0.0001$ & $1.04-1.05$ \\
\hline \multicolumn{4}{|l|}{ Sex } \\
\hline Female & referent & referent & referent \\
\hline Male & 1.38 & $<0.0001$ & $1.17-1.62$ \\
\hline \multicolumn{4}{|l|}{$\begin{array}{l}\text { Pneumococcal vaccine } \\
\text { receival status }\end{array}$} \\
\hline No & referent & referent & referent \\
\hline Yes & 0.80 & 0.0114 & $0.67-0.95$ \\
\hline Missing & 2.40 & 0.5167 & $0.17-34.06$ \\
\hline \multicolumn{4}{|l|}{$\begin{array}{l}\text { Seasonal influenza vaccine } \\
\text { receival status }\end{array}$} \\
\hline No & referent & referent & referent \\
\hline Yes & 0.82 & 0.0278 & $\begin{array}{c}0.67-0.98 \\
\end{array}$ \\
\hline Missing & 0.18 & 0.2087 & $0.01-2.59$ \\
\hline
\end{tabular}




\begin{tabular}{|c|c|c|c|}
\hline Variable & $\mathrm{AHR}^{\mathrm{a}}$ & p-value & CI (95\%) \\
\hline $\begin{array}{lll}\mathrm{PM}_{2.5} \text { (continuous), per } \\
\text { five- } \mathrm{ug} / \mathrm{m}^{3} \text { increase }\end{array}$ & 1.05 & 0.2436 & $0.97-1.14$ \\
\hline $\begin{array}{l}\text { Age at enrollment, per one- } \\
\text { year increase }\end{array}$ & 1.02 & $<0.0001$ & 1.01-1.03 \\
\hline \multicolumn{4}{|l|}{ Sex } \\
\hline Female & referent & referent & referent \\
\hline Male & 1.04 & 0.6366 & 0.88-1.23 \\
\hline \multicolumn{4}{|l|}{ Race } \\
\hline White & referent & referent & referent \\
\hline Black & 0.69 & 0.0033 & 0.54-0.88 \\
\hline Other & 0.43 & 0.4018 & $0.06-3.08$ \\
\hline \multicolumn{4}{|l|}{$\begin{array}{l}\text { Transfer to ICU at } \\
\text { hospitalization }\end{array}$} \\
\hline No & referent & referent & referent \\
\hline Yes & 1.59 & $<0.0001$ & $1.32-1.92$ \\
\hline \multicolumn{4}{|l|}{ PSI } \\
\hline I & referent & referent & referent \\
\hline II & 0.65 & 0.4813 & $0.20-2.14$ \\
\hline III & 1.54 & 0.4253 & $0.53-4.44$ \\
\hline IV & 4.06 & 0.0072 & $1.46-11.26$ \\
\hline $\mathrm{V}$ & 10.24 & $<0.0001$ & 3.66-28.67 \\
\hline \multicolumn{4}{|l|}{$\begin{array}{l}\text { Use of intravenous } \\
\text { antibiotics within the past } \\
90 \text { days }\end{array}$} \\
\hline No & referent & referent & referent \\
\hline Yes & 1.45 & 0.0001 & $1.20-1.75$ \\
\hline \multicolumn{4}{|l|}{ Smoking status } \\
\hline Non-smoker & referent & referent & referent \\
\hline Past smoker & 0.93 & 0.4354 & $0.77-1.12$ \\
\hline Current smoker & 0.81 & 0.1009 & $0.63-1.04$ \\
\hline \multicolumn{4}{|l|}{ Suspicion of aspiration } \\
\hline No & referent & referent & referent \\
\hline Yes & 1.49 & 0.0001 & 1.21-1.82 \\
\hline Missing & 0.00 & 0.9695 & $0.00-0.00$ \\
\hline \multicolumn{4}{|l|}{$\begin{array}{l}\text { Pneumococcal vaccine } \\
\text { receival status }\end{array}$} \\
\hline No & referent & referent & referent \\
\hline Yes & 0.79 & 0.0098 & 0.66-0.94 \\
\hline Missing & 1.09 & 0.9437 & $0.10-12.12$ \\
\hline \multicolumn{4}{|l|}{$\begin{array}{l}\text { Seasonal influenza vaccine } \\
\text { receival status }\end{array}$} \\
\hline No & referent & referent & referent \\
\hline Yes & 0.86 & 0.0895 & $0.72-1.02$ \\
\hline Missing & 0.38 & 0.4349 & $0.03-4.26$ \\
\hline
\end{tabular}


Cox proportional hazards regression results for the relationship between $\mathrm{PM}_{10}$ exposure divided into quartiles and mortality at thirty days can be seen in Tables 19-20, reflecting minimally adjusted (Table 19) and partially adjusted (Table 20) models. Cox proportional hazards regression results for the relationship between $\mathrm{PM}_{2.5}$ exposure divided into quartiles and mortality at thirty days can be seen in Tables 21-22, reflecting minimally adjusted (Table 21) and partially adjusted (Table 22) models. As fully adjusted models differed only slightly from partially adjusted models with minimal change in the primary relationship of interest, the results for PM for the fully adjusted models were reported here and not as a full table: $\mathrm{PM}_{10}$ (quartile 2) $\mathrm{AHR}=1.04(\mathrm{p}=0.7620,95 \% \mathrm{CI}=0.82-1.30)$ and fully adjusted $\mathrm{PM}_{2.5}$ (quartile 2) $\mathrm{AHR}=1.13(\mathrm{p}=0.3088,95 \% \mathrm{CI}=0.89-1.43), \mathrm{PM}_{10}$ (quartile 3) $\mathrm{AHR}=0.99(\mathrm{p}=0.9099,95 \% \mathrm{CI}=0.78-1.25)$ and fully adjusted $\mathrm{PM}_{2.5}$ (quartile 3) $\mathrm{AHR}=1.17(\mathrm{p}=0.1817,95 \% \mathrm{CI}=0.93-1.47), \mathrm{PM}_{10}$ (quartile 4) $\mathrm{AHR}=1.10(\mathrm{p}=$ $0.4062,95 \% \mathrm{CI}=0.88-1.39)$ and fully adjusted $\mathrm{PM}_{2.5}$ (quartile 4) $\mathrm{AHR}=1.17(\mathrm{p}=0.1906$, $95 \% \mathrm{CI}=0.93-1.47)$. Total survival time, in person days, was 173,814 person/days.

The minimally adjusted $\mathrm{PM}_{10}$ (quartile) Cox proportional hazards model revealed increased age at enrollment $(\mathrm{AOR}=1.04,95 \% \mathrm{CI}=1.04-1.05)$, male sex $(\mathrm{AOR}=1.37$, $95 \% \mathrm{CI}=1.17-1.61)$, pneumococcal vaccine receival $(\mathrm{AOR}=0.79,95 \% \mathrm{CI}=0.67-0.95)$, and seasonal influenza vaccine receival $(\mathrm{AOR}=0.83,95 \% \mathrm{CI}=0.69-0.99)$ to be significantly associated with the outcome; $\mathrm{PM}_{10}$ (quartile) was not significantly associated and no significant trend was detected. The partially adjusted $\mathrm{PM}_{10}$ (quartile) Cox proportional hazards model revealed increased age $(\mathrm{AOR}=1.02,95 \% \mathrm{CI}=1.01-1.03)$, black race $(\mathrm{AOR}=0.69,95 \% \mathrm{CI}=0.54-0.88)$, transfer to $\mathrm{ICU}$ at hospitalization $(\mathrm{AOR}=$ $1.60,95 \% \mathrm{CI}=1.32-1.93)$, elevated PSI (Class IV: $\mathrm{AOR}=4.04,95 \% \mathrm{CI}=1.45-11.22$; 
Class V: $\mathrm{AOR}=10.17,95 \% \mathrm{CI}=3.63-28.47)$, use of intravenous antibiotics within the past 90 days $(\mathrm{AOR}=1.45,95 \% \mathrm{CI}=1.20-1.75)$, suspicion of aspiration $(\mathrm{AOR}=1.49,95 \%$ $\mathrm{CI}=1.22-1.83)$, and pneumococcal vaccine receival $(\mathrm{AOR}=0.79,95 \% \mathrm{CI}=0.66-0.94)$ to be significantly associated with the outcome; $\mathrm{PM}_{10}$ (quartile) was not significantly associated and no significant trend was detected.

The minimally adjusted $\mathrm{PM}_{2.5}$ (quartile) Cox proportional hazards model revealed increased age at enrollment $(\mathrm{AOR}=1.04,95 \% \mathrm{CI}=1.04-1.05)$, male sex $(\mathrm{AOR}=1.38$, $95 \% \mathrm{CI}=1.17-1.62)$, pneumococcal vaccine receival $(\mathrm{AOR}=0.80,95 \% \mathrm{CI}=0.67-0.95)$, and seasonal influenza vaccine receival $(\mathrm{AOR}=0.82,95 \% \mathrm{CI}=0.69-0.98)$ to be significantly associated with the outcome; $\mathrm{PM}_{2.5}$ (quartile) was not significantly associated and no significant trend was detected. The partially adjusted $\mathrm{PM}_{2.5}$ (quartile) Cox proportional hazards model revealed increased age $(\mathrm{AOR}=1.02,95 \% \mathrm{CI}=1.01-1.03)$, black race $(\mathrm{AOR}=0.69,95 \% \mathrm{CI}=0.54-0.88)$, transfer to $\mathrm{ICU}$ at hospitalization $(\mathrm{AOR}=$ $1.59,95 \% \mathrm{CI}=1.31-1.92)$, elevated PSI (Class IV: $\mathrm{AOR}=4.10,95 \% \mathrm{CI}=1.48-11.38$; Class V: AOR $=10.34,95 \% \mathrm{CI}=3.69-28.96)$, use of intravenous antibiotics within the past 90 days $(\mathrm{AOR}=1.45,95 \% \mathrm{CI}=1.20-1.75)$, suspicion of aspiration $(\mathrm{AOR}=1.49,95 \%$ $\mathrm{CI}=1.21-1.82)$, and pneumococcal vaccine receival $(\mathrm{AOR}=0.79,95 \% \mathrm{CI}=0.66-0.94)$ to be significantly associated with the outcome; $\mathrm{PM}_{2.5}$ (quartile) was not significantly associated and no significant trend was detected. 


\begin{tabular}{|c|c|c|c|}
\hline Variable & $\mathrm{AHR}^{\mathrm{a}}$ & $\mathrm{p}$-value & CI $(95 \%)$ \\
\hline \multicolumn{4}{|l|}{$\mathrm{PM}_{10}$ (quartile) } \\
\hline $1\left(\leq 9.67 \mu \mathrm{g} / \mathrm{m}^{3}\right)$ & referent & referent & referent \\
\hline $\begin{array}{l}2\left(>9.67 \mu \mathrm{g} / \mathrm{m}^{3} \text { and } \leq 15.00\right. \\
\left.\mu \mathrm{g} / \mathrm{m}^{3}\right)\end{array}$ & 1.02 & 0.8795 & $0.81-1.28$ \\
\hline $\begin{array}{l}3\left(>15.00 \mu \mathrm{g} / \mathrm{m}^{3} \text { and } \leq 20.50\right. \\
\left.\mu \mathrm{g} / \mathrm{m}^{3}\right)\end{array}$ & 1.03 & 0.8071 & $0.81-1.30$ \\
\hline $4\left(>20.50 \mu \mathrm{g} / \mathrm{m}^{3}\right)$ & 1.11 & 0.3765 & $0.88-1.40$ \\
\hline p-value (trend) & \multicolumn{3}{|c|}{0.3562} \\
\hline Age at enrollment, per one-year increase & 1.04 & $<0.0001$ & 1.04-1.05 \\
\hline \multicolumn{4}{|l|}{ Sex } \\
\hline Female & referent & referent & referent \\
\hline Male & 1.37 & 0.0001 & 1.17-1.61 \\
\hline \multicolumn{4}{|l|}{ Pneumococcal vaccine receival status } \\
\hline No & referent & referent & referent \\
\hline Yes & 0.79 & 0.0104 & $0.67-0.95$ \\
\hline Missing & 2.33 & 0.5315 & $0.16-32.96$ \\
\hline \multicolumn{4}{|l|}{ Seasonal influenza vaccine receival status } \\
\hline No & referent & referent & referent \\
\hline Yes & 0.83 & 0.0357 & 0.69-0.99 \\
\hline Missing & 0.18 & 0.2119 & $0.01-2.62$ \\
\hline
\end{tabular}




\begin{tabular}{|c|c|c|c|}
\hline Variable & $\mathrm{AHR}^{\mathrm{a}}$ & p-value & CI $(95 \%)$ \\
\hline \multicolumn{4}{|l|}{$\mathrm{PM}_{10}$ (quartile) } \\
\hline $1\left(\leq 9.67 \mu \mathrm{g} / \mathrm{m}^{3}\right)$ & referent & referent & referent \\
\hline $\begin{array}{l}2\left(>9.67 \mu \mathrm{g} / \mathrm{m}^{3} \text { and } \leq 15.00\right. \\
\left.\mu \mathrm{g} / \mathrm{m}^{3}\right)\end{array}$ & 1.04 & 0.7657 & $0.82-1.30$ \\
\hline $\begin{array}{l}3\left(>15.00 \mu \mathrm{g} / \mathrm{m}^{3} \text { and } \leq 20.50\right. \\
\left.\mu \mathrm{g} / \mathrm{m}^{3}\right)\end{array}$ & 0.99 & 0.9035 & $0.78-1.25$ \\
\hline $4\left(>20.50 \mu \mathrm{g} / \mathrm{m}^{3}\right)$ & 1.10 & 0.4049 & $0.88-1.40$ \\
\hline p-value (trend) & \multicolumn{3}{|c|}{0.4646} \\
\hline Age at enrollment, per one-year increase & 1.02 & $<0.0001$ & 1.01-1.03 \\
\hline \multicolumn{4}{|l|}{ Sex } \\
\hline Female & referent & referent & referent \\
\hline Male & 1.03 & 0.6934 & $0.88-1.22$ \\
\hline \multicolumn{4}{|l|}{ Race } \\
\hline White & referent & referent & referent \\
\hline Black & 0.69 & 0.0033 & $0.54-0.88$ \\
\hline Other & 0.43 & 0.4042 & $0.06-3.09$ \\
\hline \multicolumn{4}{|l|}{ Transfer to ICU at hospitalization } \\
\hline No & referent & referent & referent \\
\hline Yes & 1.60 & $<0.0001$ & $1.32-1.93$ \\
\hline \multicolumn{4}{|l|}{ PSI } \\
\hline $\mathrm{I}$ & referent & referent & referent \\
\hline II & 0.65 & 0.4479 & $0.20-2.13$ \\
\hline III & 1.53 & 0.4306 & $0.53-4.42$ \\
\hline IV & 4.04 & 0.0074 & $1.45-11.22$ \\
\hline $\mathrm{V}$ & 10.17 & $<0.0001$ & 3.63-28.47 \\
\hline \multicolumn{4}{|l|}{$\begin{array}{l}\text { Use of intravenous antibiotics within the } \\
\text { past } 90 \text { days }\end{array}$} \\
\hline No & referent & referent & referent \\
\hline Yes & 1.45 & 0.0001 & $1.20-1.75$ \\
\hline \multicolumn{4}{|l|}{ Smoking status } \\
\hline Non-smoker & referent & referent & referent \\
\hline Past smoker & 0.93 & 0.4349 & $0.77-1.12$ \\
\hline Current smoker & 0.81 & 0.1034 & $0.64-1.04$ \\
\hline \multicolumn{4}{|l|}{ Suspicion of aspiration } \\
\hline No & referent & referent & referent \\
\hline Yes & 1.49 & $<0.0001$ & $1.22-1.83$ \\
\hline Missing & 0.00 & 0.9691 & $0.00-0.00$ \\
\hline \multicolumn{4}{|l|}{ Pneumococcal vaccine receival status } \\
\hline No & referent & referent & referent \\
\hline Yes & 0.79 & 0.0096 & $0.66-0.94$ \\
\hline Missing & 1.06 & 0.9621 & $0.10-11.58$ \\
\hline \multicolumn{4}{|l|}{ Seasonal influenza vaccine receival status } \\
\hline No & referent & referent & referent \\
\hline Yes & 0.86 & 0.1009 & $0.72-1.03$ \\
\hline Missing & 0.39 & 0.4385 & $0.04-4.25$ \\
\hline
\end{tabular}




\begin{tabular}{|c|c|c|c|}
\hline Variable & $\mathrm{AHR}^{\mathrm{a}}$ & p-value & CI $(95 \%)$ \\
\hline \multicolumn{4}{|l|}{$\mathrm{PM}_{2.5}$ (quartile) } \\
\hline $1\left(\leq 7.07 \mu \mathrm{g} / \mathrm{m}^{3}\right)$ & referent & referent & referent \\
\hline $\begin{array}{l}2\left(>7.07 \mu \mathrm{g} / \mathrm{m}^{3} \text { and } \leq 9.63\right. \\
\left.\mu \mathrm{g} / \mathrm{m}^{3}\right)\end{array}$ & 1.10 & 0.4159 & $0.87-1.39$ \\
\hline $\begin{array}{l}3\left(>9.63 \mu \mathrm{g} / \mathrm{m}^{3} \text { and } \leq 13.37\right. \\
\left.\mu \mathrm{g} / \mathrm{m}^{3}\right)\end{array}$ & 1.19 & 0.1304 & $0.95-1.50$ \\
\hline $4\left(>13.37 \mu \mathrm{g} / \mathrm{m}^{3}\right)$ & 1.14 & 0.2546 & $0.91-1.44$ \\
\hline p-value (trend) & \multicolumn{3}{|c|}{0.2615} \\
\hline Age at enrollment, per one-year increase & 1.04 & $<0.0001$ & 1.04-1.05 \\
\hline \multicolumn{4}{|l|}{ Sex } \\
\hline Female & referent & referent & referent \\
\hline Male & 1.38 & $<0.0001$ & $1.17-1.62$ \\
\hline \multicolumn{4}{|l|}{ Pneumococcal vaccine receival status } \\
\hline No & referent & referent & referent \\
\hline Yes & $\mathbf{0 . 8 0}$ & 0.0111 & $0.67-0.95$ \\
\hline Missing & 2.44 & 0.5136 & $0.17-35.55$ \\
\hline \multicolumn{4}{|l|}{ Seasonal influenza vaccine receival status } \\
\hline No & referent & referent & referent \\
\hline Yes & 0.82 & $\mathbf{0 . 0 2 8 8}$ & $0.69-0.98$ \\
\hline Missing & 0.18 & 0.2098 & $0.01-2.62$ \\
\hline
\end{tabular}




\begin{tabular}{|c|c|c|c|}
\hline Variable & $\mathrm{AHR}^{\mathrm{a}}$ & p-value & CI $(95 \%)$ \\
\hline \multicolumn{4}{|l|}{$\mathrm{PM}_{2.5}$ (quartile) } \\
\hline $1\left(\leq 7.07 \mu \mathrm{g} / \mathrm{m}^{3}\right)$ & referent & referent & referent \\
\hline $\begin{array}{l}2\left(>7.07 \mu \mathrm{g} / \mathrm{m}^{3} \text { and } \leq 9.63\right. \\
\left.\mu \mathrm{g} / \mathrm{m}^{3}\right)\end{array}$ & 1.13 & 0.3056 & $0.89-1.43$ \\
\hline $\begin{array}{l}3\left(>9.63 \mu \mathrm{g} / \mathrm{m}^{3} \text { and } \leq 13.37\right. \\
\left.\mu \mathrm{g} / \mathrm{m}^{3}\right)\end{array}$ & 1.17 & 0.1798 & $0.93-1.47$ \\
\hline $4\left(>13.37 \mu \mathrm{g} / \mathrm{m}^{3}\right)$ & 1.17 & 0.1870 & $0.93-1.48$ \\
\hline p-value (trend) & \multicolumn{3}{|c|}{0.2242} \\
\hline Age at enrollment, per one-year increase & 1.02 & $<0.0001$ & 1.01-1.03 \\
\hline \multicolumn{4}{|l|}{ Sex } \\
\hline Female & referent & referent & referent \\
\hline Male & 1.04 & 0.6353 & $0.88-1.23$ \\
\hline \multicolumn{4}{|l|}{ Race } \\
\hline White & referent & referent & referent \\
\hline Black & 0.69 & 0.0032 & $0.54-0.88$ \\
\hline Other & 0.42 & 0.3934 & $0.06-3.03$ \\
\hline \multicolumn{4}{|l|}{ Transfer to ICU at hospitalization } \\
\hline No & referent & referent & referent \\
\hline Yes & 1.59 & $<0.0001$ & $1.31-1.92$ \\
\hline \multicolumn{4}{|l|}{ PSI } \\
\hline $\mathrm{I}$ & referent & referent & referent \\
\hline II & 0.66 & 0.4886 & $0.20-2.15$ \\
\hline III & 1.55 & 0.4160 & $0.54-4.48$ \\
\hline IV & 4.10 & 0.0068 & $1.48-11.38$ \\
\hline $\mathrm{V}$ & 10.34 & $<0.0001$ & $3.69-28.96$ \\
\hline \multicolumn{4}{|l|}{$\begin{array}{l}\text { Use of intravenous antibiotics within the } \\
\text { past } 90 \text { days }\end{array}$} \\
\hline No & referent & referent & referent \\
\hline Yes & 1.45 & 0.0001 & $1.20-1.75$ \\
\hline \multicolumn{4}{|l|}{ Smoking status } \\
\hline Non-smoker & referent & referent & referent \\
\hline Past smoker & 0.93 & 0.4515 & $0.77-1.12$ \\
\hline Current smoker & 0.82 & 0.1123 & $0.64-1.05$ \\
\hline \multicolumn{4}{|l|}{ Suspicion of aspiration } \\
\hline No & referent & referent & referent \\
\hline Yes & 1.49 & 0.0001 & $1.22-1.82$ \\
\hline Missing & 0.00 & 0.9694 & $0.00-0.00$ \\
\hline \multicolumn{4}{|l|}{ Pneumococcal vaccine receival status } \\
\hline No & referent & referent & referent \\
\hline Yes & 0.79 & 0.0098 & $0.66-0.94$ \\
\hline Missing & 1.10 & 0.9379 & $0.10-12.65$ \\
\hline \multicolumn{4}{|l|}{ Seasonal influenza vaccine receival status } \\
\hline No & referent & referent & referent \\
\hline Yes & 0.86 & 0.0910 & $0.72-1.02$ \\
\hline Missing & 0.38 & 0.4373 & $0.03-4.36$ \\
\hline
\end{tabular}




\section{Aim Two}

Due to the presence of only two monitoring stations providing $\mathrm{PM}_{10}$ values within the study area and during the study timeframe, kriging could not be conducted. ArcMap was unable to conduct the interpolation given the sparsity of data available, despite attempting to use different methods to complete the kriging process. Two data points was simply too small a sample size.

Monitoring stations providing $\mathrm{PM}_{2.5}$ values varied from two to four in number, depending on the day, though three appeared to be the most common; the Durrett Lane monitoring station provided data approximately every three days, versus approximately daily for the other monitoring stations. On days where only two monitoring stations provided data, ArcGIS was unable to conduct the interpolation; this was for the same reason previously noted for the $\mathrm{PM}_{10}$ data. On almost every day where models were able to be created, the models produced seemed to not accurately represent localized PM-related fluctuations, but rather broad patterns of distribution based on the directional increase, decrease, or plateauing of $\mathrm{PM}_{2.5}$ values (Figures 7 and 8). Rarely, models (Figure 9) were created that seemed to account for some degree of local variation, but given the sparsity of point data available, the accuracy of such models is questionable. Such observations did not seem to vary depending on the time of year examined. Examples are provided.

The example models are each problematic in their own ways. Figure 7 indicates an east-to-west pattern of gradually increasing $\mathrm{PM}_{2.5}$ concentration, but the basis of the pattern is simply that the three included monitors for the given day happened to be spatially located from east to west and reported corresponding low-to-high concentration values. The monitors are located within mid, west, and southwest Louisville, and likely fail to 
accurately represent localized concentration variations in other portions of the county. Determining such a broad pattern for the relatively large Jefferson county study area based upon such a limited source of data is potentially misleading. A similar issue to that of Figure 7 manifested in Figure 8. The monitors for the given day all presented similar $\mathrm{PM}_{2.5}$ measurements, which was ultimately interpreted as the entire county having roughly the same level of exposure. Again, given the large size of the study area and only three monitors providing localized data for the given day, it seems misleading to assume the entire county had the same level of exposure based on the available data. Figure 9 did portray a semblance of the localized patterns that should be portrayed when kriging is successfully implemented, which was a minor success. However, given the issues seen in models constructed based upon three monitors, there is the possibility that these patterns are not entirely accurate, as the addition of data from a fourth monitor in much the same geographic area as the others is not a substantial increase in sample size or spatial diversity. 


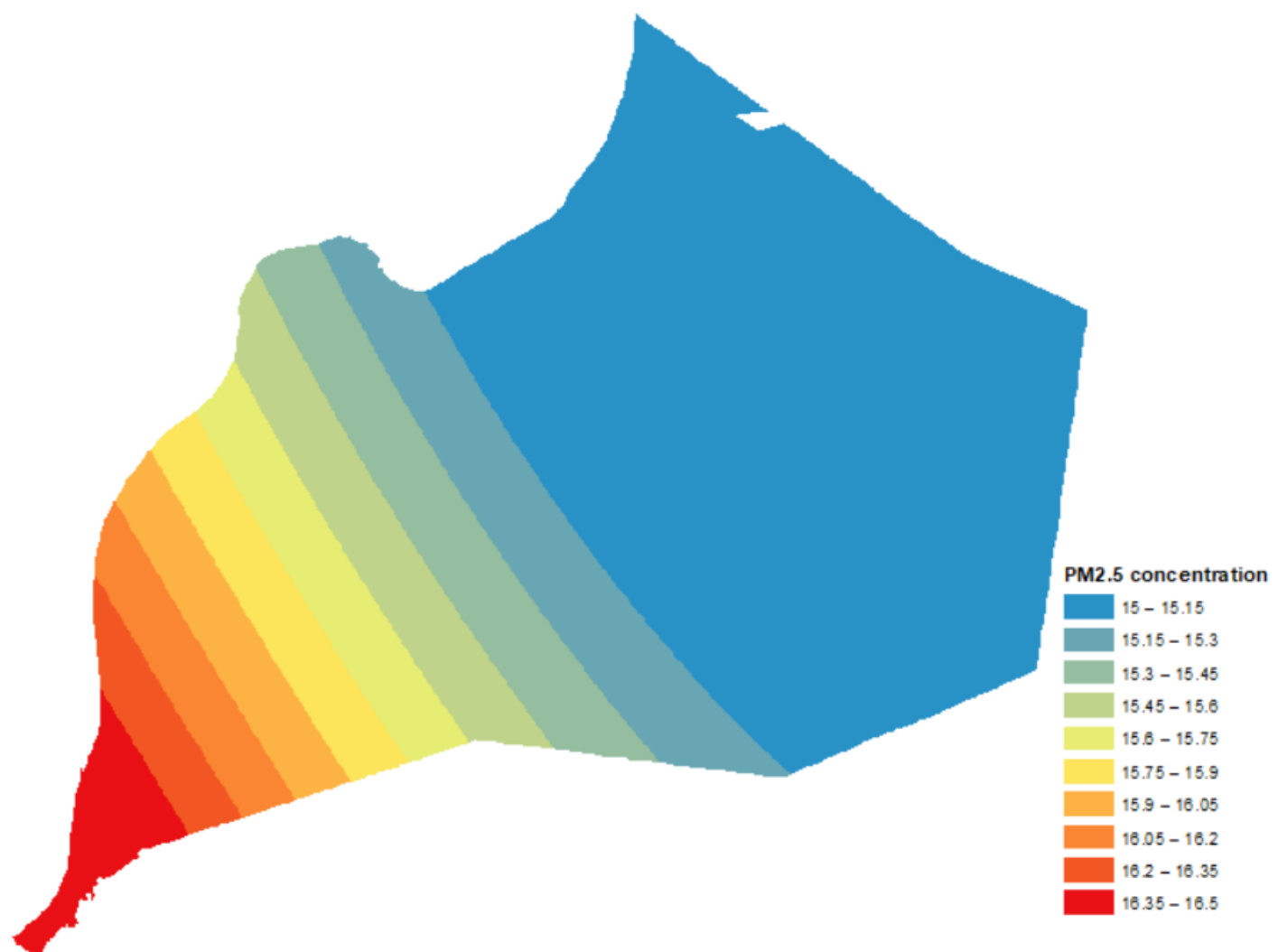

Figure 7 - Example of directional pattern of low to high values across three point sources from east to west 


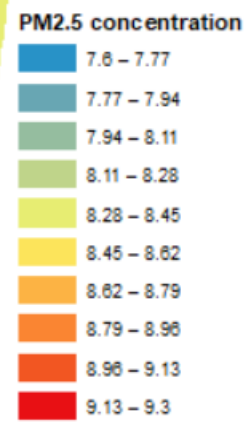

Figure 8 - Example of homogenous pattern resulting from similar values across three point sources

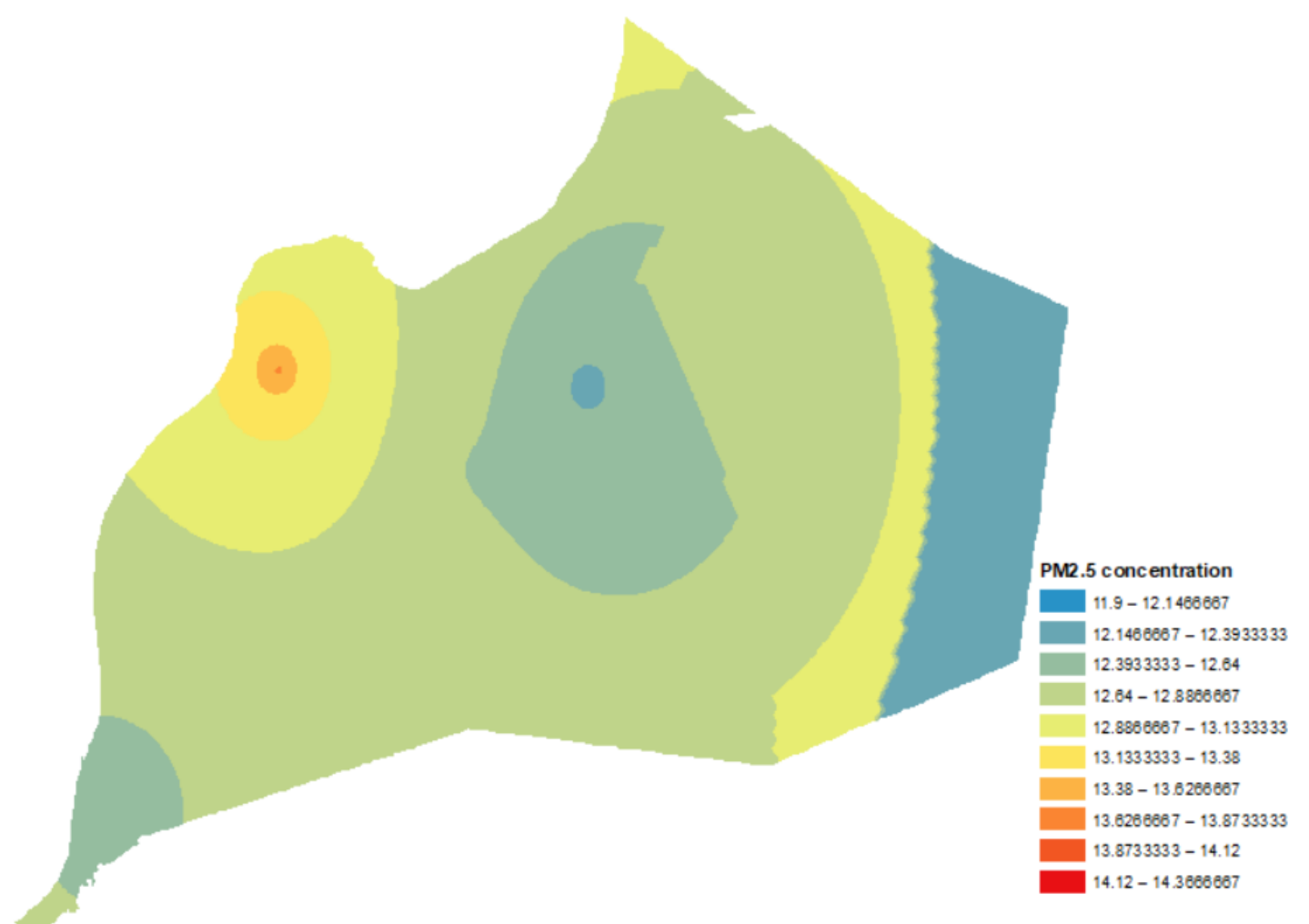

Figure 9 - Example of localized variation patterns based on differing values across four point sources 


\section{Aim Three}

Effect Modification in Spatially Averaged Data - PM 10

We examined effect modification by continuous age, sex, and race on the relationship between $\mathrm{PM}_{10}$ (continuous) exposure and mortality at 30 days and did not observe statistically significant interactions by $\mathrm{PM}_{10}$ and age, or sex, but did observe statistically significant interaction between $\mathrm{PM}_{10}$ and race. Analysis of effect modification by continuous age on the relationship between $\mathrm{PM}_{10}$ (continuous) exposure and mortality at 30 days yielded a Wald (one additional degree of freedom) p-value of 0.5324. Adjusted odds ratio from the partially adjusted logistic regression model with interaction term included was $1.01(95 \% \mathrm{CI}=0.94-1.08)$ per five-unit $\mathrm{PM}_{10}$ increase. Analysis of effect modification by sex on the relationship between $\mathrm{PM}_{10}$ (continuous) exposure and mortality at 30 days yielded a Wald (one additional degree of freedom) p-value of 0.2135. Adjusted odds ratios from the partially adjusted logistic regression model with interaction term included were as follows: female $=1.06(95 \% \mathrm{CI}=0.97-1.15)$ per five-unit $\mathrm{PM}_{10}$ increase male $=0.98(95 \% \mathrm{CI}=0.91-1.07)$ per five-unit $\mathrm{PM}_{10}$ increase. Analysis of effect modification by race on the relationship between $\mathrm{PM}_{10}$ (continuous) exposure and mortality at 30 days yielded an LRT p-value of $\mathbf{0 . 0 4 9 9}$. Adjusted odds ratios from the partially adjusted logistic regression model with interaction term included were as follows: black $=$ $1.19(95 \% \mathbf{C I}=\mathbf{1 . 0 4 - 1 . 3 7})$ per five-unit $\mathrm{PM}_{10}$ increase, white $=0.99(95 \% \mathrm{CI}=0.93-1.05)$ per five-unit $\mathrm{PM}_{10}$ increase, other $=1.27(95 \% \mathrm{CI}=0.31-5.22)$ per five-unit $\mathrm{PM}_{10}$ increase; the results indicate that for every five $\mu \mathrm{g} / \mathrm{m}^{3}$ increase in $\mathrm{PM}_{10}$ exposure, the odds of experiencing the outcome increased by $19 \%$ among black participants. 
Regarding models containing quartile-based exposures, adjusted (partial model) odds ratios for the potential effect modifiers of interest can be viewed in Tables 23-25 along with likelihood ratio test (LRT) p-values. It should be noted that due to the small number of individuals falling into the race category of "other," the results were minimally useful for that particular category and underpowered in the analysis of the relationship between $\mathrm{PM}_{10}$ (quartile) and mortality at 30 days, and were therefore excluded from effect modification analysis under these conditions.

We examined effect modification by continuous and categorical age, sex, and race on the relationship between $\mathrm{PM}_{10}$ (quartile) exposure and mortality at 30 days and did not observe statistically significant interactions by $\mathrm{PM}_{10}$ and sex, but did observe statistically significant interaction between $\mathrm{PM}_{10}$ and continuous and categorical age, and race. Analysis of effect modification by continuous age on the relationship between $\mathrm{PM}_{10}$ quartiles and mortality at 30 days yielded an LRT p-value of $\mathbf{0 . 0 0 1 3}$. Adjusted odds ratios from the partially adjusted logistic regression model with interaction term included were as follows: quartile $1=$ referent, quartile $2=0.77(95 \% \mathrm{CI}=0.56-1.05)$, quartile $3=0.97$ (95\% CI $=0.73-1.29)$, quartile $4=0.92(95 \% \mathrm{CI}=0.68-1.24)$. Analysis of effect modification by categorical age on the relationship between $\mathrm{PM}_{10}$ quartiles and mortality at 30 days yielded an LRT p-value of $\mathbf{0 . 0 0 8 8}$. Adjusted odds ratios from the partially adjusted logistic regression model with interaction term included were as follows: $<65$ years $(\mathrm{Q} 1)=$ referent, $<65$ years $(\mathrm{Q} 2)=0.48(95 \% \mathrm{CI}=0.27-0.85),<65$ years $(\mathrm{Q} 3)=0.86$ $(95 \% \mathrm{CI}=0.52-1.40),<65$ years $(\mathrm{Q} 4)=0.67(95 \% \mathrm{CI}=0.40-1.12), 65+$ years $(\mathrm{Q} 1)=$ referent, $65+$ years $(\mathrm{Q} 2)=1.28(95 \% \mathrm{CI}=0.95-1.72), 65+$ years $(\mathrm{Q} 3)=1.05(95 \% \mathrm{CI}=$ $0.77-1.43), 65+$ years $(\mathrm{Q} 4)=1.30(95 \% \mathrm{CI}=0.96-1.76)$. Analysis of effect modification 
by sex on the relationship between $\mathrm{PM}_{10}$ quartiles and mortality at 30 days yielded an LRT p-value of 0.1059 . Adjusted odds ratios from the partially adjusted logistic regression model with interaction term included were as follows: male $(\mathrm{Q} 1)=$ referent, male $(\mathrm{Q} 2)=$ $0.91(95 \% \mathrm{CI}=0.64-1.30)$, male $(\mathrm{Q} 3)=1.02(95 \% \mathrm{CI}=0.71-1.46)$, male $(\mathrm{Q} 4)=0.86(95 \%$ $\mathrm{CI}=0.60-1.23)$, female $(\mathrm{Q} 1)=$ referent, female $(\mathrm{Q} 2)=1.18(95 \% \mathrm{CI}=0.81-1.73)$, female $(\mathrm{Q} 3)=0.98(95 \% \mathrm{CI}=0.67-1.45)$, female $(\mathrm{Q} 4)=\mathbf{1 . 4 6}(95 \% \mathrm{CI}=\mathbf{1 . 0 1 - 2 . 1 4})$; the results indicate that female participants who fell within the fourth $\mathrm{PM}_{10}$ exposure quartile had $46 \%$ increased odds of experiencing the outcome. Analysis of effect modification by race on the relationship between $\mathrm{PM}_{10}$ quartiles and mortality at 30 days yielded an LRT p-value of 0.0171. Adjusted odds ratios from the partially adjusted logistic regression model with interaction term included were as follows: white $(\mathrm{Q} 1)=$ referent, white $(\mathrm{Q} 2)=1.01(95 \%$ $\mathrm{CI}=0.76-1.32)$, white $(\mathrm{Q} 3)=0.89(95 \% \mathrm{CI}=0.67-1.18)$, white $(\mathrm{Q} 4)=0.96(95 \% \mathrm{CI}=$ 0.72-1.26), black $(\mathrm{Q} 1)=$ referent, black $(\mathrm{Q} 2)=1.18(95 \% \mathrm{CI}=0.53-2.61)$, black $(\mathrm{Q} 3)=$ $2.01(95 \% \mathrm{CI}=0.95-4.27)$, black $(\mathrm{Q} 4)=\mathbf{2 . 7 0}(95 \% \mathrm{CI}=\mathbf{1 . 3 1 - 5 . 5 5})$; the results indicate that black participants who fell within the fourth $\mathrm{PM}_{10}$ exposure quartile had $170 \%$ increased odds of experiencing the outcome.

Given the large and significant association observed among black participants in Q4, further analysis of the relationship was conducted, based solely upon data from each racially stratified participant group. Relative risk was examined, calculated as the risk of outcome occurrence within the exposure group, which was being within the highest exposure quartile, divided by the risk of outcome occurrence within the remaining groups. Relative risk was found to be $1.51(95 \% \mathrm{CI}=0.95-2.39)$ for black participants. Individual risks for outcome occurrence for each quartile in the black participant group were as 
follows: $\mathrm{Q} 1=4.1 \%, \mathrm{Q} 2=4.8 \%, \mathrm{Q} 3=7.0 \%, \mathrm{Q} 4=7.9 \%$. Relative risk was found to be $1.04(95 \% \mathrm{CI}=0.86-1.25)$ for white participants. Individual risks for outcome occurrence for each quartile in the white participant group were as follows: $\mathrm{Q} 1=10.6 \%, \mathrm{Q} 2=11.1 \%$, $\mathrm{Q} 3=10.1 \%, \mathrm{Q} 4=11.0 \%$. In total, those black participants in the highest exposure quartile did seem to maintain an elevated association with the outcome compared to those in other exposure quartiles, but the association was only of borderline significance. Though white participants had individual risks for each exposure quartile that surpassed those of black participants in corresponding exposure quartiles, relative risk for the white participants in the highest exposure quartile was low and not significant.

Additionally, though individual comorbidity data was not utilized in this study, the variable PSI was assumed to serve as a summary of various factors - comorbidities among them. PSI participant percentages for each PSI class were compared for black and white participants. The percentage of black participants who fell into each PSI class was as follows: Class I $=9.83 \%$, Class II $=20.31 \%$, Class III $=19.74 \%$, Class IV $=30.70 \%$, and Class $\mathrm{V}=19.42 \%$. The percentage of white participants who fell into each PSI class was as follows: Class $\mathrm{I}=5.48 \%$, Class $\mathrm{II}=15.29 \%$, Class $\mathrm{III}=18.51 \%$, Class $\mathrm{IV}=36.86 \%$, and Class $\mathrm{V}=23.85 \%$. Based upon observations from this data, fewer black participants fell within the upper two PSI classes than white participants. It is possible this suggests that overall pneumonia mortality risk factors were not as great among black participants. Even among those black and white participants in the highest exposure quartile, a similar pattern was noted. The percentage of Q4 black participants who fell into each PSI class was as follows: Class I $=10.67 \%$, Class II $=19.21 \%$, Class III $=21.95 \%$, Class IV $=32.32 \%$, and Class $\mathrm{V}=15.85 \%$. The percentage of Q4 white participants who fell into each PSI class 
was as follows: Class I $=6.22 \%$, Class II $=14.11 \%$, Class III $=17.84 \%$, Class IV $=36.76 \%$,

and Class $\mathrm{V}=25.06 \%$.

\begin{tabular}{|c|c|c|c|}
\hline & Adju: & ds Ratios by Category & \\
\hline $\mathrm{PM}_{10}$ Quantile & $\begin{array}{c}<65 \text { years }(95 \% \mathrm{CI}) \\
\mathrm{n}=2712\end{array}$ & $\begin{array}{c}65+\text { years }(95 \% \mathrm{CI}) \\
\mathrm{n}=3433\end{array}$ & LRT p-value \\
\hline $1\left(\leq 9.67 \mu \mathrm{g} / \mathrm{m}^{3}\right)$ & $\begin{array}{c}\text { referent } \\
\mathrm{n}=658 \\
\overline{\mathrm{x}}^{\mathrm{b}}=7.45\end{array}$ & $\begin{array}{c}\text { referent } \\
\mathrm{n}=832 \\
\overline{\mathrm{x}}^{\mathrm{b}}=7.45\end{array}$ & \multirow{4}{*}{0.0088} \\
\hline $2\left(>9.67 \mu \mathrm{g} / \mathrm{m}^{3}\right.$ and $\left.\leq 15.00 \mu \mathrm{g} / \mathrm{m}^{3}\right)$ & $\begin{array}{c}0.48(0.27-0.85) \\
\mathrm{n}=653 \\
\overline{\mathrm{x}}^{\mathrm{b}}=12.37\end{array}$ & $\begin{array}{c}1.28(0.95-1.72) \\
\mathrm{n}=937 \\
\overline{\mathrm{x}}^{\mathrm{b}}=12.32\end{array}$ & \\
\hline $3\left(>15.00 \mu \mathrm{g} / \mathrm{m}^{3}\right.$ and $\left.\leq 20.50 \mu \mathrm{g} / \mathrm{m}^{3}\right)$ & $\begin{array}{c}0.86(0.52-1.40) \\
\mathrm{n}=693 \\
\overline{\mathrm{x}}^{\mathrm{b}}=17.73\end{array}$ & $\begin{array}{c}1.05(0.77-1.43) \\
\mathrm{n}=834 \\
\overline{\mathrm{x}}^{\mathrm{b}}=17.67\end{array}$ & \\
\hline $4\left(>20.50 \mu \mathrm{g} / \mathrm{m}^{3}\right)$ & $\begin{array}{c}0.67(0.40-1.12) \\
\mathrm{n}=708 \\
\overline{\mathrm{x}}^{\mathrm{b}}=27.00\end{array}$ & $\begin{array}{c}1.30(0.96-1.76) \\
\mathrm{n}=830 \\
\overline{\mathrm{x}}^{\mathrm{b}}=26.91\end{array}$ & \\
\hline
\end{tabular}

\begin{tabular}{|c|c|c|c|}
\hline \multicolumn{4}{|c|}{$\begin{array}{l}\text { Table 24: Effect modification by sex on the relationship between } \mathrm{PM}_{10} \\
\text { (quartile) exposure and mortality at } 30 \text { days }- \text { partially adjusted logistic regression } \\
\text { model }^{\mathrm{a}} \text { with interaction term }(\mathrm{N}=6145 \text {, events }=597)\end{array}$} \\
\hline & \multicolumn{3}{|c|}{ Adjusted Odds Ratios by Category } \\
\hline $\mathrm{PM}_{10}$ Quantile & $\begin{array}{c}\text { Male }(95 \% \mathrm{CI}) \\
\mathrm{n}=2857\end{array}$ & $\begin{array}{c}\text { Female }(95 \% \mathrm{CI}) \\
\mathrm{n}=3288\end{array}$ & LRT p-value \\
\hline $1\left(\leq 9.67 \mu \mathrm{g} / \mathrm{m}^{3}\right)$ & $\begin{array}{c}\text { referent } \\
\mathrm{n}=683 \\
\overline{\mathrm{x}}^{\mathrm{b}}=7.45\end{array}$ & $\begin{aligned} & \text { referent } \\
& \mathrm{n}=807 \\
& \overline{\mathrm{x}}^{\mathrm{b}}=7.45\end{aligned}$ & \multirow{4}{*}{0.1059} \\
\hline $2\left(>9.67 \mu \mathrm{g} / \mathrm{m}^{3}\right.$ and $\left.\leq 15.00 \mu \mathrm{g} / \mathrm{m}^{3}\right)$ & $\begin{array}{c}0.91(0.64-1.30) \\
\mathrm{n}=731 \\
\overline{\mathrm{x}}^{\mathrm{b}}=12.33\end{array}$ & $\begin{array}{c}1.18(0.81-1.73) \\
\mathrm{n}=859 \\
\overline{\mathrm{x}}^{\mathrm{b}}=12.35\end{array}$ & \\
\hline $3\left(>15.00 \mu \mathrm{g} / \mathrm{m}^{3}\right.$ and $\left.\leq 20.50 \mu \mathrm{g} / \mathrm{m}^{3}\right)$ & $\begin{array}{c}1.02(0.71-1.46) \\
\mathrm{n}=696 \\
\overline{\mathrm{x}}^{\mathrm{b}}=17.74\end{array}$ & $\begin{array}{c}0.98(0.67-1.45) \\
\mathrm{n}=831 \\
\overline{\mathrm{x}}^{\mathrm{b}}=17.66\end{array}$ & \\
\hline $4\left(>20.50 \mu \mathrm{g} / \mathrm{m}^{3}\right)$ & $\begin{array}{c}0.86(0.60-1.23) \\
\mathrm{n}=747 \\
\overline{\mathrm{x}}^{\mathrm{b}}=27.00\end{array}$ & $\begin{array}{c}\mathbf{1 . 4 6}(\mathbf{1 . 0 1 - 2 . 1 4}) \\
\mathrm{n}=791 \\
\overline{\mathrm{x}}^{\mathrm{b}}=26.90\end{array}$ & \\
\hline
\end{tabular}




\begin{tabular}{|c|c|c|c|}
\hline & \multicolumn{3}{|c|}{ Adjusted Odds Ratios by Category } \\
\hline $\mathrm{PM}_{10}$ Quantile & $\begin{array}{c}\text { White }(95 \% \mathrm{CI}) \\
\mathrm{n}=4872\end{array}$ & $\begin{array}{c}\text { Black }(95 \% \mathrm{CI}) \\
\mathrm{n}=1241\end{array}$ & LRT p-value \\
\hline $1\left(\leq 9.67 \mu \mathrm{g} / \mathrm{m}^{3}\right)$ & $\begin{array}{c}\text { referent } \\
\mathrm{n}=1164 \\
\overline{\mathrm{x}}^{\mathrm{b}}=7.47 \\
\end{array}$ & $\begin{array}{c}\text { referent } \\
\mathrm{n}=317 \\
\overline{\mathrm{x}}^{\mathrm{b}}=7.40 \\
\end{array}$ & \multirow{4}{*}{0.0171} \\
\hline $2\left(>9.67 \mu \mathrm{g} / \mathrm{m}^{3}\right.$ and $\left.\leq 15.00 \mu \mathrm{g} / \mathrm{m}^{3}\right)$ & $\begin{array}{c}1.01(0.76-1.32) \\
\mathrm{n}=1269 \\
\overline{\mathrm{x}}^{\mathrm{b}}=12.34\end{array}$ & $\begin{array}{c}1.18(0.53-2.61) \\
\mathrm{n}=312 \\
\overline{\mathrm{x}}^{\mathrm{b}}=12.37\end{array}$ & \\
\hline $3\left(>15.00 \mu \mathrm{g} / \mathrm{m}^{3}\right.$ and $\left.\leq 20.50 \mu \mathrm{g} / \mathrm{m}^{3}\right)$ & $\begin{array}{c}0.89(0.67-1.18) \\
\mathrm{n}=1234 \\
\overline{\mathrm{x}}^{\mathrm{b}}=17.57\end{array}$ & $\begin{array}{c}2.01(0.95-4.27) \\
\mathrm{n}=284 \\
\overline{\mathrm{x}}^{\mathrm{b}}=17.85\end{array}$ & \\
\hline $4\left(>20.50 \mu \mathrm{g} / \mathrm{m}^{3}\right)$ & $\begin{array}{c}0.96(0.72-1.26) \\
\mathrm{n}=1205 \\
\overline{\mathrm{x}}^{\mathrm{b}}=26.94\end{array}$ & $\begin{array}{c}2.70(\mathbf{1 . 3 1 - 5 . 5 5 )} \\
\mathrm{n}=328 \\
\overline{\mathrm{x}}^{\mathrm{b}}=27.01\end{array}$ & \\
\hline
\end{tabular}

Effect Modification in Spatially Averaged Data $-P M_{2.5}$

We examined effect modification by continuous age, sex, and race on the relationship between $\mathrm{PM}_{2.5}$ (continuous) exposure and mortality at 30 days and did not observe statistically significant interactions by $\mathrm{PM}_{2.5}$ and age, sex, or race. Analysis of effect modification by continuous age on the relationship between $\mathrm{PM}_{2.5}$ (continuous) exposure and mortality at 30 days yielded a Wald (one additional degree of freedom) pvalue of 0.4933 . Adjusted odds ratio from the partially adjusted logistic regression model with interaction term included was $1.04(95 \% \mathrm{CI}=0.93-1.16)$ per five-unit $\mathrm{PM}_{2.5}$ increase. Analysis of effect modification by sex on the relationship between $\mathrm{PM}_{2.5}$ (continuous) exposure and mortality at 30 days yielded a Wald (one additional degree of freedom) pvalue of 0.6974 . Adjusted odds ratios from the partially adjusted logistic regression model with interaction term included were as follows: female $=1.07(95 \% \mathrm{CI}=0.93-1.23)$ per five-unit $\mathrm{PM}_{2.5}$ increase, male $=1.04(95 \% \mathrm{CI}=0.92-1.19)$ per five-unit $\mathrm{PM}_{2.5}$ increase 
Analysis of effect modification by race on the relationship between $\mathrm{PM}_{2.5}$ (continuous) exposure and mortality at 30 days yielded an LRT p-value of 0.6102. Adjusted odds ratios from the partially adjusted logistic regression model with interaction term included were as follows: black $=1.18(95 \% \mathrm{CI}=0.91-1.53)$ per five-unit $\mathrm{PM}_{2.5}$ increase, white $=1.04$ $(95 \% \mathrm{CI}=0.94-1.15)$ per five-unit $\mathrm{PM}_{2.5}$ increase, other $=0.51(95 \% \mathrm{CI}=0.01-39.90)$ per five-unit $\mathrm{PM}_{2.5}$ increase.

Regarding models containing quartile-based exposures, adjusted (partial model) odds ratios for the potential effect modifiers of interest can be viewed in Tables 26-28 along with log ratio test (LRT) p-value. It should be noted that due to the small number of individuals falling into the race category of "other," the results are minimally useful for that particular category and underpowered in the analysis of the relationship between $\mathrm{PM}_{2.5}$ (quartile) and mortality at 30 days, making it necessary to exclude this category from effect modification analysis under these conditions.

We examined effect modification by continuous and categorical age, sex, and race on the relationship between $\mathrm{PM}_{2.5}$ (quartile) exposure and mortality at 30 days and did not observe statistically significant interactions by $\mathrm{PM}_{2.5}$ and continuous age, sex, or race, but did observe statistically significant interaction between $\mathrm{PM}_{2.5}$ and categorical age. Analysis of effect modification by continuous age on the relationship between $\mathrm{PM}_{2.5}$ quartile exposure and mortality at 30 days yielded an LRT p-value of 0.2055 . Adjusted odds ratios from the partially adjusted logistic regression model with interaction term included were as follows: quartile $1=$ referent, quartile $2=1.01(95 \% \mathrm{CI}=0.74-1.38)$, quartile $3=1.25$ $(95 \% \mathrm{CI}=0.93-1.67)$, quartile $4=1.06(95 \% \mathrm{CI}=0.78-1.45)$. Analysis of effect modification by categorical age on the relationship between $\mathrm{PM}_{2.5}$ quartiles and mortality 
at 30 days yielded an LRT p-value of $\mathbf{0 . 0 4 6 3}$. Adjusted odds ratios from the partially adjusted logistic regression model with interaction term included were as follows: $<65$ years $(\mathrm{Q} 1)=$ referent, $<65$ years $(\mathrm{Q} 2)=0.81(95 \% \mathrm{CI}=0.46-1.43),<65$ years $(\mathrm{Q} 3)=1.59$ $(95 \% \mathrm{CI}=0.96-2.64),<65$ years $(\mathrm{Q} 4)=0.95(95 \% \mathrm{CI}=0.55-1.65), 65+$ years $(\mathrm{Q} 1)=$ referent, 65+ years $(\mathrm{Q} 2)=1.21(95 \% \mathrm{CI}=0.90-1.63), 65+$ years $(\mathrm{Q} 3)=1.08(95 \% \mathrm{CI}=$ $0.80-1.46), 65+$ years $(\mathrm{Q} 4)=1.24(95 \% \mathrm{CI}=0.92-1.67)$. Analysis of effect modification by sex on the relationship between $\mathrm{PM}_{2.5}$ quartiles and mortality at 30 days yielded an LRT p-value of 0.5936. Adjusted odds ratios from the partially adjusted logistic regression model with interaction term included were as follows: male $(\mathrm{Q} 1)=$ referent, male $(\mathrm{Q} 2)=$ $0.95(95 \% \mathrm{CI}=0.66-1.37)$, male $(\mathrm{Q} 3)=1.17(95 \% \mathrm{CI}=0.82-1.66)$, male $(\mathrm{Q} 4)=1.11(95 \%$ $\mathrm{CI}=0.78-1.58)$, female $(\mathrm{Q} 1)=$ referent, female $(\mathrm{Q} 2)=1.31(95 \% \mathrm{CI}=0.90-1.92)$, female $(\mathrm{Q} 3)=1.24(95 \% \mathrm{CI}=0.85-1.82)$, female $(\mathrm{Q} 4)=1.25(95 \% \mathrm{CI}=0.85-1.83)$. Analysis of effect modification by race on the relationship between $\mathrm{PM}_{2.5}$ quartiles and mortality at 30 days yielded an LRT p-value of 0.2888. Adjusted odds ratios from the partially adjusted logistic regression model with interaction term included were as follows: white $(\mathrm{Q} 1)=$ referent, white $(\mathrm{Q} 2)=1.12(95 \% \mathrm{CI}=0.84-1.48)$, white $(\mathrm{Q} 3)=1.12(95 \% \mathrm{CI}=0.85-1.47)$, white $(\mathrm{Q} 4)=1.11(95 \% \mathrm{CI}=0.84-1.47)$, black $(\mathrm{Q} 1)=$ referent, black $(\mathrm{Q} 2)=1.04(95 \% \mathrm{CI}$ $=0.48-2.26)$, black $(\mathrm{Q} 3)=1.95(95 \% \mathrm{CI}=0.95-3.98)$, black $(\mathrm{Q} 4)=1.65(95 \% \mathrm{CI}=0.79-$ $3.44)$. 


\begin{tabular}{|c|c|c|c|}
\hline & \multirow{2}{*}{\multicolumn{3}{|c|}{ Adjusted Odds Ratios by Category }} \\
\hline & & & \\
\hline $\mathrm{PM}_{2.5}$ Quantile & $\begin{array}{c}<65 \text { years }(95 \% \mathrm{CI}) \\
\mathrm{n}=2712\end{array}$ & $\begin{array}{c}65+\text { years }(95 \% \text { CI }) \\
n=3433\end{array}$ & LRT, p-value \\
\hline $1\left(\leq 7.07 \mu \mathrm{g} / \mathrm{m}^{3}\right)$ & $\begin{array}{c}\text { referent } \\
\mathrm{n}=662 \\
\overline{\mathrm{x}}^{\mathrm{b}}=5.51\end{array}$ & $\begin{array}{c}\text { referent } \\
\mathrm{n}=868 \\
\overline{\mathrm{x}}^{\mathrm{b}}=5.54\end{array}$ & \multirow{4}{*}{0.0463} \\
\hline $2\left(>7.07 \mu \mathrm{g} / \mathrm{m}^{3}\right.$ and $\left.\leq 9.63 \mu \mathrm{g} / \mathrm{m}^{3}\right)$ & $\begin{array}{c}0.81(0.46-1.43) \\
\mathrm{n}=678 \\
\overline{\mathrm{x}}^{\mathrm{b}}=8.36\end{array}$ & $\begin{array}{c}1.21(0.90-1.63) \\
\mathrm{n}=858 \\
\overline{\mathrm{x}}^{\mathrm{b}}=8.34\end{array}$ & \\
\hline $3\left(>9.63 \mu \mathrm{g} / \mathrm{m}^{3}\right.$ and $\left.\leq 13.37 \mu \mathrm{g} / \mathrm{m}^{3}\right)$ & $\begin{array}{c}1.59(0.96-2.64) \\
\mathrm{n}=681 \\
\overline{\mathrm{x}}^{\mathrm{b}}=11.40\end{array}$ & $\begin{array}{c}1.08(0.80-1.46) \\
\mathrm{n}=865 \\
\overline{\mathrm{x}}^{\mathrm{b}}=11.39\end{array}$ & \\
\hline $4\left(>13.37 \mu \mathrm{g} / \mathrm{m}^{3}\right)$ & $\begin{array}{c}0.95(0.55-1.65) \\
\mathrm{n}=691 \\
\overline{\mathrm{x}}^{\mathrm{b}}=17.27\end{array}$ & $\begin{array}{c}1.24(0.92-1.67) \\
\mathrm{n}=842 \\
\overline{\mathrm{x}}^{\mathrm{b}}=17.23\end{array}$ & \\
\hline $\begin{array}{l}\mathrm{a}=\text { Adjusting for age at enrollment (cont } \\
\text { receival of seasonal influenza vaccine, } \\
\text { past } 90 \text { days, smoking history, and suspi } \\
\mathrm{b}=\text { Mean } \mathrm{PM}_{2.5} \text { (continuous) for exposu }\end{array}$ & $\begin{array}{l}\text { age at enrollment (c } \\
\text { direct transfer to IC } \\
\text { aspiration } \\
\text { rriate category }\end{array}$ & $\begin{array}{l}\text { ex, receival of pneur } \\
\text { f intravenous antibio }\end{array}$ & $\begin{array}{l}\text { I vaccine, } \\
\text { py within the }\end{array}$ \\
\hline
\end{tabular}

\begin{tabular}{|c|c|c|c|}
\hline & \multicolumn{3}{|c|}{ Adjusted Odds Ratios by Category } \\
\hline $\mathrm{PM}_{2.5}$ Quantile & $\begin{array}{c}\text { Male }(95 \% \text { CI }) \\
n=2857\end{array}$ & $\begin{array}{c}\text { Female }(95 \% \text { CI }) \\
n=3288\end{array}$ & LRT, p-value \\
\hline $1\left(\leq 7.07 \mu \mathrm{g} / \mathrm{m}^{3}\right)$ & $\begin{array}{c}\text { referent } \\
\mathrm{n}=703 \\
\overline{\mathrm{x}}^{\mathrm{b}}=5.50\end{array}$ & $\begin{array}{c}\text { referent } \\
\mathrm{n}=827 \\
\overline{\mathrm{x}}^{\mathrm{b}}=5.55\end{array}$ & \multirow{4}{*}{0.5936} \\
\hline $2\left(>7.07 \mu \mathrm{g} / \mathrm{m}^{3}\right.$ and $\left.\leq 9.63 \mu \mathrm{g} / \mathrm{m}^{3}\right)$ & $\begin{array}{c}0.95(0.66-1.37) \\
\mathrm{n}=728 \\
\overline{\mathrm{x}}^{\mathrm{b}}=8.40\end{array}$ & $\begin{array}{c}1.31(0.90-1.92) \\
\mathrm{n}=808 \\
\overline{\mathrm{x}}^{\mathrm{b}}=8.30\end{array}$ & \\
\hline $3\left(>9.63 \mu \mathrm{g} / \mathrm{m}^{3}\right.$ and $\left.\leq 13.37 \mu \mathrm{g} / \mathrm{m}^{3}\right)$ & $\begin{array}{c}1.17(0.82-1.66) \\
\mathrm{n}=709 \\
\overline{\mathrm{x}}^{\mathrm{b}}=11.42\end{array}$ & $\begin{array}{c}1.24(0.85-1.82) \\
\mathrm{n}=837 \\
\overline{\mathrm{x}}^{\mathrm{b}}=11.38\end{array}$ & \\
\hline $4\left(>13.37 \mu \mathrm{g} / \mathrm{m}^{3}\right)$ & $\begin{array}{c}1.11(0.78-1.58) \\
\mathrm{n}=717 \\
\overline{\mathrm{x}}^{\mathrm{b}}=17.35\end{array}$ & $\begin{array}{c}1.25(0.85-1.83) \\
\mathrm{n}=816 \\
\overline{\mathrm{x}}^{\mathrm{b}}=17.16\end{array}$ & \\
\hline $\begin{array}{l}\mathrm{a}=\text { Adjusting for age at enrollment (cont } \\
\text { seasonal influenza vaccine, race, PSI, dir } \\
\text { within the past } 90 \text { days, smoking history } \\
\mathrm{b}=\text { Mean } \mathrm{PM}_{2.5} \text { (continuous) for exposur }\end{array}$ & $\begin{array}{l}\text { ous), sex, receival } \\
\text { transfer to ICU, re } \\
\text { d suspicion of aspi } \\
\text { covariate category }\end{array}$ & $\begin{array}{l}\text { neumococcal vacc } \\
\text { val of intravenous } \\
\text { on }\end{array}$ & $\begin{array}{l}\text { receival of } \\
\text { iotic therapy }\end{array}$ \\
\hline
\end{tabular}




\begin{tabular}{|c|c|c|c|}
\hline & \multicolumn{3}{|c|}{ Adjusted Odds Ratios by Category } \\
\hline $\mathrm{PM}_{2.5}$ Quantile & $\begin{array}{c}\text { White }(95 \% \text { CI }) \\
\mathrm{n}=4872\end{array}$ & $\begin{array}{c}\text { Black (95\% CI) } \\
n=1241\end{array}$ & LRT, p-value \\
\hline $1\left(\leq 7.07 \mu \mathrm{g} / \mathrm{m}^{3}\right)$ & $\begin{array}{c}\text { referent } \\
\mathrm{n}=1219 \\
\overline{\mathrm{x}}^{\mathrm{b}}=5.55\end{array}$ & $\begin{array}{c}\text { Referent } \\
\mathrm{n}=302 \\
\mathrm{x}^{\mathrm{b}}=5.46\end{array}$ & \multirow{4}{*}{0.2888} \\
\hline $2\left(>7.07 \mu \mathrm{g} / \mathrm{m}^{3}\right.$ and $\left.\leq 9.63 \mu \mathrm{g} / \mathrm{m}^{3}\right)$ & $\begin{array}{c}1.12(0.84-1.48) \\
\mathrm{n}=1203 \\
\overline{\mathrm{x}}^{\mathrm{b}}=8.36\end{array}$ & $\begin{array}{c}1.04(0.48-2.26) \\
\mathrm{n}=322 \\
\overline{\mathrm{x}}^{\mathrm{b}}=8.30\end{array}$ & \\
\hline $3\left(>9.63 \mu \mathrm{g} / \mathrm{m}^{3}\right.$ and $\left.\leq 13.37 \mu \mathrm{g} / \mathrm{m}^{3}\right)$ & $\begin{array}{c}1.12(0.85-1.47) \\
\mathrm{n}=1225 \\
\overline{\mathrm{x}}^{\mathrm{b}}=11.38\end{array}$ & $\begin{array}{c}1.95(0.95-3.98) \\
\mathrm{n}=315 \\
\overline{\mathrm{x}}^{\mathrm{b}}=11.47\end{array}$ & \\
\hline $4\left(>13.37 \mu \mathrm{g} / \mathrm{m}^{3}\right)$ & $\begin{array}{c}1.11(0.84-1.47) \\
\mathrm{n}=1225 \\
\overline{\mathrm{x}}^{\mathrm{b}}=17.29\end{array}$ & $\begin{array}{c}1.65(0.79-3.44) \\
\mathrm{n}=302 \\
\overline{\mathrm{x}}^{\mathrm{b}}=17.10\end{array}$ & \\
\hline \multicolumn{4}{|c|}{$\begin{array}{l}\mathrm{a}=\text { Adjusting for age at enrollment (continuous), sex, receival of pneumococcal vaccine, receival of } \\
\text { seasonal influenza vaccine, race, PSI, direct transfer to ICU, receival of intravenous antibiotic therapy } \\
\text { within the past } 90 \text { days, smoking history, and suspicion of aspiration } \\
\mathrm{b}=\text { Mean } \mathrm{PM}_{2.5} \text { (continuous) for exposure / covariate category }\end{array}$} \\
\hline
\end{tabular}




\section{DISCUSSION}

The purpose of this study was to determine the impact of particulate matter exposure on the incidence of mortality assumed to be associated with community-acquired pneumonia. It is generally understood that PM is detrimental to humans in a number of ways, but the extent of this harm is still being studied, with new findings being reported each year. Though perhaps falling away from the spotlight in recent time due to the demands of the global SARS coronavirus 2 pandemic, the threat of this omnipresent pollutant remains present and substantive. PM exposure has placed a great burden upon human populations across the world, both in terms of morbidity and mortality, and its impact has been felt even more greatly among those populations lacking the resources to reduce such exposures. The oft invisible threat of airborne pollutants such as PM is as much a matter of health equity, of environmental justice, as it is of general health concern; it is only by fully understanding the scope and magnitude of this issue that we can begin to take meaningful steps to reverse it.

The initial regression models examined in Aim One of this study seemed to indicate that little in the way of significant association existed between PM exposures and mortality within thirty days. The results in the literature are often to the contrary, generally suggesting that PM is associated with increased mortality to some degree $(54,69,79-82$, 98). It is possible that the lack of significant findings in Aim One may have been partly due to residual confounding in analyzed relationships, present as a result of variable 
categorization choices or by failure to include unnoted confounders. Attempts were made to reduce residual confounding by utilizing variables as they were defined in the dataset and without extensive categorical modification; for example, continuous age was utilized over categorized age in the bulk of modeling, as continuous age was the stronger variable and was also the variable presented in the dataset. Additionally, spatial averaging is a fairly simplistic interpolation technique, and the combination of the use of this method along with limited PM monitoring data may have resulted in the presence of error in the utilized exposure data. The Aim One results varied little between the two regression types used, as well as between the PM groups analyzed. It was only after examining the role of PM and mortality among select groups that the less-evident impact of exposure became more apparent.

Analysis of $P M_{10}$ Exposure

Based upon likelihood ratio test results, race was significantly indicated as an effect modifier in the relationship between $\mathrm{PM}_{10}$ exposure and mortality at thirty days. This effect was seen when examining exposure from both a continuous perspective and as quartiles. Black participants in the study had $19 \%$ higher odds of death at thirty days for every fiveunit increase of $\mathrm{PM}_{10}$ exposure that occurred on the day of their hospitalization. Those black participants that fell into the fourth quartile of $\mathrm{PM}_{10}$ exposure had 2.7-times higher odds of death within thirty days than those in the first quartile of exposure after adjusting for confounders and strong predictors. No such relationships between $\mathrm{PM}_{10}$ and mortality were detected among the white population of the study. Though not the same pollutant, increased $\mathrm{PM}_{2.5}$ exposure has been linked to elevated mortality risk among nonwhite and black participants among the 2000-2012 US Medicare population compared to white 
participants, suggesting the harmful impact of PM exposure may be unequally experienced among racial groups in the US $(79,80)$.

Overall, examination of race and $\mathrm{PM}_{10}$ exposure indicated a possible disproportionate and worryingly high association with mortality at thirty days among black participants in the highest exposure quartile. Geospatial mapping of participant racial distribution placed the vast majority of black participants within west and central Louisville; this could be of concern assuming this sample distribution is representative of the general population distribution, as localized PM sources within these areas could disproportionately impact a large section of the black population due to limited residential variation across space. The map itself was not included to protect the identities of study participants. To a limited extent, the findings revealed that black participants had slightly elevated means of $\mathrm{PM}_{10}$ exposure versus white participants (e.g., Q4 black participants: mean $=27.01 \mu \mathrm{g} / \mathrm{m}^{3}$; Q4 white participants: mean $\left.=26.94 \mu \mathrm{g} / \mathrm{m}^{3}\right)$. This idea was in line with existing literature, which has suggested that black individuals within the US have an average PM burden 1.5 times that of the overall population (87), though the magnitude of observed mean differences was not as extensive within this study.

Additional examination of the black participant population revealed that those who fell within the highest exposure quartile had elevated relative risk of outcome occurrence versus those who fell within the lower exposure quartiles, but the association was only of borderline significance (relative risk $=1.51,95 \% \mathrm{CI}=0.95-2.39$ ). Though individual risks associated with each exposure quartile were below $10 \%$ and therefore relatively rare, it was possible the calculated relative risk was different from the observed adjusted odds ratio due to the inherent possibility that odds ratios can overestimate relative risk; also, the calculated 
relative risk did not account for confounders and predictors. It was also noted that black participants seemed to fall within the PSI classes IV and V less than white participants, possibly suggesting black participants ultimately had fewer risk factors for pneumonia mortality than white participants. If that were the case, however, why was it that significant or borderline significant elevations in odds or relative risk of outcome occurrence were only observed among black participants, and only among those with the highest levels of $\mathrm{PM}_{10}$ exposure? Ultimately, the outcome used in the study only examined all-cause mortality within thirty days, so it may be that elevated $\mathrm{PM}_{10}$ influenced thirty-day mortality due to non-pneumonia causes disproportionately among black participants, despite the likelihood of pneumonia mortality being generally lower for this sub-population. Other factors not examined in this study, such as socioeconomic status and proximity to roadways and other PM point-sources, may have also influenced the observed results, and will be included in future analyses (99-101).

Both continuous and categorized age were also recognized as significant effect modifiers in the relationship between $\mathrm{PM}_{10}$ quartiles of exposure and mortality at thirty days based upon LRT results, though no significant measures of association were observed among the age/quartile relationships examined. Though not significant, the $65+$ years old group consistently seemed to show increased odds of mortality in $\mathrm{PM}_{10}$ exposure quartiles two through three, as compared to the referent quartile $(\mathrm{Q} 2: \mathrm{AOR}=1.28,95 \% \mathrm{CI}=0.95$ 1.72; $\mathrm{Q} 3: \mathrm{AOR}=1.05,95 \% \mathrm{CI}=0.77-1.43 ; \mathrm{Q} 4: \mathrm{AOR}=1.30,95 \% \mathrm{CI}=0.96-1.76)$. Greater age being attributed to greater mortality associated with PM exposure has been observed in past literature, such as in the 2000-2012 US Medicare population previously mentioned, where individuals 85 years and older had significantly elevate relative risk associated with 
each $10 \mu \mathrm{g} / \mathrm{m}^{3}$ increase in $\mathrm{PM}_{2.5}$ they were exposed to, versus those who were 69 years and younger (79). It should be noted that continuous age was also a significant confounder of the main relationship examined in the regression models (e.g. $2 \%$ increase in odds per oneyear increase in the partially adjusted continuous $\mathrm{PM}_{10}$ logistic model).

Sex was not recognized to be an effect modifier as the previous two variables were, but still presented some significant findings. First, quantile exposure analysis revealed that female participants in the fourth exposure quartile had $46 \%$ higher odds of death within thirty days than those in the first exposure quartile. Such a relationship was not observed among male participants. Though not entirely clear, it is possible that female participants are more greatly impacted, or simply differently impacted, by environmental contaminants such as $\mathrm{PM}_{10}$ than male participants. This phenomenon has been observed in the literature, where females have been noted to have greater total and coarse particle deposition in the lungs than males (83). Additionally, females have been found to be at greater risk of death via respiratory illness induced by PM exposure (78). Female marathon runners, but not their male counterparts, have been found to have significantly reduced performance as a result of increased $\mathrm{PM}_{10}$ exposure (84). The findings of our study, as well as those found in the literature, suggest the possibility that females experience PM exposure differently from males, and that elevated exposure may be a significantly greater source of harm for them.

Sex was also noted to be a confounder in the regression models, though it seemed to only maintain statistical significance in the minimally adjusted models. In the minimally adjusted Aim One regression models, it was found that male participants had higher odds of death at thirty days than female participants (e.g., male participants had increased odds 
of $41 \%$ in the minimally adjusted continuous $\mathrm{PM}_{10}$ logistic model). The outcome reversal among the two sexes that occurred at greater levels of $\mathrm{PM}_{10}$ exposure does lend credence to the possibility that female participants were more susceptible to the harmful effects of PM exposure at higher levels than male participants, despite males seemingly having higher thirty-day mortality in general.

Receival status of both the pneumococcal and seasonal influenza vaccinations were variables recognized as confounders, and both presented significant findings of interest in the Aim One regression models. Pneumococcal vaccine receival status was consistently significant throughout the models and appeared to be associated with a substantial reduction in outcome likelihood (e.g., participants who had received the vaccine had reduced odds of $24 \%$ in the partially adjusted continuous $\mathrm{PM}_{10}$ logistic model). Seasonal influenza vaccine receival status was only significant in the minimally adjusted models but was associated with reduced outcome likelihood under these conditions (e.g., participants who had received the vaccine had reduced odds of $18 \%$ in the minimally adjusted continuous $\mathrm{PM}_{10}$ logistic model). Though the benefits of the seasonal influenza vaccine are questionable for the outcome of this particular study, the results do indicate that the pneumococcal vaccine can potentially improve survival likelihood in patients hospitalized for CAP.

Not surprisingly, several variables linked to increased CAP risk or severity of disease in past literature were consistently found to be significant predictors of increased mortality at thirty days throughout the Aim One models $(19,32,33,37,52)$; all values presented in this paragraph are from the partially adjusted continuous $\mathrm{PM}_{10}$ logistic model. Those participants who fell within the PSI classes IV and V had greater odds of mortality 
within thirty days than those who were in class I, with AORs of 4.05 and 11.13, respectively. Those who were transferred to the ICU upon hospitalization had $65 \%$ greater odds of dying within thirty days than those who were not transferred to the ICU. Those who received intravenous antibiotic therapy within the past ninety days had $55 \%$ greater odds of dying within thirty days than those who did not receive IV antibiotics. Those who were considered to be at-risk for aspiration had $62 \%$ greater odds of dying within thirty days than those not at risk for aspiration.

Surprisingly, smoking status was not significantly associated with increased likelihood of outcome. Most current smokers were comparatively younger in age, with $68.6 \%$ being under the age of 65 years. The majority of past smokers, $73.3 \%$, were 65 years or older. Though not significant, it was strange to observe that participants among the previously mentioned categories were at reduced likelihood of mortality at thirty days compared to non-smokers. It is unclear why such relationships were observed. One possibility is that the current smokers who participated in the study may be relatively lowrisk smokers. This could mean that those who were at greater risk of the outcome due to smoking may have already died, while those left may be less prone to complications due to smoking. In addition to being younger, $55 \%$ of the current smokers within the study fell within the first three classes of the PSI, suggesting the majority of the included current smoker population was at lower risk of mortality resulting from pneumonia, often due to having less risk factors (e.g., comorbidities) that would increase pneumonia severity. Assuming it is the case that the included current smokers were lower risk smokers, this appears to be an example of volunteer bias, meaning that those current smokers who 
volunteered to take part in the study did not necessarily represent the current smokers within the general population.

\section{Comments Concerning Analysis of PM2.5 Exposure}

Largely, results of models containing variations of $\mathrm{PM}_{2.5}$ as the exposure closely mimicked those of corresponding $\mathrm{PM}_{10}$ models. In Aim One, AORs and AHRs for all covariates from models containing variations of $\mathrm{PM}_{2.5}$ as the exposure were very similar to those reported in corresponding models containing variations of $\mathrm{PM}_{10}$ as the exposure and were significant in all the same ways. Diverging from this similarity were the $\mathrm{PM}_{2.5}$ exposure models of Aim Three, which did not reflect the same effect modification results and significant findings as those reported for the $\mathrm{PM}_{10}$ exposure models. It was found that categorized age was an effect modifier of the main relationship of study, but no other significant associations were otherwise revealed. No significant relationships were observed among the Aim Three analyses, despite the fact that past studies have found increased levels of $\mathrm{PM}_{2.5}$ to be associated with elevated relative risk of mortality for older individuals, nonwhites, and female and male individuals $(79,80) . \mathrm{PM}_{10}$ and $\mathrm{PM}_{2.5}$, though both forms of particulate matter, are distinct particles, and form from different processes and likely have differing chemical compositions $(60,61)$; it is possible that the differences in observed results between the two forms of particulate matter in Aim Three analyses are partially due to biological differences in how participants reacted to the two types of exposure particulates.

\section{Comments Concerning the Use of Kriging}

The models resulting from the attempted use of kriging in this study were ultimately of little use from a prediction standpoint. Inability to run kriging models for small amounts 
of data and the observation of questionable patterns based on sparse data points were significant indicators that more advanced geospatial / geostatistical interpolation methods require robust sources of data to adequately function. A sufficient sample size is required to yield useful results for Kriging. The results clearly illustrated the importance of sufficient sample size when conducting kriging. No concrete lower quantity limit of data point sources exists for this method, but the number is likely dependent on the size of the area being examined. In this case, the study area was quite large, and the number of point sources comparatively small, numbering four or fewer for the entire 398 square mile area. Future kriging efforts pertaining to PM concentrations would benefit greatly from either the use of alternative, more spatially abundant data sources or by the taking of new, localized PM measurements for a variety of points across the study area.

\section{Strengths}

There are several strengths evident within the study. First, the HAPPI dataset itself is robust and effectively mimics the established demographic profile of the study region in many ways, with clear exception being given to the average age of study participants versus that of the general population. This is to be expected, given the HAPPI population is entirely composed of CAP-hospitalized individuals, who tend to be inherently older in age. Second, the HAPPI dataset accurately characterizes the burden of CAP among hospitalized individuals within the study timeframe, given the relative accessibility of the study and the high level of recruitment involved. Third, the HAPPI sample is relatively large in size, ensuring adequate power for most of the analyses that were carried out. Fourth, though relatively simplistic in methodology, the use of spatial averaging allowed for estimation of participant PM exposure where more advanced methods could not adequately function. 
Fifth, the HAPPI dataset supplied temporal data for the cohort, which allowed for survival analysis to be conducted. The temporal data also provided a clear timeline for exposure and outcome occurrence, ultimately proving that the former preceded the latter. Sixth, participant information was based upon electronic medical records, which are largely accurate and up-to-date, and often reduce the chance for issues such as recall bias that result from the use of alternate data sources (e.g., self-completed questionnaires). Finally, access to limited death certificate information ensured that those who were reported as manifesting the outcome did truly experience the outcome.

\section{Limitations}

As in any study, some limitations were present. Perhaps the most substantial limitation was the fact that address-specific PM concentration measurements were not available for study participants, and that such values had to be interpolated from data provided by the small number of monitoring stations located within the study area. Though having to interpolate such values was not ideal, it did provide experience in utilizing geostatistical methods. A second limitation was that the sparsity of monitoring stations, and therefore PM point values, severely limited the ability to use more complicated geostatistical interpolation methods - kriging, in this case. A third limitation was that cause of death information was largely unavailable for study participants, necessitating the use of a proxy outcome in place of mortality directly attributed to CAP. A fourth limitation was that the current study only examined PM exposure at the time of hospitalization. This allowed for the examination of the short-term impact of PM on thirty-day mortality, but not the long-term impact. Examining the impact of PM concentrations at alternative points in time, such as at one month prior to hospitalization, may have given a better 
understanding of the exposure/outcome relationship in the long-term. Data for analysis of long-term impacts are available, meaning the capacity exists to examine these relationships going forward. A final limitation was that the current study did not account for socioeconomic status, proximity to PM point-sources, or seasonality; these variables were not directly included in the datasets utilized.

\section{Future Research}

The key associations of interest largely yielded results that were not statistically significant; however, the findings that were significant provided useful insights into factors that may influence the outcome and into groups that may be at greater risk due to exposure. Being able to address the data limitations present in the current study would serve as a boon to further research endeavors on the subject. Use of a more abundant exposure data source that better characterizes the entirety of the study area would be ideal (e.g., having a larger number of sampling sites distributed across the county, use of remote sensing data to characterize PM levels (102) by census block group). Having access to cause of death information would also be ideal, as it would allow for a more thorough examination of the impact of PM on CAP-specific mortality. It is clear from the existing literature, and from the study to a certain extent, that PM exposure is potentially harmful, and further work is needed to determine the exact nature of the relationship between PM exposure and CAPassociated mortality. In addition to fixing data limitation issues, such work would include

examination of long-term PM exposure impact on the occurrence of the outcome, as well as incorporation of possible missed confounders (e.g., seasonality).

\section{Conclusions}


Those female and black participants who fell within the highest levels of $\mathrm{PM}_{10}$ exposure within the established exposure quartiles had significantly increased odds of mortality at thirty days, as compared to those who fell within the referent lowest exposure quartile. Additionally, numerous other factors, including pneumococcal vaccine receival status, elevated PSI class, transfer to the ICU at the time of hospitalization, receival of intravenous antibiotic therapy within the past ninety days, and being at risk for aspiration, were significantly associated with the outcome, and may influence or help predict outcome likelihood. Kriging is a robust spatial interpolation method, and though it was not found to be a functional option within this particular study, may be useful in future work where exposure point data are more plentiful. All-together, the results indicate that elevated particulate matter exposure may increase the odds of mortality among certain groups within a population of adults hospitalized for community-acquired pneumonia, suggesting that reduction of such exposures could be key in saving lives going forward. 


\section{REFERENCES}

1. CDC. Vaccines Help Prevent Pneumonia. In: Pneumonia. https://www.cdc.gov/pneumonia/prevention.html: CDC; 2018.

2. WHO. The top 10 causes of death. In: Fact sheets. https://www.who.int/newsroom/fact-sheets/detail/the-top-10-causes-of-death: WHO; 2018.

3. Micek ST, Kollef KE, Reichley RM, Roubinian N, Kollef MH. Health Care-Associated Pneumonia and Community-Acquired Pneumonia: a Single-Center Experience. Antimicrobial Agents and Chemotherapy 2007;51(10):3568-3573.

4. Pahal P, Sharma S. Typical Bacterial Pneumonia. In: StatPearls. Treasure Island (FL); 2020.

5. Olasupo O, Xiao H, Brown JD. Relative Clinical and Cost Burden of Community-Acquired Pneumonia Hospitalizations in Older Adults in the United States-A Cross-Sectional Analysis. Vaccines (Basel) 2018;6(3).

6. Jain S, Self WH, Wunderink RG, Fakhran S, Balk R, Bramley AM, et al. CommunityAcquired Pneumonia Requiring Hospitalization among U.S. Adults. N Engl J Med 2015;373(5):415-27.

7. Mandell LA, Wunderink RG, Anzueto A, Bartlett JG, Campbell GD, Dean NC, et al. Infectious Diseases Society of America/American Thoracic Society Consensus Guidelines on the Management of Community-Acquired Pneumonia in Adults. Clinical Infectious Diseases 2007;44(Supplement_2):S27-S72.

8. $\quad$ Seong GM, Kim M, Lee J, Lee JH, Jeong SY, Choi Y, et al. Healthcare-Associated Pneumonia among Hospitalized Patients: Is It Different from Community Acquired Pneumonia? Tuberculosis and Respiratory Diseases 2014;76(2):66.

9. Society AT. Guidelines for the Management of Adults with Hospital-acquired, Ventilatorassociated, and Healthcare-associated Pneumonia. American Journal of Respiratory and Critical Care Medicine 2005;171(4):388-416.

10. Marston BJ, Plouffe JF, File TM, Jr., Hackman BA, Salstrom SJ, Lipman HB, et al. Incidence of community-acquired pneumonia requiring hospitalization. Results of a population-based active surveillance Study in Ohio. The Community-Based Pneumonia Incidence Study Group. Arch Intern Med 1997;157(15):1709-18.

11. Zingone F, Abdul Sultan A, Crooks CJ, Tata LJ, Ciacci C, West J. The risk of communityacquired pneumonia among 9803 patients with coeliac disease compared to the general population: a cohort study. Alimentary Pharmacology \& Therapeutics 2016;44(1):57-67.

12. Ewig S, Birkner N, Strauss R, Schaefer E, Pauletzki J, Bischoff H, et al. New perspectives on community-acquired pneumonia in 388406 patients. Results from a nationwide mandatory performance measurement programme in healthcare quality. Thorax 2009;64(12):1062-1069. 13. Rozenbaum MH, Mangen M-JJ, Huijts SM, Van Der Werf TS, Postma MJ. Incidence, direct costs and duration of hospitalization of patients hospitalized with community acquired pneumonia: A nationwide retrospective claims database analysis. Vaccine 2015;33(28):31933199. 
14. Ramirez JA, Wiemken TL, Peyrani P, Arnold FW, Kelley R, Mattingly WA, et al. Adults Hospitalized With Pneumonia in the United States: Incidence, Epidemiology, and Mortality. Clin Infect Dis 2017;65(11):1806-1812.

15. Takahashi K, Suzuki M, Minh LN, Anh NH, Huong LTM, Son TVV, et al. The incidence and aetiology of hospitalised community-acquired pneumonia among Vietnamese adults: a prospective surveillance in Central Vietnam. BMC Infectious Diseases 2013;13(1):296.

16. Azmi S, Aljunid SM, Maimaiti N, Ali A-A, Muhammad Nur A, De Rosas-Valera M, et al. Assessing the burden of pneumonia using administrative data from Malaysia, Indonesia, and the Philippines. International Journal of Infectious Diseases 2016;49:87-93.

17. Torres A, Peetermans WE, Viegi G, Blasi F. Risk factors for community-acquired pneumonia in adults in Europe: a literature review. Thorax 2013;68(11):1057-1065.

18. Farr BM, Woodhead MA, Macfarlane JT, Bartlett CLR, McCracken JS, Wadsworth J, et al. Risk factors for community-acquired pneumonia diagnosed by general practitioners in the community. 2000;94(5):422-427.

19. Loeb M, Neupane B, Walter SD, Hanning R, Carusone SC, Lewis D, et al. Environmental risk factors for community-acquired pneumonia hospitalization in older adults. J Am Geriatr Soc 2009;57(6):1036-40.

20. Brown JD, Harnett J, Chambers R, Sato R. The relative burden of community-acquired pneumonia hospitalizations in older adults: a retrospective observational study in the United States. BMC Geriatr 2018;18(1):92.

21. Ho JC, Chan KN, Hu WH, Lam WK, Zheng L, Tipoe GL, et al. The effect of aging on nasal mucociliary clearance, beat frequency, and ultrastructure of respiratory cilia. Am J Respir Crit Care Med 2001;163(4):983-8.

22. Meyer KC. The role of immunity in susceptibility to respiratory infection in the aging lung. Respir Physiol 2001;128(1):23-31.

23. Janssens J-P, Krause K-H. Pneumonia in the very old. The Lancet Infectious Diseases 2004;4(2):112-124.

24. Renshaw M, Rockwell J, Engleman C, Gewirtz A, Katz J, Sambhara S. Cutting edge: impaired Toll-like receptor expression and function in aging. J Immunol 2002;169(9):4697-701.

25. Marik PE. Aspiration pneumonitis and aspiration pneumonia. N Engl J Med 2001;344(9):665-71.

26. Riquelme R, Torres A, El-Ebiary M, Mensa J, Estruch R, Ruiz M, et al. Communityacquired Pneumonia in the Elderly. American Journal of Respiratory and Critical Care Medicine 1997;156(6):1908-1914.

27. Juthani-Mehta M, De Rekeneire N, Allore H, Chen S, O'Leary JR, Bauer DC, et al. Modifiable Risk Factors for Pneumonia Requiring Hospitalization of Community-Dwelling Older Adults: The Health, Aging, and Body Composition Study. 2013;61(7):1111-1118.

28. Jackson ML, Nelson JC, Jackson LA. Risk Factors for Community-Acquired Pneumonia in Immunocompetent Seniors. Journal of the American Geriatrics Society 2009;57(5):882-888.

29. Vinogradova Y, Hippisley-Cox J, Coupland C. Identification of new risk factors for pneumonia: population-based case-control study. British Journal of General Practice 2009;59(567):e329-e338.

30. Teepe J, Grigoryan L, Verheij TJM. Determinants of community-acquired pneumonia in children and young adults in primary care. European Respiratory Journal 2010;35(5):1113-1117. 31. Müllerova H, Chigbo C, Hagan GW, Woodhead MA, Miravitlles M, Davis KJ, et al. The natural history of community-acquired pneumonia in COPD patients: A population database analysis. Respiratory Medicine 2012;106(8):1124-1133. 
32. Almirall J, Bolibar I, Serra-Prat M, Roig J, Hospital I, Carandell E, et al. New evidence of risk factors for community-acquired pneumonia: a population-based study. European Respiratory Journal 2008;31(6):1274-1284.

33. Schnoor M, Klante T, Beckmann M, B, Welte T, Raspe H, et al. Risk factors for community-acquired pneumonia in German adults: the impact of children in the household. Epidemiology and Infection 2007;135(8):1389-1397.

34. Vila-Corcoles A, Ochoa-Gondar O, Rodriguez-Blanco T, Raga-Luria X, Gomez-Bertomeu F. Epidemiology of community-acquired pneumonia in older adults: A population-based study. 2009;103(2):309-316.

35. Murcia J, Llorens P, Sánchez-Payá J, Reus S, Boix V, Merino E, et al. Functional status determined by Barthel Index predicts community acquired pneumonia mortality in general population. Journal of Infection 2010;61(6):458-464.

36. Michael, Kathleen, William, David, Yu O, Christi, et al. The Burden of CommunityAcquired Pneumonia in Seniors: Results of a Population-Based Study. 2004;39(11):1642-1650.

37. Almirall J, Bolibar I, Balanzo X, Gonzalez CA. Risk factors for community-acquired pneumonia in adults: a population-based case-control study. Eur Respir J 1999;13(2):349-55.

38. Almirall J, Serra-Prat M, Bolibar I, Palomera E, Roig J, Hospital I, et al. Passive smoking at home is a risk factor for community-acquired pneumonia in older adults: a population-based case-control study. BMJ Open 2014;4(6):e005133-e005133.

39. Ruiz M, Ewig S, Torres A, Arancibia F, Marco F, Mensa J, et al. Severe Communityacquired Pneumonia. American Journal of Respiratory and Critical Care Medicine 1999;160(3):923-929.

40. Hind CR. Pulmonary complications of intravenous drug misuse. 2. Infective and HIV related complications. Thorax 1990;45(12):957-961.

41. De Roux A, Cavalcanti M, Marcos MA, Garcia E, Ewig S, Mensa J, et al. Impact of Alcohol Abuse in the Etiology and Severity of Community-Acquired Pneumonia. 2006;129(5):1219-1225.

42. Brown JS. Community-acquired pneumonia. Clinical Medicine 2012;12(6):538-543.

43. Moberley S, Holden J, Tatham DP, Andrews RM. Vaccines for preventing pneumococcal infection in adults. Cochrane Database Syst Rev 2013(1):CD000422.

44. Farr BM, Bartlett CLR, Wadsworth J, Miller DL. Risk factors for community-acquired pneumonia diagnosed upon hospital admission. Respiratory Medicine 2000;94(10):954-963. 45. Neupane B, Jerrett M, Burnett RT, Marrie T, Arain A, Loeb M. Long-Term Exposure to Ambient Air Pollution and Risk of Hospitalization with Community-acquired Pneumonia in Older Adults. American Journal of Respiratory and Critical Care Medicine 2010;181(1):47-53.

46. Restrepo MI, Faverio P, Anzueto A. Long-term prognosis in community-acquired pneumonia. Current Opinion in Infectious Diseases 2013;26(2):151-158.

47. Stupka JE, Mortensen EM, Anzueto A, Restrepo MI. Community-acquired pneumonia in elderly patients. Aging Health 2009;5(6):763-774.

48. Violi F, Cangemi R, Falcone M, Taliani G, Pieralli F, Vannucchi V, et al. Cardiovascular Complications and Short-term Mortality Risk in Community-Acquired Pneumonia. Clinical Infectious Diseases 2017;64(11):1486-1493.

49. Fine MJ, Auble TE, Yealy DM, Hanusa BH, Weissfeld LA, Singer DE, et al. A Prediction Rule to Identify Low-Risk Patients with Community-Acquired Pneumonia. New England Journal of Medicine 1997;336(4):243-250.

50. Aujesky D, Michael. The Pneumonia Severity Index: A Decade after the Initial Derivation and Validation. Clinical Infectious Diseases 2008;47(S3):S133-S139.

51. Arnold FW, Ramirez JA, McDonald LC, Xia EL. Hospitalization for community-acquired pneumonia: the pneumonia severity index vs clinical judgment. Chest 2003;124(1):121-4. 
52. Kothe H, Bauer T, Marre R, Suttorp N, Welte T, Dalhoff K. Outcome of communityacquired pneumonia: influence of age, residence status and antimicrobial treatment. European Respiratory Journal 2008;32(1):139-146.

53. Restrepo MI. COPD is associated with increased mortality in patients with communityacquired pneumonia. European Respiratory Journal 2006;28(2):346-351.

54. Pirozzi CS, Jones BE, Vanderslice JA, Zhang Y, Paine R, Dean NC. Short-Term Air Pollution and Incident Pneumonia. A Case-Crossover Study. Annals of the American Thoracic Society 2018;15(4):449-459.

55. Toren K, Qvarfordt I, Bergdahl IA, Jarvholm B. Increased mortality from infectious pneumonia after occupational exposure to inorganic dust, metal fumes and chemicals. Thorax 2011;66(11):992-996.

56. Williams PT. Dose-Response Relationship between Exercise and Respiratory Disease Mortality. 2014;46(4):711-717.

57. WHO. WHO's First Global Conference on Air Pollution and Health. In: Newsroom. https://www.who.int/news-room/events/detail/2018/10/30/default-calendar/who-s-firstglobal-conference-on-air-pollution-and-health: WHO; 2018.

58. Vodonos A, Kloog I, Boehm L, Novack V. The impact of exposure to particulate air pollution from non-anthropogenic sources on hospital admissions due to pneumonia. European Respiratory Journal 2016;48(6):1791-1794.

59. Thomas. Community-Acquired Pneumonia in the Elderly. Clinical Infectious Diseases 2000;31(4):1066-1078.

60. EPA. Particulate Matter Emissions. In: Report on the Environment. https://www.epa.gov/roe/: EPA; 2018.

61. Anderson JO, Thundiyil JG, Stolbach A. Clearing the Air: A Review of the Effects of Particulate Matter Air Pollution on Human Health. Journal of Medical Toxicology 2012;8(2):166175.

62. Adams K, Greenbaum DS, Shaikh R, Van Erp AM, Russell AG. Particulate matter components, sources, and health: Systematic approaches to testing effects. Journal of the Air \& Waste Management Association 2015;65(5):544-558.

63. Schwartz J, Dockery DW, Neas LM. Is Daily Mortality Associated Specifically with Fine Particles? Journal of the Air \& Waste Management Association 1996;46(10):927-939.

64. Brown JS, Gordon T, Price O, Asgharian B. Thoracic and respirable particle definitions for human health risk assessment. Particle and Fibre Toxicology 2013;10(1):12.

65. EPA. NAAQS Table. In. https://www.epa.gov/criteria-air-pollutants/naaqs-table: EPA; 2016.

66. Schwartz J. Air pollution and daily mortality: a review and meta analysis. Environ Res 1994;64(1):36-52.

67. Dockery DW, Pope CA, Xu X, Spengler JD, Ware JH, Fay ME, et al. An Association between Air Pollution and Mortality in Six U.S. Cities. New England Journal of Medicine 1993;329(24):1753-1759.

68. Puett RC, Hart JE, Yanosky JD, Paciorek C, Schwartz J, Suh H, et al. Chronic fine and coarse particulate exposure, mortality, and coronary heart disease in the Nurses' Health Study. Environ Health Perspect 2009;117(11):1697-701.

69. Medina-Ramón M, Zanobetti A, Schwartz J. The Effect of Ozone and PM10 on Hospital Admissions for Pneumonia and Chronic Obstructive Pulmonary Disease: A National Multicity Study. American Journal of Epidemiology 2006;163(6):579-588. 
70. Qiu H, Tian LW, Pun VC, Ho K-F, Wong TW, Yu ITS. Coarse particulate matter associated with increased risk of emergency hospital admissions for pneumonia in Hong Kong. Thorax 2014;69(11):1027-1033.

71. Yatavelli RLN, Fahrni JK, Kim M, Crist KC, Vickers CD, Winter SE, et al. Mercury, PM2.5 and gaseous co-pollutants in the Ohio River Valley region: Preliminary results from the Athens supersite. Atmospheric Environment 2006;40(34):6650-6665.

72. Anderson RR, Martello DV, White CM, Crist KC, John K, Modey WK, et al. The Regional Nature of PM2.5 Episodes in the Upper Ohio River Valley. Journal of the Air \& Waste Management Association 2004;54(8):971-984.

73. Fischer G, Talley Sr K. Louisville Metro Air Pollution Control District - 2018 Annual Report. In: APCD, editor.

https://louisvilleky.gov/sites/default/files/air pollution control district/documents/allother/20 19/apcd 2018 annual report.pdf; 2018.

74. Bureau USC. 2017: ACS 5-Year Estimates Data Profiles. In.

https://data.census.gov/cedsci/table?d=ACS\%205-

Year\%20Estimates\%20Data\%20Profiles\&table=DP03\&tid=ACSDP5Y2017.DP03\&g=0400000US21 \&vintage $=2017 \& y=2017$ : U.S. Census Bureau; 2017.

75. Google. Jefferson County. In.

https://www.google.com/maps/place/Jefferson+County,+KY/@38.1884721,85.9569587,10z/data=!3m1!4b1!4m5!3m4!1s0x88690a8f2b861309:0xba4eaf1d738964fd!8m2! 3d38.1938097!4d-85.643487: Google; 2020.

76. Zeka A, Zanobetti A, Schwartz J. Individual-Level Modifiers of the Effects of Particulate Matter on Daily Mortality. American Journal of Epidemiology 2006;163(9):849-859.

77. Zanobetti A, Schwartz J. Race, gender, and social status as modifiers of the effects of PM10 on mortality. J Occup Environ Med 2000;42(5):469-74.

78. Faustini A, Stafoggia M, Berti G, Bisanti L, Chiusolo M, Cernigliaro A, et al. The relationship between ambient particulate matter and respiratory mortality: a multi-city study in Italy. Eur Respir J 2011;38(3):538-47.

79. Di Q, Dai L, Wang Y, Zanobetti A, Choirat C, Schwartz JD, et al. Association of Short-term Exposure to Air Pollution With Mortality in Older Adults. JAMA 2017;318(24):2446.

80. Di Q, Wang Y, Zanobetti A, Wang Y, Koutrakis P, Choirat C, et al. Air Pollution and Mortality in the Medicare Population. New England Journal of Medicine 2017;376(26):25132522.

81. Næss $\varnothing$, Nafstad P, Aamodt G, Claussen B, Rosland P. Relation between Concentration of Air Pollution and Cause-Specific Mortality: Four-Year Exposures to Nitrogen Dioxide and Particulate Matter Pollutants in 470 Neighborhoods in Oslo, Norway. American Journal of Epidemiology 2007;165(4):435-443.

82. Dong $\mathrm{G}-\mathrm{H}$, Zhang $\mathrm{P}$, Sun $\mathrm{B}$, Zhang $\mathrm{L}$, Chen $\mathrm{X}$, Ma N, et al. Long-Term Exposure to Ambient Air Pollution and Respiratory Disease Mortality in Shenyang, China: A 12-Year Population-Based Retrospective Cohort Study. Respiration 2012;84(5):360-368.

83. Kim CS, Hu SC. Regional deposition of inhaled particles in human lungs: comparison between men and women. Journal of Applied Physiology 1998;84(6):1834-1844.

84. Marr LC, Ely MR. Effect of air pollution on marathon running performance. Med Sci Sports Exerc 2010;42(3):585-91.

85. Yitshak-Sade M, Lane KJ, Fabian MP, Kloog I, Hart JE, Davis B, et al. Race or racial segregation? Modification of the PM2.5 and cardiovascular mortality association. PLOS ONE 2020;15(7):e0236479. 
86. Hausmann LRM, Ibrahim SA, Mehrotra A, Nsa W, Bratzler DW, Mor MK, et al. Racial and Ethnic Disparities in Pneumonia Treatment and Mortality. Medical Care 2009;47(9):1009-1017.

87. Mikati I, Benson AF, Luben TJ, Sacks JD, Richmond-Bryant J. Disparities in Distribution of Particulate Matter Emission Sources by Race and Poverty Status. American Journal of Public Health 2018;108(4):480-485.

88. Wong DW, Yuan L, Perlin SA. Comparison of spatial interpolation methods for the estimation of air quality data. Journal of Exposure Science \& Environmental Epidemiology 2004;14(5):404-415.

89. University C. Kriging. In: Population Health Methods.

https://www.mailman.columbia.edu/research/population-health-methods/kriging: Columbia University Mailman School of Public Health; 2019.

90. ArcGIS. How Kriging works. In: Raster Interpolation toolset concepts.

https://desktop.arcgis.com/en/arcmap/10.3/tools/3d-analyst-toolbox/how-krigingworks.htm\#: :text=Kriging\%20assumes\%20that\%20the\%20distance,explain\%20variation\%20in \%20the\%20surface.\&text=Kriging\%20is\%20most\%20appropriate\%20when,in\%20soil\%20science \%20and\%20geology.: ArcGIS; 2016.

91. ArcGIS. How IDW works. In: Raster Interpolation toolset concepts. https://desktop.arcgis.com/en/arcmap/10.3/tools/3d-analyst-toolbox/how-idw-works.htm: ArcGIS; 2016.

92. Census US. ACS Demographic and Housing Estimates. In. data.census.gov: U.S. Census; 2017.

93. Chang G-M, Tung Y-C. Factors Associated with Pneumonia Outcomes: A Nationwide Population-Based Study over the 1997-2008 Period. Journal of General Internal Medicine 2012;27(5):527-533.

94. Bratzler DW, Normand S-LT, Wang Y, O'Donnell WJ, Metersky M, Han LF, et al. An Administrative Claims Model for Profiling Hospital 30-Day Mortality Rates for Pneumonia Patients. PLoS ONE 2011;6(4):e17401.

95. Government LM. Air Monitoring Sites. In: Air Pollution Control District. LouisvilleKy.gov: LouisvilleKy.gov; 2020.

96. EPA. Download Daily Data. In: EPA, editor. Outdoor Air Quality Data. EPA.gov: EPA; 2020.

97. Fletcher J. Crosstabulation with Nominal Variables. In: POL242 LAB MANUAL: EXERCISE 3A. Research Methods Homepage - Department of Political Science; 2008.

98. Simoni M, Baldacci S, Maio S, Cerrai S, Sarno G, Viegi G. Adverse effects of outdoor pollution in the elderly. J Thorac Dis 2015;7(1):34-45.

99. Laurent O, Bard D, Filleul L, Segala C. Effect of socioeconomic status on the relationship between atmospheric pollution and mortality. Journal of Epidemiology \&amp; Community Health 2007;61(8):665-675.

100. Rosenbloom JI, Wilker EH, Mukamal KJ, Schwartz J, Mittleman MA. Residential Proximity to Major Roadway and 10-Year All-Cause Mortality After Myocardial Infarction. Circulation 2012;125(18):2197-2203.

101. Cakmak S, Hebbern C, Vanos J, Crouse DL, Tjepkema M. Exposure to traffic and mortality risk in the 1991-2011 Canadian Census Health and Environment Cohort (CanCHEC).

Environment International 2019;124:16-24.

102. Kuhns HD, Mazzoleni C, Moosmüller H, Nikolic D, Keislar RE, Barber PW, et al. Remote sensing of $\mathrm{PM}, \mathrm{NO}, \mathrm{CO}$ and $\mathrm{HC}$ emission factors for on-road gasoline and diesel engine vehicles in Las Vegas, NV. Science of The Total Environment 2004;322(1-3):123-137. 


\title{
CURRICULUM VITA
}

\author{
Jack Anthony Pfeiffer, MS \\ 485 East Gray Street, Louisville, KY 40202 \\ (502) 852-3299 |japfei02@louisville.edu \\ U.S. Citizen
}

\section{Education}

\section{University of Louisville}

2017-present PhD, Epidemiology

- Anticipated degree completion date May 2021

- Defense completed March 25, 2021

○ Dissertation: “Airborne Particulate Matter Exposure and Mortality Risk in Jefferson County Residents Hospitalized for Community-Acquired Pneumonia"

2014-2017 MS, Epidemiology

- Thesis concentration in environmental epidemiology

Title "Coal ash exposure and asthma in children."

2011-2014 BA (Honors) in Biological Anthropology

\section{Public Health Experience}

Jefferson County Department of Public Health

July 2020-April 2021

Louisville, KY

Epidemiologist - LMPHW Infectious Diseases

- Tracing of close contacts of confirmed or probable COVID-19 cases reported to health department

- Maintaining routine communication with points of contact at facilities where cases of COVID-19 have been reported

- Conducting initial investigation of confirmed or probable COVID-19 cases, especially as pertaining to substance abuse rehabilitation facilities, correctional facilities, local government facilities, and cross-jurisdictional settings, and developing and communicating guidance relevant to such facilities and settings 
- Transferring and completing investigations for COVID-19 cases and contacts involving cross-jurisdictional circumstances

- Entering COVID-19 case laboratory reports and vaccination documents as time allows

- Performing infectious disease-related on-call duties

Jefferson County Department of Public Health

Louisville, KY

Volunteer - LMPHW COVID-19 Response

- Tracing of close contacts of confirmed or probable COVID-19 cases reported to health department

- Routine contact with confirmed or probable COVID-19 cases to ensure adherence to quarantine orders, monitor symptoms, and provide aid in acquiring essential items

- Initial investigation of confirmed or probable COVID-19 cases

Kentucky Department of Public Health

September 2019

Volunteer - CDC Epi-Aid Investigation 2019

- Worked with CDC EIS Officer, State Health Officials

- Interviewed individuals involved with or witnessed to a local disaster

- Aided in providing logistical support for investigation team

- Provided in-depth group debrief at end of working days

The University of Louisville, School of Public Health July 2018-November 2018 Louisville, KY

Volunteer - Riverside Gardens Environmental Health Impact Assessment

- Recruit participants through door to door visits

- Communicate with community members about the health assessment

- Communicate with the community about environmental concerns

- Gather participant information using questionnaires and interviews

- Assist in meetings with the community

The University of Louisville, Department of Communications January 2018-Current Louisville, KY

Graduate Research Assistant- Green Heart Louisville / Superfund / ATRAC

- Recruit participants through mailing lists and door-to-door distribution of flyers

- Perform study participant consenting practices

- Process and analyze participant information and data

- Gather participant information and data through various types of equipment as needed 
- Communicating the results to the participants

The University of Louisville, School of Public Health $\quad$ November 2017-Current Louisville, KY

Graduate Research Assistant - Coal Ash Exposure and Neurobehavioral Symptoms in Children

- Recruit participants through mailing lists and door-to-door distribution of flyers

- Responsible for air sampling equipment in lab and in participant's homes

- Gather participant information and data through the use of various environmental monitoring technologies and questionnaires

- Perform study participant consenting practices

- Enter and maintain data

- Analyze participant data related to coal ash exposure and health of children

- Communicate findings to community members who participated in the study

The University of Louisville, School of Public Health August 2015-August 2016 Louisville, KY

Volunteer Researcher - Coal Ash Exposure and Neurobehavioral Symptoms in Children

- Recruit participants through mailing lists and door-to-door distribution of flyers

- Responsible for air sampling equipment in lab and in participant's homes

- Gather participant information and data using various environmental monitoring technologies

- Process and analyze participant data

The University of Louisville

September 2013-December 2013

Louisville, KY

Intern - MAPS Laboratory

- Learned basic laboratory techniques and methods such as gel electrophoresis, DNA extraction, and PCR

- Increased familiarity with various types of laboratory equipment

\section{Other Experience}

\section{St. Matthews Community Pharmacy}

August 2016-October 2017

Louisville, KY

Certified Pharmacy Technician

Manager of Merchandising and Social Media

- Maintain patient prescription information, fill patient prescriptions, and resolve conflicts relating to patient prescriptions on file 
- Communicate with insurance companies to resolve patient prescription complications

- Handle most pharmacy merchandising functions, including management of key over the counter product lines

- Utilize Rx30 software for a variety of pharmacy functions

- Communicate pharmacy and health related news and articles via use of company social media page

The White Squirrel

September 2011-May 2014

Louisville, KY

Volunteer Editor

- Assisted in management of the University's student-run literary arts magazine

- Contacted local businesses and helped manage sales and distribution of magazine

- Presented creative writing pieces at public open microphone events

\section{$\underline{\text { Awards }}$}

- Research and Practice (Public Health), $1^{\text {st }}$ Place

- 2019, Research! Louisville

- "Coal fly ash, aluminum, and short-term memory among children 6-14 years old."

- Louisville, KY

- DNTS Annual Meeting Travel Award

- 2019, Developmental Neurotoxicology Society

- San Diego, CA

- APHA Environment Section Travel Scholarship

- 2018, American Public Health Association / National Institutes of Environmental Health Sciences

- San Diego, CA

- School of Public Health and Information Sciences Travel Scholarship

○ 2018, University of Louisville

- Department of Epidemiology Travel Scholarship

- 2018, University of Louisville

- Graduate Research Assistantship

- 2018, University of Louisville

- Graduate Student Tuition Scholarship

- 2016, University of Louisville

- Trustees' Scholarship

○ 2011, University of Louisville 


\section{Publications}

1. Mattingly D, Pfeiffer J, Walker K, Hart J. August 2, 2020. "Sex differences in associations between receiving and sharing tobacco-related information and tobacco product use among Appalachian Youth.” Population Medicine. 25. doi: 10.18332/popmed/125911. PMID: 33629078; PMCID: PMC7899165.

2. Mattingly D, Pfeiffer J, Tompkins L, Rai J, Sears C, Walker K, Hart J. March 24, 2020. "Associations between Appalachian Youth Tobacco Consumption and Communication Channel Use." Tobacco Prevention and Cessation. 6. $10.18332 / \mathrm{tpc} / 118234$

3. Pfeiffer J, Tompkins L, Hart J, Kesh A, Groom A, Vu T, Ma J, Landry R, Payne T, Giachello A, Robertson R, Walker K. March 18, 2020. "Relationship between population characteristics, e-nicotine- and tobacco-related perceptions, and likelihood of ever using e-nicotine products." Tobacco Prevention and Cessation. 6(20). 10.18332/tpc/117477.

4. Odoh C, Sears C, Tompkins L, Hagemeyer A, Pfeiffer J, Polivka B, Sears L, Brock G, Zhang C, Zierold K. October 9, 2019. Recruitment strategies and challenges: Lessons learned from a coal ash and children's health study. Research in Nursing \& Health. 42(6). 10.1002/nur.21986.

5. Pfeiffer J. "Coal ash exposure and asthma in children." 2017. Electronic Theses and Dissertations. Paper 2806. https://doi.org/10.18297/etd/2806

\section{Manuscripts in Work and Review}

1. Pfeiffer J, Wood L, Tomlinson M, Gilkey D, Walker K, Hart J. "If Looks Could Kill - Views of Nature and Depression in Adults."

2. El-Shahawy O, Walker K, Groom A, Payne T, Tompkins L, Kesh A, Landry R, Pfeiffer J, Giachello A, Vu T-H, Ma J, Robertson R, Sherman S, Blaha M, Hart, J. "Initial experimentation with tobacco is associated with current tobacco use patterns among youth in the United States."

3. Wood L, Hart J, Pfeiffer J, Walker K, Tomlinson M, Keith R, Smith T, Yeager II R, Kerstiens S, Gilkey D, Riggs D, Gao H, Turner J, Srivastava S, Bhatnagar A. "Sleepless Indoors: Does Time Spent Outdoors Improve Sleep Normalcy?" 
4. Tomlinson M, Hart J, Walker K, Wood L, Pfeiffer J, Bhatnagar A, Kerstiens S, Gilkey D, Smith T, Yeager II R, Gao H, Riggs D, Turner J, Srivastava S, Keith R. "Neighborhood Safety Perceptions and Autoimmune Disease."

\section{Peer-Reviewed Abstracts}

1. Pfeiffer J, Sears L, Winn J, Norton C, Zierold KM. "Is Coal keeping children off the honor roll? Coal fly ash exposure and school performance in children aged 614 years old." Developmental Neurotoxicology Society Annual Meeting. June 2020 (cancelled due to COVID-19). Charleston, SC, USA.

2. Hart J, Wood L, Pfeiffer J, Gilkey D, Zachary A, Walker L. "Relational Dialectics in Community-Rooted Research and Partnerships." $2^{\text {nd }}$ International Electronic Conference on Environmental Health Sciences. November 4-29, 2019. Online.

3. Wood L, Walker K, Pfeiffer J, Gilkey D, Hart J, Bhatnagar A. "Collaborative initiatives with urban youth and young adults: The heart of the matter." Superfund Research Program annual meeting. November 2019. Seattle, WA, USA.

4. Wood L, Pfeiffer J, Gilkey D, Zachary A, Tompkins L, Kerstiens S, Walker K, Hart J. "Blurring borders, breaking boundaries: Classroom and community collaborations." Annual Kentucky Communication Association. September 2019. Cadiz, KY, USA.

5. Tompkins L, Pfeiffer J, Wood L, Zachary A, Walker K, Hart J. “Translating Research for Community Members: Learning Partnerships and Change Mechanisms." Southern States Communication Association $89^{\text {th }}$ Annual Meeting. April 3-7, 2019. Montgomery, AL, USA.

6. Tompkins L, Sears C, Lee A, Smith C, Siu A, Pfeiffer J, Wood L, Zachary A, Walker K, Hart J. "Engaging Communities, Engaging Change: Rural Middle and High School Youth and Tobacco Products." Southern States Communication Association $89^{\text {th }}$ Annual Meeting. April 3-7, 2019. Montgomery, AL, USA.

7. Hart J, Tompkins L, Pfeiffer J, Wood L, Zachary A, Carter S, Gilkey D, Mattingly D, Thornsbury A, Walker K. "Growing Together: Community Engagement and Student Involvement." Southern States Communication Association $89^{\text {th }}$ Annual Meeting. April 3-7, 2019. Montgomery, AL, USA.

8. El-Shahawy O, Walker K, Groom A, Tompkins L, Kesh A, Landry R, Pfeiffer J, Payne T, Giachello A, Vu T, Ma J, Robertson R, Sherman S, \& Hart J.

"Association of Experimentation with Tobacco and Nicotine-Containing Products and Current Tobacco Use Status Among Youth in the US: Findings from a 
National Online Survey (2017)." Society for Research on Nicotine and Tobacco Annual Meeting. February 20-23, 2019. San Francisco, CA, USA.

9. Hart J, Heberle L, Walker K, Tompkins L, Wheeler J, Pfeiffer J, Wood L, Gilkey D, Zachary A, Bhatnagar A. "UofL Superfund Research Center: Engaging and Communicating Across Disciplinary, Professional, and Institutional Boundaries." Superfund Research Program Annual Meeting. November 28-30, 2018. Sacramento, CA, USA.

10. Noa de la Paz M, Thornsbury A, Carter S, Tompkins L, Wood L, Zachary A, Pfeiffer J, Gilkey D, Walker K, Hart J. "Community Collaborations: Building Partnerships and Scientific Understanding." Ohio Valley Society of Toxicology Annual Meeting. November 30, 2018. Louisville, KY, USA

11. Hart J, Walker K, Tompkins L, Zachary A, Wood L, Mattingly D, Pfeiffer J. "Environmental health: engaging a community in research, partnership, and practice." Kentucky Communication Association $87^{\text {th }}$ Annual Meeting. September 14-15, 2018. Prestonsburg, KY, USA.

\section{Conference / Abstract Presentations}

1. Pfeiffer J, Tompkins L, Sears L, Zierold, K. Poster. "Coal fly ash, aluminum, and short-term memory among children 6-14 years old." Research! Louisville. September 11, 2019. Louisville, KY, USA.

2. Pfeiffer J, Tompkins L, Sears L, Zierold, Z. Poster. "Coal fly ash, aluminum, and short-term memory among children 6-14 years old." Developmental Neurotoxicology Society Annual Meeting. June 23, 2019. San Diego, CA, USA.

3. Pfeiffer J, Tompkins L, Walker K, Hart J. Poster. "Harm Perceptions of Tobacco Products and ENDS.” Ohio Valley Society of Toxicology Annual Meeting. November 30, 2018. Louisville, KY, USA.

4. Pfeiffer J, Polivka B, Sears L, Zierold K. Poster. "Coal fly ash and wheezing among children 6-14 years old." American Public Health Association 146 ${ }^{\text {th }}$ Annual Meeting. November 13, 2018. San Diego, CA, USA.

5. Pfeiffer J, Polivka B, Sears L, Zierold K. Poster. "Coal fly ash and asthma among children 6-14 years old." Society of Epidemiological Research 2018 Meeting. June 21, 2018. Baltimore, MD, USA. 


\section{$\underline{\text { Skills }}$}

\section{Technical}

- Proficient in Microsoft Word, Excel, PowerPoint, and in navigation of the Internet.

- Proficient knowledge of SAS and STATA statistical programs.

- OSHA and Laboratory Safety certified.

- Working knowledge of GIS for public health purposes.

- Proficient in use of REDCap survey tool.

\section{Writing}

- Extensive knowledge of academic writing and reading.

- Excellent grammar skills.

\section{Presentation}

- Strong public-speaking skills and familiarity with speaking in front of groups.

- Comfortable working in field / community environments.

- Comfortable presenting research findings in conference settings.

\section{Training}

University of Louisville, Community Engagement Academy 2018-2019

- Learned methods and skills to best address the need for increased community engaged research in modern academia

- Discussed research ethics as they apply to community engagement

- Developed a community engaged research project in connection with Green Heart Louisville utilizing learned methods and skills 